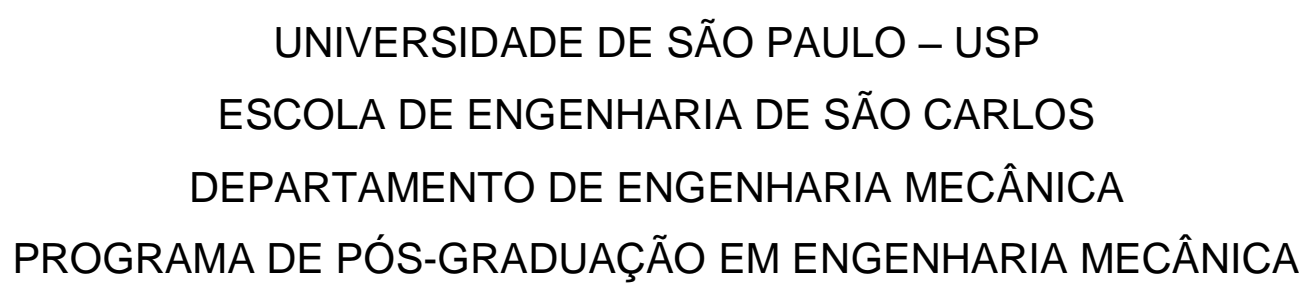

PAULO ROBERTO CHIAROLANZA VILELA

\title{
MODELAGEM, SIMULAÇÃO E OTIMIZAÇÃO DINÂMICA APLICADA A UM PROCESSO DE FERMENTAÇÃO ALCOÓLICA EM BATELADA ALIMENTADA
}

São Carlos 



\section{MODELAGEM, SIMULAÇÃO E OTIMIZAÇÃO DINÂMICA APLICADA A UM PROCESSO DE FERMENTAÇÃO ALCOÓLICA EM BATELADA ALIMENTADA}

Dissertação apresentada à Escola de Engenharia de São Carlos da Universidade de São Paulo como parte dos requisitos para obtenção do Título de Mestre em Ciências.

Área de Concentração: Dinâmica das Máquinas e Sistemas

Orientador: Prof. Dr. Adriano A. G. Siqueira

ESTE EXEMPLAR TRATA-SE DA VERSÃO CORRIGIDA.

A VERSÃO ORIGINAL ENCONTRASE DISPONIIVEL JUNTO AO

DEPARTAMENTO DE ENGENHARIA MECÂNICA DA EESC-USP.

São Carlos

2015 


\title{
AUTORIZO A REPRODUÇÃO TOTAL OU PARCIAL DESTE TRABALHO, POR QUALQUER MEIO CONVENCIONAL OU ELETRÔNICO, PARA FINS DE ESTUDO E PESQUISA, DESDE QUE CITADA A FONTE.
}

\author{
Vilela, Paulo Roberto Chiarolanza \\ V695m Modelagem, simulação e otimização dinâmica aplicada \\ a um processo de fermentação alcoólica em batelada \\ alimentada / Paulo Roberto Chiarolanza Vilela; \\ orientador Adriano Almeida Gonçalves Siqueira. São \\ Carlos, 2015. \\ Dissertação (Mestrado) - Programa de Pós-Graduação \\ em Engenharia Mecânica e Área de Concentração em \\ Dinâmica de Máquinas e Sistemas -- Escola de Engenharia \\ de São Carlos da Universidade de São Paulo, 2015.
}

1. Modelagem Matemática. 2. Fermentação Etanólica. 3. Batelada Alimentada. 4. H infinito. 5. Linear a Parâmetros Variantes. I. Título. 
FOLHA DE JULGAMENTO

Candidato: Engenheiro PAULO ROBERTO CHIAROLANZA VILELA.

Título da dissertação: "Modelagem, simulação e otimização dinâmica aplicada a um processo de fermentação alcoólica em batelada alimentada".

Data da defesa: 09/10/2015

Comissão Julgadora:

Resultado:

Prof. Associado Adriano Almeida Gonçalves Siqueira (Orientador)

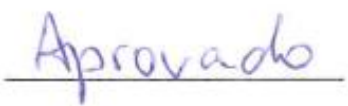

(Escola de Engenharia de São Carlos/EESC)

Prof. Associado Marco Henrique Terra

(Escola de Engenharia de São Carlos/EESC)

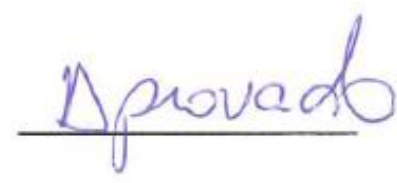

Dr. Mário Lúcio Lopes

APROUADO

(Fermentec Ltda.)

Coordenador do Programa de Pós-Graduação em Engenheira Mecânica: Prof. Associado Gherhardt Ribatski

Presidente da Comissão de Pós-Graduação:

Prof. Associado Paulo César Lima Segantine 

Dedicatória

À minha esposa Vanina, meus filhos Enzo e Felipe, meus pais Anna e Roberto e minha irmã Karina por todo o apoio e compreensão durante a elaboração deste trabalho. 

À minha esposa Vanina pelo apoio durante todo o período em que me dediquei a pesquisa.

Aos meus filhos Enzo e Felipe por emprestarem um pouco do seu tempo para que eu me dedicasse a pesquisa.

A meu pai Roberto e minha mãe Anna e também minha irmã Karina.

Ao meu orientador Adriano Siqueira por toda a paciência, compreensão e dedicação durante o período em que estive envolvido na pesquisa.

À Fermentec Ltda. Tecnologias em Açúcar e Álcool por fornecer todos os recursos necessários para a execução dos experimentos e análises.

Às minhas amigas Bruna, Crisla, Juliana, Milene, Silene e Vanessa pelo auxílio e suporte durante os experimentos e análises.

Aos meus amigos Júlio e Marcel pelo apoio e motivação dado direta ou indiretamente durante o período de estudos.

Ao meu amigo Rudimar pelos artigos fornecidos e dúvidas esclarecidas durante os estudos.

Ao Dr. Mário Lúcio Lopes e ao Dr. Henrique Vianna de Amorim pelo seu apoio e contribuições inestimáveis na elaboração deste trabalho.

Por fim, a todos que auxiliaram de maneira direta ou indireta na execução deste trabalho e que não foram citados, desculpem a omissão. 

Vilela, P. R. C. Modelagem, simulação e otimização dinâmica aplicada a um processo de fermentação alcoólica em batelada alimentada. 2015. 109 f. Dissertação (Mestrado) - Programa de Pós-Graduação em Engenharia Mecânica e Área de Concentração em Dinâmica de Máquinas e Sistemas -Escola de Engenharia de São Carlos da Universidade de São Paulo, 2015.

O uso de etanol combustível no Brasil é hoje considerado o mais importante programa de combustível comercial renovável do mundo, sendo um potencial substituto aos derivados de petróleo. O aumento de rendimento fermentativo e a diminuição das perdas são objetivos de estudo em diversos centros de pesquisa, sendo o estudo da modelagem matemática e simulação do processo de grande importância para tal. A presente pesquisa apresenta como função identificar um modelo matemático para a linhagem isolada de Saccharomyces cerevisiae PE-2, de maneira a otimizar a maneira como é realizada a sua alimentação através de um controle $H_{\infty}$ por representação quasi-LPV. São realizados 9 ensaios de fermentação em 3 temperaturas distintas sob mesmas condições de concentração de substrato entrante. Após a finalização dos experimentos $\mathrm{e}$ análises, realiza-se a estimativa dos parâmetros componentes das equações diferenciais que modelam a cinética fermentativa, através de um algoritmo Quasi-Newton. De posse do modelo matemático, desenvolve-se um controle otimizado para a temperatura de $33^{\circ} \mathrm{C}$ (temperatura usual de controle no processo industrial), considerando os parâmetros " $s$ " e " $v$ " variantes no tempo e os parâmetros $x=150 \mathrm{~g} / \mathrm{l}$ e $p=70 \mathrm{~g} / \mathrm{l}$ fixados, sendo valores médios obtidos durante o experimento. A utilização do controle desenvolvido possibilita um aumento de produtividade na faixa de $10 \%$ com relação a alimentação realizada em laboratório. Os resultados finais comprovam a eficiência do modelo matemático desenvolvido, comparado a outros estudos semelhantes, a influência da temperatura nos parâmetros cinéticos e a possibilidade de otimizar o processo através de um controle avançado do processo.

Palavras-chave: Modelagem Matemática. Fermentação Etanólica. Batelada Alimentada. H-infinito. Linear a Parâmetros Variantes. 
Vilela, P. R. C. Modeling, simulation and dynamic optimization applied to an alcoholic fermentation process in fed-batch. 2015. $109 \mathrm{f}$. Thesis (Master's degree) - Graduate Program in Mechanical Engineering and Concentration Area in Machine and System Dynamics - School of Engineering of São Carlos, University of São Paulo, 2015.

The use of ethanol in Brazil is considered the most important commercial renewable fuel program in the world, with a potential substitute for oil products. The increase in fermentation yield and losses reduction are objectives of study in various research centers, where the study of mathematical modeling and simulation of the process is of significant importance. This research presents as function to identify a mathematical model for the isolated strain of Saccharomyces cerevisiae PE-2, in order to optimize the way their substrate is fed, through a $H_{\infty}$ control based on quasi-LPV representation. Nine fermentation tests are performed at three different temperatures under the same conditions for incoming substrate concentration. After the experiments and analysis, it is carried out the estimation of parameters which are components of the differential equations that explain the fermentation kinetics, through a QuasiNewton algorithm. With the mathematical model obtained, it is developed an optimal control for temperature $33^{\circ} \mathrm{C}$ (usual temperature control in the industrial process), considering the parameters " $s$ " $e$ " $v$ " variyng in time and the parameters $x=150 \mathrm{~g} / \mathrm{l}$ e $p=70 \mathrm{~g} / \mathrm{l}$ set, which are average values obtained over the tests. The use of the control developed, applied to the flow variation, allows increasing productivity in $10 \%$ when compared with the flow performed in the tests conditions. The final results demonstrated the efficacy of the developed mathematical model, compared to other similar studies, the influence of temperature on the kinetic parameters and the possibility to optimize the process through an advanced process control.

Keywords: Mathematical Modeling. Ethanol fermentation. Fed batch. H-infinity. Linear Parameter Varying. 
"Os que se encantam com a prática sem a ciência são como os timoneiros que entram no navio sem timão nem bússola, nunca tendo certeza do seu destino"

(Leonardo da Vinci) 



\section{Lista de Figuras}

Figura 1 - Produção de Álcool Combustível no Brasil nos últimos 10 anos (UNICA, 2015).

Figura 2 - Curva de crescimento microbiano (DORAN, 1995).

Figura 3 - Classificação dos Métodos de Otimização (BORGES, 2008). * Métodos de Otimização Não Determinísticos são considerados métodos de ordem zero.

Figura 4 - Nove biorreatores igualmente distribuídos em 3 temperaturas $\left(30^{\circ} \mathrm{C}, 33^{\circ} \mathrm{C} \mathrm{e}\right.$ $36^{\circ} \mathrm{C}$ ) controladas individualmente.

Figura 5 - Células de levedura ao microscópio óptico sob ação do corante eritrosina (Fonte: FERMENTEC, 2014a).

Figura 6 - Câmara de Neubauer utilizada na contagem de células de levedura (Fonte: FERMENTEC, 2014a).

Figura 7 - Câmara de Neubauer apresentando os locais onde deve ser realizada a contagem (Fonte: FERMENTEC, 2014a).

Figura 8 - Comparação referente à Viabilidade nos dois ciclos e nas três temperaturas utilizadas durantes os procedimentos experimentais.

Figura 9 - Comparação referente à quantidade de Biomassa nos dois ciclos e nas três temperaturas utilizadas durantes os procedimentos experimentais.

Figura 10 - Variação da Quantidade de Manitol [mg/l] para cada uma das temperaturas analisadas.

Figura 11 - Variação da Porcentagem de Glicerol para cada uma das temperaturas analisadas.

Figura 12 - Volume, Concentração de Biomassa, Substrato e Produto na temperatura de $30 \circ \mathrm{C}$. 13 - Volume, Concentração de Biomassa, Substrato e Produto na temperatura de

$33^{\circ} \mathrm{C}$. $36^{\circ}$. Volume, Concentração de Biomassa, Substrato e Produto na temperatura de

Figura 15 - Taxa de Conversão média ao final do processo fermentativo de substrato em produto em cada uma das temperaturas analisadas. $\quad 85$

Figura 16 - Taxa de Conversão média ao final do processo fermentativo de substrato em células em cada uma das temperaturas analisadas.

Figura 17 - Produtividade média ao final do processo fermentativo em cada uma das temperaturas analisadas.

Figura 18 - Resultado da estimação dos parâmetros para temperatura de $30^{\circ} \mathrm{C}$, comparando os dados experimentais e a estimação dos parâmetros - Biomassa ( $g / \mathrm{l})$

Figura 19 - Resultado da estimação dos parâmetros para temperatura de $30^{\circ} \mathrm{C}$, comparando os dados experimentais e a estimação dos parâmetros - Substrato (g/l)

Figura 20 - Resultado da estimação dos parâmetros para temperatura de $30^{\circ} \mathrm{C}$, comparando os dados experimentais e a estimação dos parâmetros - Produto (g/l)

Figura 21 - Resultado da estimação dos parâmetros para temperatura de $30^{\circ} \mathrm{C}$, comparando os dados experimentais e a estimação dos parâmetros - Volume do Tanque (I)

Figura 22 - Resultado da estimação dos parâmetros para temperatura de $33^{\circ} \mathrm{C}$, comparando os dados experimentais e a estimação dos parâmetros - Biomassa (g/l)

Figura 23 - Resultado da estimação dos parâmetros para temperatura de $33^{\circ} \mathrm{C}$, comparando os dados experimentais e a estimação dos parâmetros - Substrato (g/l)

Figura 24 - Resultado da estimação dos parâmetros para temperatura de 33ㄷ, comparando os dados experimentais e a estimação dos parâmetros - Produto (g/l) 
Figura 25 - Resultado da estimação dos parâmetros para temperatura de $33^{\circ} \mathrm{C}$, comparando os dados experimentais e a estimação dos parâmetros - Volume do Tanque (I)

Figura 26 - Resultado da estimação dos parâmetros para temperatura de $36^{\circ} \mathrm{C}$, comparando os dados experimentais e a estimação dos parâmetros - Biomassa (g/l)

Figura 27 - Resultado da estimação dos parâmetros para temperatura de 36ㄷ, comparando os dados experimentais e a estimação dos parâmetros - Substrato (g/l)

Figura 28 - Resultado da estimação dos parâmetros para temperatura de 36ㅇ, comparando os dados experimentais e a estimação dos parâmetros - Produto ( $(\mathrm{g} / \mathrm{l})$

Figura 29 - Resultado da estimação dos parâmetros para temperatura de $36 \circ C$, comparando os dados experimentais e a estimação dos parâmetros - Volume do Tanque (I)

Figura 30 - Resultado da otimização da vazão de entrada sobre a concentração de produto.

Figura 31 - Resultado do controlador sobre a vazão de entrada. 


\section{Lista de Tabelas}

Tabela 1 - Funções objetivo empregadas em fermentações alcoólicas conduzidas em bateladas alimentadas (BORGES, 2008).

Tabela 2 - Restrições impostas no Problema de Otimização Dinâmica envolvendo fermentação alcoólica em batelada alimentada (BORGES, 2008). ..............................53

Tabela 3 - Viabilidade e Brotamento no 10 Ciclo..............................................................74

Tabela 4 - Viabilidade e Brotamento no 20 Ciclo.................................................................75

Tabela 5 - Concentração média de biomassa [ $\mathrm{g} / \mathrm{l}]$ existente nos biorreatores cuja

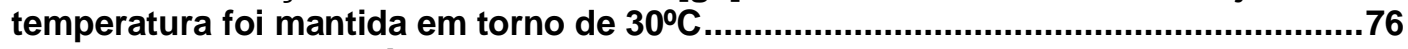

Tabela 6 - Concentração média de biomassa [g/l] existente nos biorreatores cuja temperatura foi mantida em torno de 33ㄷ.........................................................76

Tabela 7 - Concentração média de biomassa [g/l] existente nos biorreatores cuja temperatura foi mantida em torno de 36ㄷ.................................................................77

Tabela 8 - Variação da Concentração média de etanol nas amostras de vinho coletadas para cada uma das temperaturas analisadas.................................................................78

Tabela 9 - Valores de pH para cada um dos biorreatores e cada um dos ciclos executados...............................................................................................................79

Tabela 10 - Variação da quantidade de Açúcares Redutores Totais (ART) [g/l] para cada uma das temperaturas analisadas....................................................................79

Tabela 11 - Densidade [g/l], massa [g] e volume [l] médios para a temperatura de $30^{\circ} \mathrm{C} .81$

Tabela 12 - Densidade [g/l], massa [g] e volume [l] médios para a temperatura de $33^{\circ} \mathrm{C} .82$

Tabela 13 - Densidade [g/l], massa [g] e volume [l] médios para a temperatura de 36ㅇ .82

Tabela 14 - Rendimento Fermentativo nos dois ciclos, para cada uma das temperaturas estudadas neste trabalho.

Tabela 15 - Resultados experimentais da fermentação em batelada alimentada: condições iniciais e finais dos experimentos.

Tabela 16 - Dados experimentais utilizados na obtenção do modelo matemático (Temperatura $\left.=30^{\circ} \mathrm{C}\right)$.

Tabela 17 - Dados experimentais utilizados na obtenção do modelo matemático $\left(\right.$ Temperatura $\left.=33^{\circ} \mathrm{C}\right)$

Tabela 18 - Dados experimentais utilizados na obtenção do modelo matemático $\left(\right.$ Temperatura $\left.=36^{\circ} \mathrm{C}\right)$.

Tabela 19 - Comparação entre os métodos Runge-Kutta 23 e Runge-Kutta 45 durante a

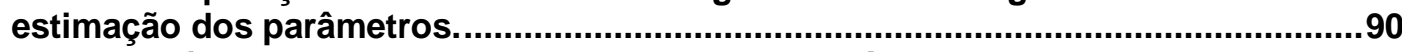

Tabela 20 - Parâmetros Iniciais e estimados usando o método Runge-Kutta 45..............91

Tabela 21 - Valor de Correlação Linear R-Múltiplo (\%) entre as variáveis independentes e a variável dependente Temperatura [ $\left.{ }^{\circ} \mathrm{C}\right]$.

Tabela 22 - Resultados dos ganhos do controlador..........................................................99 



\section{Lista de Siglas e Nomenclaturas}

Siglas Utilizadas

UNICA União da Indústria de Cana-de-Açúcar

ANP Agência Nacional do Petróleo, Gás Natural e Biocombustíveis

ADP Adenosina Difosfato

ATP Adenosina Trifosfato

POD Problemas de Otimização Dinâmica

PCO Problemas de Controle Ótimo

IDP Programação Dinâmica Iterativa

HDE Evolução Diferencial Híbrida

FO Função Objetivo

LPV Sistemas Lineares a Parâmetros Variantes

LMI Inequações Matriciais Lineares

NLMI Inequações Matriciais Não-Lineares

ART Açúcares Redutores Totais

Subscritos

max Limites superiores das variáveis

min Limites inferiores das variáveis

Cél Células

Prod Produto

Sub Substrato

$0 \quad$ Valor Inicial

Nomenclaturas nas Equações

$A R T_{\text {mosto(p/v) }}$ ART do mosto (peso/volume) $\%$

$\mathrm{EtOH}$ Teor Alcoólico $\%$

EtOHa Teor Alcoólico da fermentação anterior $\%$

$f \quad$ Fator dependente do Açúcar Total do mosto e volume alimentado

$k_{s} \quad$ Constante de saturação para o crescimento celular g/l 


\begin{tabular}{|c|c|}
\hline$k_{i}$ & $\begin{array}{l}\text { Constante de inibição do crescimento celular pelo } \\
\text { substrato }\end{array}$ \\
\hline $\mathrm{m}_{\mathrm{s}}$ & $\begin{array}{l}\text { Constante de manutenção celular: relativo a } \\
\text { quantidade necessária de substrato para a célula } \\
\text { manter-se viva }\end{array}$ \\
\hline$m$ & Índice da influência da inibição pela biomassa \\
\hline$n$ & Índice da influência da inibição pelo produto \\
\hline$\dot{p}$ & $\begin{array}{l}\text { Taxa de variação da concentração de produto no } \\
\text { meio }\end{array}$ \\
\hline$p$ & Concentração de produto no meio \\
\hline$p_{0}$ & Concentração inicial de produto no meio \\
\hline$p_{m}$ & $\begin{array}{l}\text { Concentração máxima de produto onde cessa o } \\
\text { crescimento microbiano }\end{array}$ \\
\hline$p_{F}$ & Concentração de produto ao final do processo \\
\hline$p(t)$ & Concentração de produto no instante $t$ \\
\hline$Q_{p}$ & Produtividade \\
\hline$\dot{s}$ & $\begin{array}{l}\text { Taxa de variação da concentração de substrato no } \\
\text { meio }\end{array}$ \\
\hline$s_{F}$ & Concentração do substrato entrante \\
\hline$s$ & Concentração de substrato no meio \\
\hline$s_{0}$ & Concentração inicial de substrato no meio \\
\hline$s(t)$ & Concentração de substrato no instante t \\
\hline$t$ & Tempo \\
\hline$t_{F}$ & Tempo total de fermentação \\
\hline$u$ & Vazão de entrada de substrato \\
\hline$v$ & Volume preenchido do biorreator \\
\hline$\dot{v}$ & Taxa de variação do volume do meio \\
\hline$v_{0}$ & Volume inicial preenchido do meio \\
\hline$v_{f}$ & Volume final preenchido do meio \\
\hline$v(t)$ & Volume preenchido do biorreator no instante $t$ \\
\hline$V_{\text {mosto }}$ & Volume de mosto alimentado \\
\hline$V_{v}$ & Volume de vinho \\
\hline
\end{tabular}




\begin{tabular}{|c|c|c|}
\hline$V_{F}$ & Volume de fermento & I \\
\hline$V_{v a}$ & Volume de vinho da fermentação anterior & I \\
\hline$V_{\mathrm{Fa}}$ & Volume de fermento da fermentação anterior & 1 \\
\hline$V_{r}$ & $\begin{array}{l}\text { Volume de amostra retirado para análises - quando } \\
\text { for considerável }\end{array}$ & I \\
\hline$\dot{x}$ & $\begin{array}{l}\text { Taxa de variação da concentração de biomassa no } \\
\text { meio }\end{array}$ & $g / / / h$ \\
\hline$x$ & Concentração de biomassa no meio & $g / l$ \\
\hline$x_{0}$ & Concentração inicial de células no meio & $g / l$ \\
\hline$x_{v}$ & Concentração de biomassa viva no meio & $g / l$ \\
\hline$x_{d}$ & Concentração de biomassa morta no meio & $g / l$ \\
\hline$x_{m}$ & $\begin{array}{l}\text { Concentração máxima de biomassa onde cessa o } \\
\text { crescimento microbiano }\end{array}$ & $g / l$ \\
\hline$x(t)$ & Concentração de biomassa no instante $t$ & $g / l$ \\
\hline$y_{x s}$ & $\begin{array}{l}\text { Rendimento de crescimento celular: relativo a } \\
\text { quantidade de substrato desviado para multiplicação } \\
\text { celular (reprodução) }\end{array}$ & $g_{\text {cél } / g_{\text {sub }}}$ \\
\hline$y_{p s}$ & $\begin{array}{l}\text { Rendimento de formação de produto: relativo a } \\
\text { quantidade de substrato utilizado na geração de } \\
\text { produto }\end{array}$ & $\mathrm{g}_{\text {prod }} / \mathrm{g}_{\mathrm{sub}}$ \\
\hline
\end{tabular}

Letras Gregas

$\begin{array}{lll}\sigma & \text { Taxa de consumo de substrato } & 1 / \mathrm{h} \\ \pi & \text { Taxa de formação de produto } & 1 / \mathrm{h} \\ \mu & \text { Taxa de crescimento celular específico } & 1 / \mathrm{h} \\ \mu_{m} & \text { Taxa específica máxima de crescimento celular } & 1 / \mathrm{h}\end{array}$





\section{Sumário}

Capítulo $1 \quad 25$

1 Introdução $\quad 25$

1.1 Motivação 25

1.2 Objetivos 28

1.3 Descrição do Trabalho 28

1.4 Disposição dos Capítulos 29

Capítulo $2 \quad 30$

2 Revisão Bibliográfica $\quad \mathbf{3 0}$

2.1 Histórico da Fermentação Alcoólica 30

2.2 Processos de Produção de Etanol e Condução da Fermentação 31

2.2.1 Fermentação Descontínua 31

2.2.2 Fermentação Descontínua Alimentada 32

2.2.3 Fermentação Semicontínua 33

2.2.4 Fermentação Contínua 33

2.2.5 Comparando os tipos de Fermentação 34

2.3 Breve Descrição do processo de Fermentação Alcoólica 34

2.4 Influência das Linhagens de Leveduras na produção de Etanol 37

2.5 A Cinética da Fermentação Alcoólica em Batelada Alimentada 39

2.6 Modelagem do crescimento celular 42

2.7 Métodos de identificação dos parâmetros do modelo cinético 45

2.8 Otimização Dinâmica de um processo fermentativo em batelada alimentada 49

2.8.1 Problema Geral da Otimização 51

2.9 Controle Não-Linear $H_{\infty}$

2.10 Controle $H_{\infty}$ via inequações matriciais lineares 54

2.11 Controle $H_{\infty}$ por representação quasi-LPV 55

Capítulo $3 \quad 59$

3 Procedimento para identificação dos parâmetros do modelo matemático e da otimização dinâmica

3.1 Condições de teste e procedimento experimental 59

3.2 Análises Microbiológicas 61

3.3 Análises Químicas 64

3.3.1 Determinação da concentração de glicose, frutose, sacarose, manitol e glicerol por cromatografia de troca aniônica 64 3.3.2 Determinação da concentração de Açúcares Redutores Totais em amostras de mosto. 65

3.3.3 Determinação do teor de sólidos solúveis dissolvidos na amostra pela medida de densidade em mosto.

3.4 Cálculos de Taxas de Conversão, Produtividade e Rendimento 66

3.5 Obtenção do Modelo Matemático utilizando MATLAB ${ }^{\circledR}$ 
4 Resultados Experimentais, Modelagem Matemática e Otimização do Processo de Fermentação Alcoólica em Batelada Alimentada

4.1 Condições de teste e procedimento experimental 73

$\begin{array}{lll}\text { 4.1.1 Análises Microbiológicas } & 74\end{array}$

$\begin{array}{lll}\text { 4.1.2 Análises Químicas } & 78\end{array}$

4.1.3 Taxas de Conversão, produtividade e rendimento fermentativo 85

4.2 Obtenção do modelo matemático 88

4.3 Otimização dinâmica da alimentação do biorreator 98

$\begin{array}{ll}\text { Capítulo } 5 & 101\end{array}$

5 Conclusões e Sugestões de Trabalhos Futuros 101

$\begin{array}{lll}5.1 \text { Conclusões } & 101\end{array}$

5.2 Sugestões de Trabalhos Futuros 102

$\begin{array}{ll}\text { Referências Bibliográficas } & 104\end{array}$ 


\section{Capítulo 1}

Neste capítulo é apresentada a motivação para o desenvolvimento do trabalho e o detalhamento de como será conduzido o mesmo. Dados sobre a situação atual do mercado brasileiro de produção de etanol são mostrados, revelando um panorama geral $\mathrm{e}$ as necessidades futuras com relação à importância do etanol de cana-de-açúcar no cenário internacional.

\section{Introdução}

\subsection{Motivação}

A necessidade da substituição de derivados de petróleo, a redução da emissão de gases poluentes e o efeito estufa tornaram a produção e uso de etanol combustível no Brasil o mais importante programa de combustível comercial renovável do mundo até hoje.

Segundo a UNICA (União da Indústria de Cana-de-Açúcar), durante a Safra 2013/2014 foram moídas mais de 650 milhões de toneladas de cana-deaçúcar, produzindo-se mais de 37 milhões de toneladas de açúcar e 27 bilhões de litros de etanol. A cana ocupa hoje cerca de 9 milhões de hectares, o que corresponde a aproximadamente $2,5 \%$ de toda área arável do país. Estes números tornam o Brasil o maior produtor mundial de cana-de-açúcar, seguido por Índia, Tailândia e Austrália.

O consumo de etanol no Brasil atingiu em 2014, segundo a ANP (Agência Nacional do Petróleo, Gás Natural e Biocombustíveis), a marca de 21,1 bilhões de litros, considerando-se tanto o etanol hidratado (combustível) quanto o anidro (misturado na gasolina). Estes números são aproximadamente 19\% superiores aos registrados em 2013.

O consumo de álcool combustível vem crescendo nas últimas décadas, principalmente devido a sua utilização como aditivo à gasolina e a sua 
característica "verde". A Figura 1 mostra a evolução da produção de etanol combustível no Brasil nos últimos 10 anos.

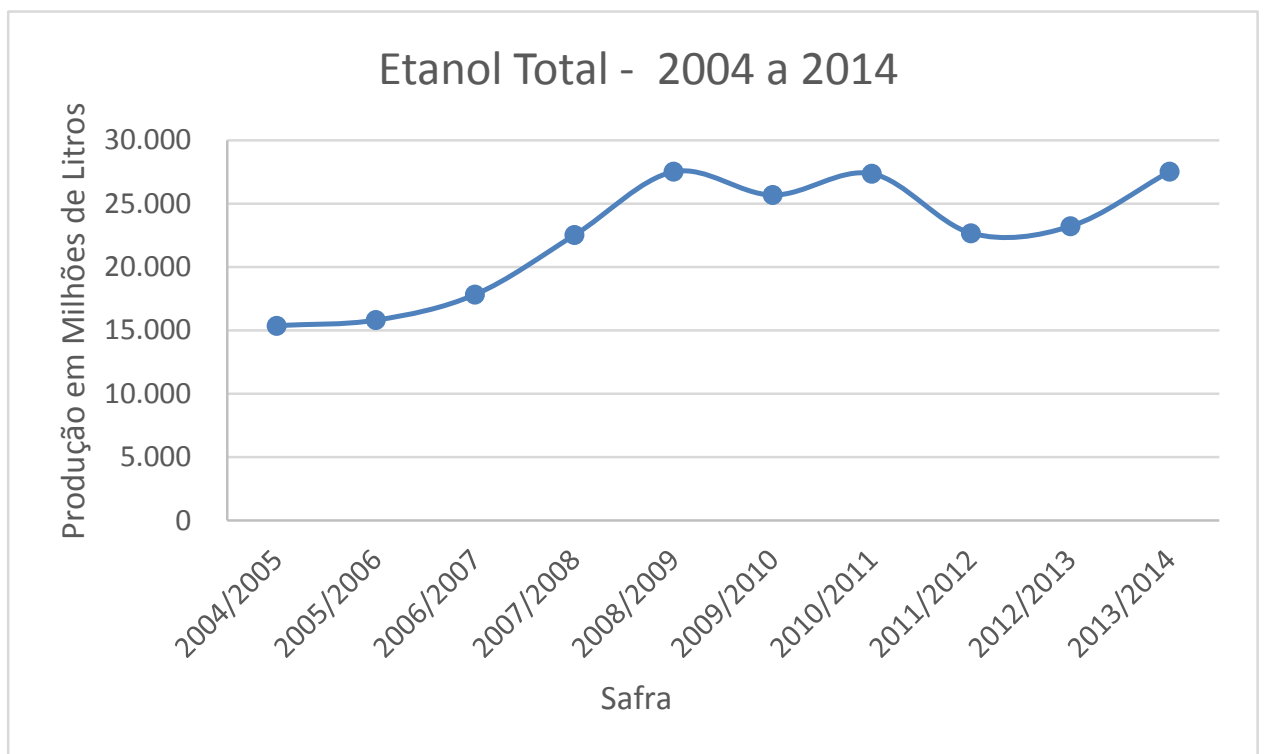

Figura 1 - Produção de Álcool Combustível no Brasil nos últimos 10 anos (UNICA, 2015).

Dentre as vantagens do consumo de etanol no Brasil, é possível citar (PACHECO, 2010):

- Menor emissão de poluentes: grande parte dos resíduos da queima de etanol são reabsorvidos na plantação de cana-de-açúcar e os resíduos das usinas na produção de etanol são quase totalmente aproveitados na indústria e na lavoura;

- Subprodutos geram renda: utilização do bagaço para produção de energia elétrica e de vinhaça como fertilizante.

- Menor dependência de combustíveis fósseis: combustíveis fósseis são muito poluentes, de difícil obtenção, fornecem riscos ao ambiente desde a sua retirada da fonte até a queima para geração de energia motora e são não-renováveis.

- Geração de divisas internacionais: produto de exportação fácil, principalmente em tempos de escassez do petróleo e de conscientização ecológica. 
Logo, pode-se concluir que, caso o Brasil vislumbre ser referência na produção de etanol combustível e desenvolvimento de tecnologias modernas para implantação de destilarias e necessário investir-se em pesquisas para melhoria do desempenho da produção de etanol (PACHECO, 2010).

A ampliação da produção de etanol só foi possível devido à evolução das tecnologias utilizadas tanto na área agrícola quanto na área industrial. Tais evoluções contribuíram para uma diminuição dos custos de produção e plantio.

Entre as décadas de 1980 e 2000, uma maior flexibilidade na operação integrada com os dois produtos da cana (açúcar e álcool) contou também com avanços em:

- Novas variedades de Cana

- Novos sistemas de moagem

- Aumento da capacidade dos biorreatores

- Utilização da vinhaça como fertilizante

- Controle biológico da broca

- Otimização das operações agrícolas

- Venda do excedente de energia

- Melhor gerenciamento em todas as áreas da indústria e agrícola

- Novos sistemas de colheita e transporte da cana

- Avanços da Automação Industrial

Tais fatores, segundo a UNICA (2012), contribuíram para a evolução do setor:

- Aumento de produtividade $33 \%$ t cana / ha;

- Aumento de $8 \%$ no teor de açúcar na cana;

- Aumento de $14 \%$ na taxa de conversão do açúcar na cana para etanol;

- Aumento de $130 \%$ da produtividade na fermentação $\left(\mathrm{m}^{3}\right.$ etanol $/ \mathrm{m}^{3}$ reator.dia) 
Para possibilitar um avanço ainda maior da rentabilidade deste processo, através do desenvolvimento tecnológico, torna-se necessário aprofundar ainda mais os estudos baseados em modelagem matemática e simulação do processo. Tal ferramenta possibilita prever o comportamento dinâmico e estacionário do processo, inclusive para condições não testadas empiricamente, determinando condições de operação ótimas, auxiliando no projeto e ajuste de sistemas de controle, sendo que o modelo matemático formulado constitui parte integrante do mesmo (SCHMIDELL e FACCIOTTI, 2001).

\subsection{Objetivos}

O objetivo geral deste trabalho é avaliar o processo de fabricação de etanol utilizando biorreatores em batelada alimentada com recirculação de fermento, de forma a otimizar a conversão de açúcar em etanol.

Entre os objetivos específicos, podem ser citados:

- Estudo do efeito inibitório do produto e do substrato;

- Estudo dos efeitos da temperatura sobre o processo de fermentação alcoólica

- Estudo e otimização da curva de vazão de entrada de substrato considerando os efeitos da temperatura.

\subsection{Descrição do Trabalho}

Esta dissertação de mestrado está dividida em duas partes. A primeira parte do trabalho é a modelagem da fermentação alcoólica em batelada alimentada considerando efeitos inibitórios de substrato e produto, bem como a relação da temperatura com a condução da fermentação alcoólica. A segunda parte trata da otimização dinâmica da alimentação de substrato durante 0 processo.

Durante a modelagem do sistema dinâmico realizado na primeira parte do trabalho, são realizadas simulações computacionais de maneira a comparar o 
sistema modelado com dados reais obtidos através de experimentos laboratoriais. Nesta modelagem são considerados os efeitos de inibição de substrato e produto.

$\mathrm{Na}$ segunda parte do trabalho é realizada a otimização dinâmica da alimentação de substrato de maneira a maximizar a produtividade de etanol, minimizando a quantidade de açúcares residuais ao final da fermentação. Os resultados obtidos são então comparados com os retratados na literatura.

\subsection{Disposição dos Capítulos}

No Capítulo 2 é realizada a Revisão Bibliográfica para o desenvolvimento desta dissertação.

No Capítulo 3 é descrita a Metodologia utilizada na modelagem não estruturada do processo de fermentação alcoólica em batelada alimentada, bem como a obtenção dos parâmetros cinéticos e a otimização dinâmica da alimentação de substrato.

No Capítulo 4 são apresentados os resultados da modelagem matemática e da otimização dinâmica.

No Capítulo 5 são apresentadas as conclusões e sugestões de trabalhos futuros. 


\section{Capítulo 2}

Neste capítulo apresenta-se a revisão bibliográfica realizada a respeito do tema abordado, destacando o histórico da fermentação alcoólica, os tipos de condução do processo de fermentação alcoólica, a cinética da fermentação alcoólica, as metodologias para estimação dos parâmetros cinéticos necessários para obter um modelo adequado e a otimização da fermentação alcoólica em batelada alimentada, através de algoritmos de controle ótimo e robustos.

\section{Revisão Bibliográfica}

\subsection{Histórico da Fermentação Alcoólica}

Produtos da fermentação, como pão, vinho e cerveja, são consumidos desde que se iniciou a prática da agricultura. Existem relatos que comprovam o consumo e fabricação de cerveja antes de 6000 A.C. (VILLEN, 2009).

No século XVII, Johann Joachim Bechner (1635 - 1682) afirmou que somente os líquidos açucarados são capazes de entrar em fermentação alcoólica. O álcool se formava durante 0 processo de fermentação, erradamente julgando a necessidade de ar para causar o fenômeno que dizia ser semelhante à combustão. Já no século XVIII, Joseph Black (1728-1799) postulou que o álcool etílico e o gás carbônico eram os únicos produtos formados do açúcar durante a fermentação alcoólica (PACHECO, 2010).

Lavoisier, em 1789, foi o primeiro a efetuar um estudo quantitativo da fermentação alcoólica, identificou além do álcool etílico e do gás carbônico um outro composto, o ácido acético. Porém coube a Pasteur, em 1857, explicar a natureza da fermentação alcoólica, atribuindo-a a atuação de seres vivos, as leveduras, como agentes causais (PACHECO, 2010). 


\subsection{Processos de Produção de Etanol e Condução da Fermentação}

A produção de etanol pode ser conduzida de quatro maneiras diferentes. São elas: descontínua, semicontínua, descontínua alimentada (também conhecida como batelada alimentada) ou contínua. Todos estes processos podem ser conduzidos com ou sem recirculação de fermento (SCHMIDELL e FACCIOTTI, 2001).

Na prática industrial, os processos utilizados são o contínuo e o batelada, onde o processo em batelada corresponde à batelada alimentada. São utilizados, na maioria dos casos, biorreatores de aço fechados, também denominados Dornas de Fermentação, que possuem sistema de agitação e temperatura controlada entre $32^{\circ} \mathrm{C}$ e $35^{\circ} \mathrm{C}$, quando a concentração de etanol se situa na faixa de 7 a $12^{\circ} \mathrm{GL}$. É também usual, quando da utilização de dornas fechadas, a presença de um sistema de recuperação de etanol arrastado com 0 gás carbônico produzido, que corresponde a aproximadamente $1,5 \%$ de todo o etanol produzido no processo (PACHECO, 2010).

\subsubsection{Fermentação Descontínua}

Também conhecida como Fermentação em Batelada. O procedimento para se realizar uma fermentação em batelada segue o seguinte processo:

- Adiciona-se em um biorreator, uma quantidade adequada de substrato de forma a suprir as necessidades de nutrição e desenvolvimento do microrganismo e ao acúmulo do produto desejado.

- Adiciona-se o microrganismo responsável pelo processo biológico desejado e aguarda-se que o mesmo ocorra. 
- Passado o tempo de fermentação necessário, retira-se o caldo fermentado do biorreator e executam-se as operações necessárias para obtenção do produto final.

- Executa-se assepsia do reator e dos outros equipamentos envolvidos, possibilitando o início de uma nova batelada (SCHMIDELL e FACCIOTTI, 2001).

Fermentações deste tipo não são indicadas industrialmente, pois a adição do substrato de maneira direta, no início da fermentação, exerce efeito inibitório, repressivo ou desvia o metabolismo celular para subprodutos que não interessam ao processo. (CARVALHO e SATO, 2001).

A aplicação de fermentação do tipo batelada só acontece em escala laboratorial ou pequenas destilarias de aguardente (PACHECO, 2010).

\subsubsection{Fermentação Descontínua Alimentada}

Pode ser denominada também como Batelada Alimentada ou "MelleBoinot". O procedimento adotado na fermentação descontínua alimentada é o seguinte:

- Em um biorreator, adiciona-se o microrganismo previamente tratado para remoção de contaminantes

- Adiciona-se, de maneira contínua ou intermitente, o(s) substrato(s). A vazão de entrada pode ser constante ou variar com o tempo.

- Preenchidos os biorreatores, aguarda-se tempo suficiente para que o consumo do substrato e, consequentemente, a obtenção do produto final desejado seja realizada (SCHMIDELL e FACCIOTTI, 2001).

Neste processo reduz-se a inibição da fermentação pelo substrato, já que o açúcar é inserido no reator de forma contínua e/ou intermitente. Porém, os efeitos inibitórios do acúmulo de etanol ao final do processo não têm seus efeitos reduzidos (SOUZA, 2009). 
Possui como vantagens a facilidade na assepsia dos equipamentos envolvidos no processo, a possibilidade de trabalhar com altas concentrações do substrato tendo-se um acréscimo na produtividade do etanol e uma diminuição do volume do reator e da quantidade de vinhaça produzida (IMPE VAN et al., 1994)

\subsubsection{Fermentação Semicontínua}

$\mathrm{Na}$ fermentação semicontínua, depois de inseridos no biorreator o substrato e o microrganismo, seguem-se o seguinte procedimento:

- Aguarda-se o término da fermentação;

- Remove-se parte do meio fermentado, mantendo-se o restante no biorreator;

- Adiciona-se no biorreator um volume de substrato igual ao retirado na operação anterior (SCHMIDELL e FACCIOTTI, 2001).

O processo é repetido enquanto não houver queda de produtividade. Este processo é chamado de semi-contínuo por que, tanto a entrada de substrato quanto a saída de material fermentado são realizadas de maneira intermitente. Este processo, apesar de suas poucas aplicações, era utilizado na fabricação de vinagre a partir do vinho (SCHMIDELL e FACCIOTTI, 2001).

\subsubsection{Fermentação Contínua}

Na fermentação contínua, o reator é alimentado de maneira contínua com o substrato desejado, mantendo-se o volume de reação constante através da retirada contínua do caldo de fermentação (SCHMIDELL e FACCIOTTI, 2001).

As principais vantagens do processo contínuo sobre o descontínuo tradicional são decorrentes da operação em estado estacionário, já que se reduz o "tempo morto", o caldo obtido é mais uniforme, maior facilidade para 
emprego de sistemas de controle mais sofisticados e menor necessidade de mão-de-obra (SOUZA, 2009; PACHECO, 2010).

Entretanto é necessário um maior investimento inicial na planta, a ocorrência de mutações genéticas e possível seleção de uma variedade menos produtiva ou ainda a possibilidade maior de contaminação bacteriana por se tratar de um sistema aberto, são algumas das desvantagens deste tipo de processo de fermentação (SOUZA, 2009).

\subsubsection{Comparando os tipos de Fermentação}

Segundo AMORIM (2005) e SCHMIDELL e FACCIOTTI (2001), a utilização de processo de batelada alimentada apresenta maior rendimento, possibilidade de aumento do teor alcoólico e consequente redução da quantidade de vinhaça produzida, maior flexibilidade do processo e menor susceptibilidade às contaminações. Já a fermentação contínua apresenta maior facilidade de automação e menor custo de instalação devido ao menor volume de equipamentos necessários, tais como dornas e trocadores de calor.

\subsection{Breve Descrição do processo de Fermentação Alcoólica}

O processo de fermentação não ocorre por acaso. A levedura utiliza a fermentação para conseguir energia e assim sobreviver. O etanol produzido na fermentação é apenas um dos subprodutos deste processo. Logo se torna necessário entender e oferecer as condições necessárias e ideais para que a levedura produza etanol com a maior eficiência possível.

Durante a fermentação alcoólica, as leveduras produzem uma enzima chamada invertase, responsável por hidrolisar (decompor) a sacarose $\left(\mathrm{C}_{12} \mathrm{H}_{22} \mathrm{O}_{11}\right)$ em duas moléculas menores, chamadas monossacarídeos, a qual possibilita a formação do etanol. Os monossacarídeos produzidos nesta decomposição são a D-glicose e a D-frutose, que apesar de possuírem a mesma fórmula molecular, apresentam diferentes fórmulas estruturais. A inversão é demonstrada na Equação 1 (SOUZA, 2009). 
$\mathrm{C}_{12} \mathrm{H}_{22} \mathrm{O}_{11}+\mathrm{H}_{2} \mathrm{O} \stackrel{\text { invertase }}{\longrightarrow} \underset{\substack{D \\ D \text {-glicose }}}{\mathrm{C}_{12} \mathrm{O}_{6}}+\underset{\text { D-frutose }}{\mathrm{C}_{6} \mathrm{H}_{12} \mathrm{O}_{6}}$

Equação 1

$\mathrm{Na}$ ausência de oxigênio, a atuação enzimática da levedura tende a produzir etanol $\left(\mathrm{C}_{2} \mathrm{H}_{5} \mathrm{OH}\right)$ e água $\left(\mathrm{H}_{2} \mathrm{O}\right)$ a partir do ácido pirúvico $(P I)$. Este processo ocorre no citoplasma da célula e o seu balanço está representado pelo Equação 2, chamada de Equação de Gay-Lussac. Na presença de oxigênio, parte do ácido pirúvico é deslocado para o Ciclo de Krebs (Equação $3)$, onde enzimaticamente será oxidado, produzindo dióxido de carbono $\left(\mathrm{CO}_{2}\right)$ e água $\left(\mathrm{H}_{2} \mathrm{O}\right)$ (SOUZA, 2009).

$$
\begin{array}{ll}
\mathrm{C}_{6} \mathrm{H}_{12} \mathrm{O}_{6}+2 \mathrm{Pi}+2 \mathrm{ADP} \longrightarrow 2 \mathrm{C}_{2} \mathrm{H}_{5} \mathrm{OH}+2 \mathrm{CO}_{2}+2 \mathrm{ATP}+57 \mathrm{kcal} & \text { Equação } 2 \\
\mathrm{C}_{6} \mathrm{H}_{12} \mathrm{O}_{6}+6 \mathrm{O}_{2} \longrightarrow 6 \mathrm{CO}_{2}+6 \mathrm{H}_{2} \mathrm{O}+38 \mathrm{ATP}+688 \mathrm{kcal} & \text { Equação } 3
\end{array}
$$

Apesar de não ser possível distinguir limites de separação, identificam-se 3 períodos durante a fermentação alcoólica (SCHMIDELL e FACCIOTTI, 2001):

1. Fase preliminar: adaptação da levedura ao meio, restrição de produção de gás carbônico.

2. Fase principal (ou tumultuosa): intensa produção de gás carbônico e etanol, com consequente aumento da temperatura do meio.

3. Fase complementar: queda da produção de etanol e exaustão da quantidade de substrato no meio.

Quanto ao crescimento celular, identificam-se as seguintes fases, mostradas na Figura 2 (DORAN, 1995):

1. Fase lag: adaptação metabólica da levedura ao estresse osmótico inicial a qual está sendo submetida.

2. Fase exponencial: crescimento de biomassa apresenta sua maior taxa 
3. Fase estacionária: quantidade de células que se multiplicam e mortas estão em equilíbrio (taxa de crescimento é igual a taxa de mortalidade)

4. Fase de declínio: aumento da taxa de mortalidade com relação a taxa de crescimento celular, ou seja, morrem mais células do que nascem.

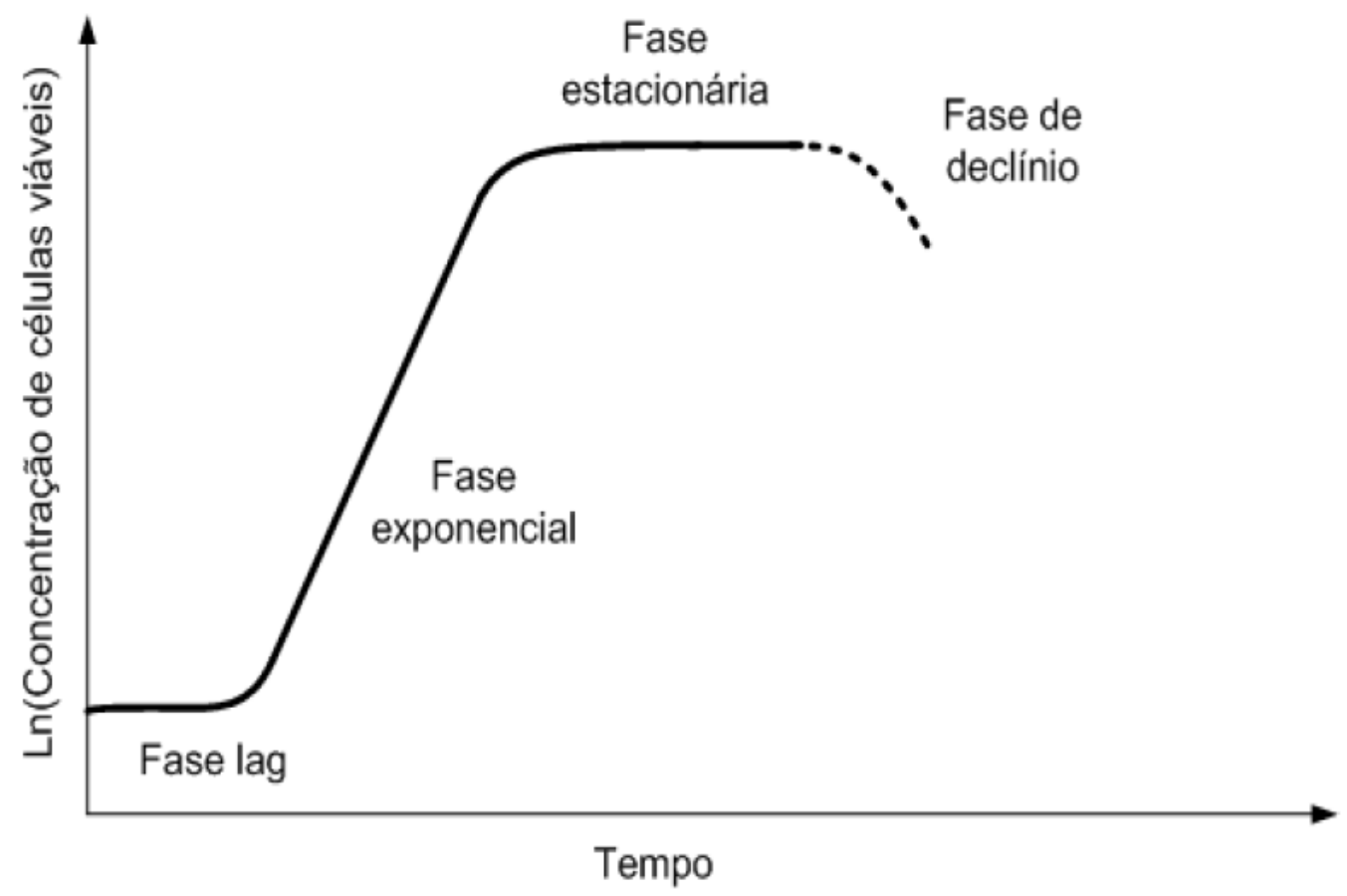

Figura 2 - Curva de crescimento microbiano (DORAN, 1995).

Em fermentações do tipo Batelada Alimentada tenta-se controlar o processo de modo que a última fase seja a estacionária, seguida então pela fase de centrifugação e tratamento ácido (AMORIM, 2005; YABARRENA, 2012).

Teoricamente, o rendimento ( $\mathrm{Y} / \mathrm{S})$ para produção de etanol é de 0,511

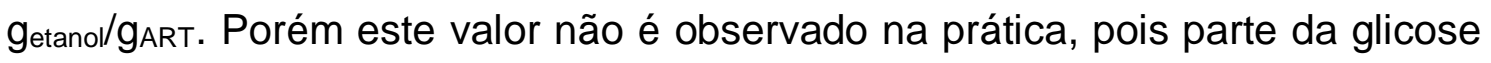
é desviada para produção de glicerol, alcoóis superiores entre outros subprodutos (PACHECO, 2010).

Devido as diversas reações catalisadas enzimaticamente, percebe-se a influência de diversos fatores externos, como $\mathrm{pH}$, temperatura, pressão, concentração de reagentes, nutrientes, acúmulo de etanol (SOUZA, 2009; 
PACHECO, 2010), sendo que alguns influenciam mais severamente o metabolismo das leveduras, provocando assim redução da viabilidade celular e consequentemente diminuição da produtividade de etanol.

As leveduras que apresentam melhor desempenho, com alta eficiência fermentativa são as Saccharomyces cerevisiae, as quais vêm sendo selecionadas para atuar em ambientes industriais com características que as tornam mais tolerantes aos produtos da fermentação (BORGES, 2008).

\subsection{Influência das Linhagens de Leveduras na produção de Etanol}

As leveduras do gênero Saccharomyces estão entre os organismos mais importantes e mais estudados em ciências biológicas e sua importância histórica na economia e na cultura é indiscutível (DUNN, 2012).

A seleção de leveduras para produção eficiente de etanol combustível leva em consideração diversos fatores. O número de fatores que influenciam no comportamento da produção de etanol pelas leveduras vem sofrendo um aumento gradual, conforme os pesquisadores aprendem mais sobre a fisiologia e genética envolvida neste processo (PANCHAL, 1990; AMORIM, 2005).

Uma levedura "ideal" para produção de etanol combustível deveria possuir como características principais (PANCHAL, 1990):

- Possuir resistência a toxicidade do etanol

- Ser osmotolerante

- Ser geneticamente estável

- Possuir tolerância a ácido

- Possuir tolerância a temperatura

- Fermentar de maneira rápida e eficiente

- Propagar facilmente

- Fermentar diversos tipos de substratos

- Ter baixa taxa de geração de calor durante a fermentação

- Ser dominante com relação a outras leveduras no processo 
PANCHAL (1990) afirma que não existe uma levedura que possua todas estas características, porém as pesquisas neste assunto continuam.

Teoricamente, as leveduras convertem $1 \mathrm{~g}$ de glicose em 0,51 g de etanol e 0,49 g de dióxido de carbono. Na prática, porém, o crescimento celular ocorre durante a fermentação, desviando parte do açúcar e resultando em 0,46 g de etanol e 0,44 $\mathrm{g}$ de dióxido de carbono, resultando assim em rendimentos próximos a 90\% na conversão do carbono. São muitos os fatores que provocam diminuição do rendimento, entre os quais podem ser citados:

- Inibição pelo produto

- Inibição pelos subprodutos, como ácidos orgânicos

- Inibição pela pressão osmótica (concentração do substrato)

- Inibição por elevadas temperaturas

- Inibição da fermentação pela aeração, com aumento do crescimento celular

- Inibição da fermentação devido contaminação bacteriana ou por outras leveduras, ou por altos níveis de certos cátions

- Inibição da fermentação devido à instabilidade da linhagem, gerando mutações ou variantes menos resistentes.

Segundo BASSO et al. (1993), as Unidades Industriais que produzem etanol no Brasil, geralmente, iniciam a safra utilizando levedura de panificação. Porém, tais leveduras são incapazes de permanecer no processo, competindo com leveduras "selvagens" (leveduras contaminantes no processo, provenientes da matéria prima ou de mutações genéticas) além de não suportarem as condições adversas provenientes do ambiente industrial.

BASSO et al (2008) avaliou o potencial de 340 leveduras da espécie Saccharomyces, obtidas em 50 destilarias brasileiras. Destas, 67\% produziam grande quantidade de espuma, 33\% eram floculantes e 53\% não foram capazes de metabolizar todo o açúcar existente no meio. Apenas $20 \%$ das leveduras avaliadas não possuíam estas características restritivas e poderiam ser aproveitadas no meio industrial. Uma vez inseridas em uma destilaria, 
linhagens selecionadas reduzem o custo de produção através do aumento do rendimento e da redução do consumo de insumos como, por exemplo, antiespumantes.

\subsection{A Cinética da Fermentação Alcoólica em Batelada Alimentada}

O estudo da cinética de fermentação alcoólica possui grande potencial industrial e econômico e, devido a isso, é de grande interesse aos centros de pesquisa especializados.

O objetivo do estudo da cinética de fermentação é relacionar produtividade com taxas de crescimento celular, consumo de substrato e demais parâmetros correlatos. Assim como todo modelo matemático, a complexidade da descrição cinética depende invariavelmente da aplicação realizada e dos parâmetros envolvidos (BORGES, 2008).

Para projetar de maneira adequada um controle baseado no modelo matemático é necessário primeiramente identificar o modelo a ser utilizado e seus parâmetros, sendo assim, algumas considerações devem ser realizadas sobre esta fase do projeto. Modelar matematicamente uma fermentação apresenta como principal dificuldade determinar as equações que regem tal reação bioquímica.

A formulação do processo de fermentação em batelada alimentada para produção de etanol utilizando-se Saccharomyces cerevisiae é indicado por minimizar os efeitos da alta concentração de substrato e produto, que ocorrem no início e final do processo, respectivamente. Equação 4 a Equação 9 descrevem o comportamento dinâmico do processo.

Considerando que o crescimento celular depende da diluição das células (devido à entrada de mosto) e também da multiplicação (reprodução) das células (taxa de crescimento celular específico, Equação 12), tem-se a Equação 4. 
$\dot{x}=-\frac{u}{v} x+\mu x$

$$
x(0)=x_{0}
$$

Equação 4

sendo:

- $\quad \dot{x} \rightarrow$ Taxa de variação da concentração de biomassa no meio (crescimento celular) [g/l/h],

- $\quad u \rightarrow$ vazão de entrada de substrato [l/h],

- $\quad v \rightarrow$ volume preenchido do biorreator [l],

- $\quad x \rightarrow$ concentração de biomassa no meio $[\mathrm{g} / \mathrm{l}]$,

- $\quad \mu \rightarrow$ taxa de crescimento celular específico [1/h],

- $x(0)=x_{0} \rightarrow$ concentração inicial de células no meio $[\mathrm{g} / \mathrm{l}]$.

A Equação 5 mostra que a taxa de variação do substrato depende da quantidade de substrato que está entrando no processo e sendo diluída no vinho e da taxa específica de consumo pelas células, mostrada na Equação 6.

$$
\begin{array}{ll}
\dot{s}=\frac{u}{v}\left(s_{F}-s\right)-\sigma x & s(0)=s_{0} \\
\sigma=\left(\frac{1}{y_{x s}} \mu+m_{s}\right) &
\end{array}
$$

Equação 6 sendo:

- $\dot{s} \rightarrow$ Taxa de variação da concentração de substrato no meio $[\mathrm{g} / \mathrm{l} / \mathrm{h}]$,

- $S_{F} \rightarrow$ Concentração do substrato entrante [g/l],

- $s \rightarrow$ concentração de substrato no meio $[\mathrm{g} / \mathrm{l}]$,

- $\sigma \rightarrow$ taxa de consumo de substrato [1/h],

- $s(0)=s_{0} \rightarrow$ concentração inicial de substrato no meio [g/l],

- $\mathrm{y}_{\mathrm{xs}} \rightarrow$ Rendimento de crescimento celular: relativo a quantidade de substrato desviado para multiplicação celular (reprodução) [ $\left.g_{\text {células }} / g_{\text {substrato }}\right]$,

- $\mathrm{m}_{\mathrm{s}} \rightarrow$ Constante de manutenção celular: relativo a quantidade necessária de substrato para a célula manter-se viva [1/h]. 
A taxa de produção de etanol, mostrada na Equação 7, depende da diluição do etanol no vinho e da taxa específica de formação de produto pela levedura (conversão de açúcar em etanol), mostrada na Equação 8.

$$
\begin{aligned}
& \dot{p}=-\frac{u}{v} p+\pi x \\
& \pi=\frac{y_{p s}}{y_{x s}} \mu
\end{aligned}
$$$$
p(0)=p_{0}
$$

Equação 8

sendo:

- $\dot{p} \rightarrow$ Taxa de variação da concentração de produto no meio [g///h],

- $p \rightarrow$ concentração de produto no meio [g/l],

- $\pi \rightarrow$ taxa de formação de produto [1/h],

- $p(0)=p_{0} \rightarrow$ concentração inicial de produto no meio [g/l],

- $y_{p s} \rightarrow$ Rendimento de formação de produto: relativo a quantidade de substrato utilizado na geração de produto $\left[\mathrm{g}_{\text {produto }} / \mathrm{g}_{\text {substrato }}\right]$,

- $\mathrm{y}_{\mathrm{xs}} \rightarrow$ Rendimento de crescimento celular: relativo a quantidade de substrato desviado para multiplicação celular (reprodução) [gélulas $/ g_{\text {substrato], }}$

- $\mu \rightarrow$ taxa de crescimento celular específico [1/h].

Na Equação 9 pode-se verificar a que a variação do volume do biorreator depende basicamente da entrada de mosto. Neste trabalho não está sendo considerada a variação no volume devido a liberação de dióxido de carbono $\left(\mathrm{CO}_{2}\right)$.

$\dot{v}=u$

$$
v(0)=v_{0} \text { e } v\left(t_{f}\right)=v_{f}
$$

sendo:

- $\quad \dot{v} \rightarrow$ Taxa de variação do volume do meio [l/h],

- $v(0)=v_{0} \rightarrow$ volume inicial de do meio [l],

- $v\left(t_{f}\right)=v_{f} \rightarrow$ volume final do meio [l]. 


\subsection{Modelagem do crescimento celular}

A equação mais simples utilizada para descrever a taxa de crescimento microbiano é a Equação 10, conhecida como Equação de Monod (LUONG, 1985), que considera apenas a presença de substrato como limitante, sem considerar a toxicidade dos produtos metabólicos presentes no meio.

$$
\mu=\mu_{m} \cdot \frac{s}{k_{s}+s}
$$

sendo:

- $\mu_{m} \rightarrow$ Taxa específica máxima de crescimento celular [1/h],

- $k_{s} \rightarrow$ Constante de saturação para o crescimento celular [g/l].

Estudos realizados por LUONG (1985) e FERREIRA (1998) indicam que a capacidade de produção de etanol é completamente inibida quando a concentração de etanol no meio atinge valor de $115 \mathrm{~g} / \mathrm{L}$.

Quando se trata da inibição devido ao substrato, que desativa importantes enzimas e modifica o caminho metabólico, vital à sobrevivência das leveduras, o valor obtido por THATIPAMALA et al. (1992) foi de $150 \mathrm{~g} / \mathrm{L}$.

A temperatura é outro parâmetro que afeta a fermentação alcoólica. O maior rendimento alcoólico é obtido com temperaturas entre $15^{\circ} \mathrm{C}$ e $20^{\circ} \mathrm{C}$, porém demoram a obter a população máxima. Temperaturas entre $25^{\circ} \mathrm{C}$ e $30^{\circ}$ $C$ aumentam a taxa inicial de fermentação, enquanto temperaturas superiores a $35^{\circ} \mathrm{C}$ afetam a viabilidade celular, favorecendo o aumento das perdas por sobra de açúcar e da contaminação bacteriana. A temperatura usual na indústria varia de $32^{\circ} \mathrm{C}$ a $35^{\circ} \mathrm{C}$ (BORGES, 2008; AMORIM, 2005).

Segundo SANTOS et al. (2005), BORGES (2008) e LOBATO (2011), o modelo que mais se adequa a dados experimentais é o modelo de GHOSE e THYAGI (1979) com o parâmetro $n$ diferente de 1 , modificado por TOSETTO (apud BORGES, 2008), apresentado na Equação 11, que contabiliza tanto os efeitos inibitórios do substrato quanto do produto. Este modelo é aplicável para concentrações na faixa de 0 - $120 \mathrm{~g} / \mathrm{L}$ (SANTOS, 2005) e em condições que só se utiliza um único substrato (BORGES, 2008). 


$$
\mu=\mu_{m} \cdot \frac{s}{s+k_{s}+\frac{s^{2}}{k_{i}}} \cdot\left(1-\frac{p}{p_{m}}\right)^{n}
$$

sendo:

- $\quad k_{i} \rightarrow$ Constante de inibição do crescimento celular pelo substrato $[\mathrm{g} / \mathrm{l}]$,

- $\quad p_{m} \rightarrow$ concentração máxima de produto onde cessa o crescimento microbiano $[\mathrm{g} / \mathrm{l}]$,

- $n \rightarrow$ Índice da influência da inibição pelo produto.

BORGES (2008), utilizou uma cepa de Saccharomyces cerevisiae, com meio de cultivo sendo açúcar cristal diluído e suplementos nutricionais para a levedura. O processo utilizado foi de batelada alimentada, variando-se o tempo de enchimento de 3 a 5 horas e a concentração de açúcar do mosto de 217 a $285 \mathrm{~g} / \mathrm{L}$. Baixos tempos de alimentação, ou seja, altas vazões de entrada de substrato, favoreceram a multiplicação celular, desviando o foco da fermentação. O aumento da concentração de açúcares, aliado a um tempo maior de alimentação (diminuição da vazão de entrada de substrato) favoreceu a produção de etanol, aumentando a produtividade e o rendimento.

A utilização de substratos (melaços) sintéticos demonstram resultados diferentes dos obtidos quando se utiliza melaços a partir da cana-de-açúcar. Sabe-se que melaço de cana-de-açúcar, apesar de ser um bom substrato, contém componentes que podem agir como inibidores no processo de fermentação alcoólica. Logo, trabalhos que tem como objetivo estudar a cinética de fermentação em condições industriais, devem usar melaço de canade-açúcar como substrato (ATALA et al. 2001).

ANDRIETTA et al. (2003) considerou também os efeitos da concentração de biomassa no meio como limitante do crescimento celular (Equação 12).

$$
\mu=\mu_{m} \cdot \frac{s}{s+k_{s}+\frac{s^{2}}{k_{i}}} \cdot\left(1-\frac{p}{p_{m}}\right)^{n}\left(1-\frac{x}{x_{m}}\right)^{m}
$$


sendo:

- $x_{m} \rightarrow$ concentração máxima de biomassa onde cessa o crescimento microbiano $[\mathrm{g} / \mathrm{l}]$,

- $\quad m \rightarrow$ Índice da influência da inibição pela biomassa.

ATALA et al. (2001) e FILHO et al. (2009) consideraram os efeitos da temperatura em suas simulações e também que a biomassa total é composta por células vivas (ativas) e células mortas (inativas), pois muitos pesquisadores concordaram em suas pesquisas que existe uma perda de viabilidade durante a fermentação alcoólica. O modelo adotado por FILHO et al. (2009) está mostrado na Equação 13.

$\mu=\mu_{m} \cdot \frac{s}{s+k_{s}} \cdot e^{-k_{i} s} \cdot\left(1-\frac{p}{p_{m}}\right)^{n} \cdot\left(1-\frac{x_{v}+x_{d}}{x_{m}}\right)^{m}$

sendo:

- $\quad x_{v} \rightarrow$ concentração de biomassa viva no meio [ $\left.\mathrm{g} / \mathrm{l}\right]$,

- $\quad x_{d} \rightarrow$ concentração de biomassa morta no meio $[\mathrm{g} / \mathrm{l}]$.

ATALA et al. (2001) aplicou altas taxas de alimentação de substrato, em torno de $25 \mathrm{~kg} /\left(\mathrm{m}^{3} \cdot \mathrm{h}\right)$, estudando a fermentação em temperaturas de $28^{\circ} \mathrm{C}$ a $40^{\circ} \mathrm{C}$, de $3^{\circ} \mathrm{C}$ em $3^{\circ} \mathrm{C}$. A produtividade atingiu um máximo em $31^{\circ} \mathrm{C}$, diminuindo até o mínimo ser atingido a $40^{\circ} \mathrm{C}$. 


\subsection{Métodos de identificação dos parâmetros do modelo cinético}

A identificação dos parâmetros do modelo cinético se baseia em um Problema de Identificação de Parâmetros ou Problema Inverso (BORGES, 2008). A solução de um problema inverso se reduz a determinar quais as causas que fundamentaram os efeitos obtidos (ENGL, 1996).

São diversas as formas de modelar matematicamente um sistema, sendo que uma destas formas é diferenciar pelo conhecimento das leis físicas do sistema. Para este caso, pode-se separar em modelo de caixa branca, modelo de caixa cinza e modelo de caixa preta (AGUIRRE, 2007).

Um modelo de caixa branca (white box) é um modelo na qual são conhecidos de maneira completa o comportamento do sistema, bem como as leis físicas que o regem.

Um modelo de caixa preta (black box) é aquele no qual não se torna necessário conhecer profundamente o sistema, tendo o seu conhecimento obtido de forma empírica.

Modelos do tipo caixa cinza (gray box) são aqueles intermediários, entre os caixa preta e caixa branca, que utilizam informações auxiliares, às quais não se encontram no conjunto de dados utilizados durante a identificação (AGUIRRE, 2007).

As principais etapas de um problema de identificação de sistemas são (AGUIRRE, 2007):

1. Testes e coletas de dados;

2. Representação matemática adequada;

3. Estrutura do modelo;

4. Determinação dos parâmetros a serem estimados;

5. Validação do modelo através de sensibilidade paramétrica.

Segundo CARRERA et al. (2010), ao determinar o modelo matemático, através da estimação de parâmetros com dados coletados, apresentam-se 
dificuldades associadas a identificação, estabilidade e unicidade dos parâmetros.

A obtenção dos parâmetros de maneira otimizada pode ser realizada por Métodos de Otimização Clássicos (ou determinísticos) ou por Métodos de Otimização Não-determinísticos, também conhecidos como estocásticos ou randômicos.

Os Métodos Clássicos apresentam vantagem de possuir rápida taxa de convergência em regiões próximas ao ponto de ótimo, porém podem apresentar dificuldades numéricas e problemas de robustez, além da dificuldade de obtenção de aproximações numéricas das matrizes Jacobiana e Hessiana para casos de alta dimensão (VANDERPLAATS, 1999; EDGAR et al., 2001).

Os Métodos Não-determinísticos, baseados em conceitos biológicos de seleção natural, surgiram na década de 1950, porém os estudos dos algoritmos genéticos conhecidos hoje em dia iniciou-se apenas em 1975, na Universidade de Michigan, sob a direção de John Holland. Estes métodos apresentam como características principais não necessitar do uso de derivadas para determinar a direção da busca e serem capazes de escapar de ótimos locais, o que não ocorre com os Métodos Clássicos. As principais desvantagens destes métodos são a variação do seu desempenho em cada execução pelo fato de serem métodos estocásticos e serem mais dispendiosos computacionalmente do que os Métodos Clássicos do ponto de vista da avaliação da função objetivo (VANDERPLAATS, 1999; EDGAR et al., 2001).

A classificação das técnicas utilizadas em otimização pode ser vista na Figura 3. 


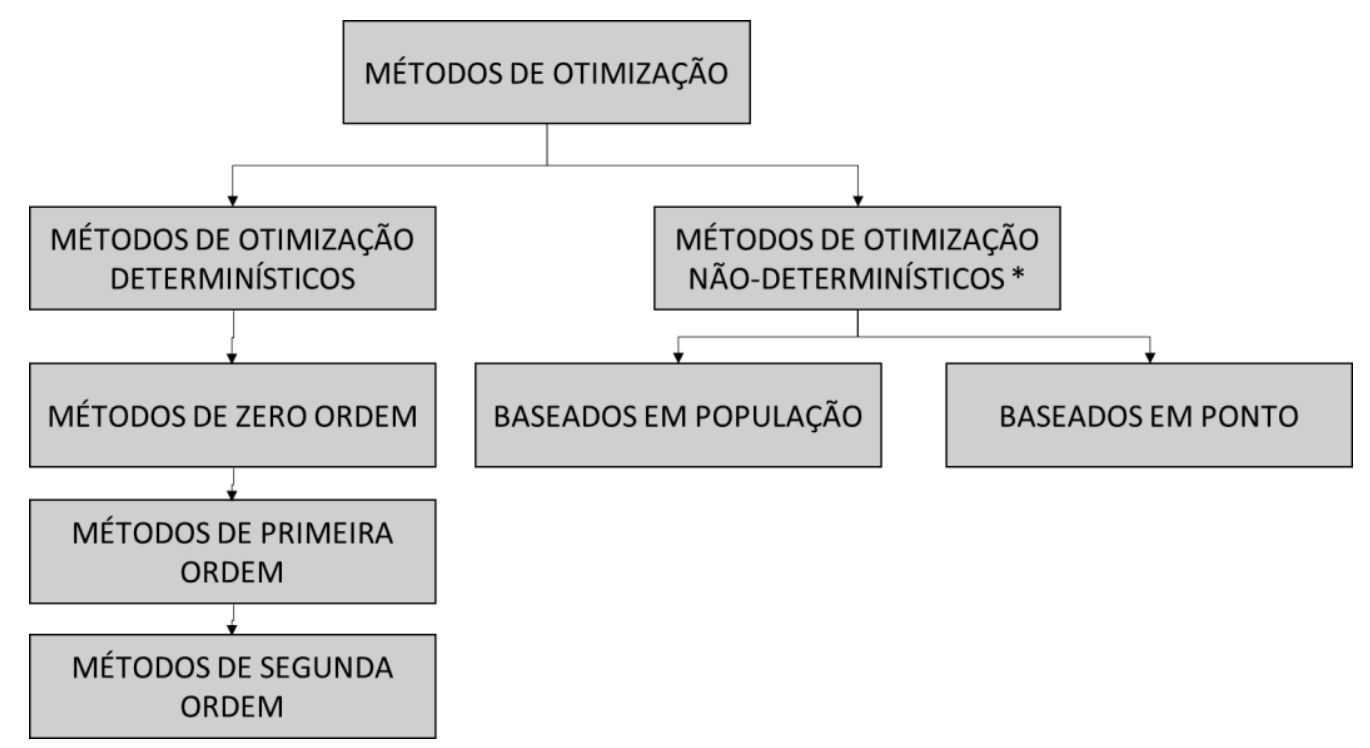

Figura 3 - Classificação dos Métodos de Otimização (BORGES, 2008). * Métodos de Otimização Não Determinísticos são considerados métodos de ordem zero.

Durante a revisão bibliográfica, percebeu-se que são variadas as metodologias de identificação dos parâmetros, tanto por técnicas determinísticas como por técnicas não-determinísticas.

THATIPAMALA et al. (1992) aplicou o algoritmo de mínimos quadrados de Levenberg-Marquadt em dados experimentais realizados em fermentação batelada alimentada com diversas concentrações iniciais de produto e substrato, utilizando $S$. cerevisiae como microrganismo.

LEE et al. (1995) obteve os dados dos coeficientes de rendimento diretamente pelos dados experimentais. As taxas de crescimento máxima foram estimadas usando uma spline cúbica suave através de validação cruzada. As constantes de repressão ( $\left.k_{i}\right)$ e Monod ( $k_{g}$ e $k_{m}$ ) foram obtidas através de um método estatístico. As concentrações máximas de células e etanol foram abstraídas por dados prévios de experimentos de culturas contínuas.

Através de um programa de otimização com técnicas de regressão nãolinear, BARD (1974), GOSWAMI e SRIVASTAVA (2000) estimaram os parâmetros cinéticos de um modelo não estruturado, utilizando para isso dados obtidos em um experimento em batelada.

A técnica de sliding mode observers foi utilizada por DRAKUNOV e LAW (2007) para estimar parâmetros de modelos não lineares. Foram desenvolvidos 
e demonstrados observadores para o modelo de Monod. O controle do sistema deve ser muito robusto, já que incertezas são adicionadas devido à falta de conhecimento de alguns dos estados do sistema.

Adota-se com mais frequência técnicas não-determinísticas ou modelos híbridos com técnicas clássicas (BORGES, 2008). Entre os mais relevantes, citam-se os trabalhos abaixo.

Dados experimentais obtidos com levedura $S$. diastaticus, que é altamente tolerante a etanol, em experimentos em batelada e batelada alimentada foram utilizados para estimar os parâmetros do modelo cinético, através de Evolução Diferencial Híbrida (HDE) por WANG e SHEU (2000) e WANG et al. (2001).

KRUMOV et al. (2006) aplicou algoritmo genético (GA) híbrido no procedimento de obtenção dos parâmetros do modelo não-linear.

A técnica de evolução diferencial (ED) foi utilizada por BORGES (2008) para estimação dos parâmetros cinéticos, a partir de experimentos em batelada e batelada alimentada. Justifica-se a escolha desta técnica devido a sua alta aplicabilidade em variadas áreas do conhecimento. Utilizou-se uma versão implementada em Matlab ${ }^{\circledR}$ por STORN e PRICE (1996).

RIVERA (2006) comparou o desempenho do modelo descrito por ATALA et al. (2001) quando os parâmetros cinéticos são otimizados usando Algoritmo Quasi-Newton e Algoritmo Genético de Codificação Real (RGA).

YABARRENA (2012) utilizou algoritmo genético baseado em evolução diferencial para determinar os parâmetros cinéticos que compõe as equações diferenciais da cinética da fermentação conduzindo ensaios onde existia interação entre leveduras e bactérias. Ao finalizar a estimativa dos parâmetros, avaliou os mesmos através de uma análise de sensibilidade paramétrica. 


\subsection{Otimização Dinâmica de um processo fermentativo em batelada alimentada}

A abordagem de análise somente faz sentido quando temos um número reduzido de casos a serem estudados. Aplicar a abordagem de análise para problemas em que o número de combinações possíveis é muito grande gastaria tempos impraticáveis. Logo, uma segunda abordagem deve ser realizada, chamada de otimização, que se caracteriza por uma busca racional de uma solução, através de algoritmos numéricos, reduzindo assim drasticamente o tempo para que a solução ótima seja encontrada (SILVA, 2015).

Os problemas de otimização dinâmica (POD) também podem ser chamados de problemas de controle ótimo (PCO). Tais problemas são caracterizados por possuírem uma função objetivo que deve ser minimizada ou maximizada (dependendo da necessidade), à qual pode ou não estar sujeita a restrições de igualdade ou desigualdade, além de equações diferenciais ordinárias e parciais, bem como restrições laterais (PFEIFER, 2007). A automatização da tomada de decisões obtidas com tal ferramenta abre novas perspectivas de aplicações e vem se tornando uma ferramenta útil para análise de processos (BORGES, 2008). No caso da fermentação em batelada alimentada, deseja-se maximizar a produção de etanol através do controle da vazão de entrada do substrato (LOBATO, 2011).

Segundo BORGES (2008), são várias as estratégias aplicadas para encontrar curvas de alimentação ótimas de forma a melhorar o desempenho de processos bioquímicos em batelada alimentada. Entre estas, pode-se citar Programação Dinâmica Iterativa (IDP), Redes Neurais, Aproximações não singulares e estratégias evolutivas baseadas em algoritmos genéticos. Com exceção das redes neurais, as outras estratégias adotam modelos matemáticos detalhados da cinética e do balanço de massa do sistema.

MODAK et al. (1986) determinou que a fase inicial da alimentação deveria favorecer o crescimento celular e só então propiciar a formação do produto. Através do Princípio de Pontryagin (decorrente da imposição de que o Hamiltoniano de um sistema contínuo com restrições de desigualdade nas 
variáveis de controle deve ser minimizado para qualquer conjunto possível desta variáveis de controle, sendo aplicável a problemas com varrições fortes e restrições de fim) e da Teoria do Controle Singular, propuseram uma sequência ótima de taxas de alimentação em função das taxas de crescimento específico, condições iniciais do processo e formação de produto.

MODAK e LIM (1987) descreveram ume esquema de otimização do tipo feedback, onde a taxa de alimentação era função não linear das variáveis de estado.

FU e BARFORD (1993) aplicaram modelagem algébrico-diferencial em processos de fermentação. A fim de transformar o problema da determinação da taxa volumétrica de alimentação de substrato em um problema não singular, derivado da aplicação do princípio máximo de Pontryagin, utilizaram uma transformação proposta por KELLEY (1965), que reduziu a dimensão do problema original através de uma transformação de variáveis de estado.

A resolução de um POD com restrições e de um POD simplificado do processo de fermentação foi feito através de um algoritmo modificado de IDP e com a utilização de programação quadrática seqüencial para comparar os resultados (WANG e SHYU, 1997; CHIOU e WANG, 1999). O método da Evolução Diferencial Híbrida (HDE) aliado ao de atualização dos multiplicadores foi utilizado para resolver o POD simplificado.

WANG et al. (2001) utilizou o método HDE com a introdução de um método do tipo Lagrangeano, permitindo que fossem usadas restrições de desigualdade no problema de otimização. O experimento foi validado comparando-o com caso de alimentação constante e também com realizandose variações na concentração de substrato. Os autores concluíram que a alimentação ótima, para o caso do modelo utilizado, é mais adequada quando comparado como perfil de alimentação constante.

LOBATO et al. (2006) e BORGES (2008) utilizaram o princípio de Pontryagin com a transformação do problema original em um problema de identificação de fases com índice diferencial flutuante e definindo os respectivos tempos de troca. Assim o problema original se transformou em vários problemas definidos por fases, com características definidas pelos respectivos índices e pela sequência de eventos. Quando comparado aos resultados da literatura, o desempenho da metodologia desenvolvida foi bom. 


\subsubsection{Problema Geral da Otimização}

Função objetivo é a função que associa cada ponto no espaço de soluções a um número real. Este número permite quantificar a qualidade de uma resposta. No caso de minimizações, quanto menor o número obtido, melhor a resposta. No caso de maximizações, quanto maior o número obtido, melhor a resposta. $O$ tratamento de problemas de maximização e minimização na visão matemática é análogo (BISCAIA JR., 2007 apud BORGES, 2008).

O critério de otimização a ser minimizado é a soma dos custos terminal e integral, conforme a Equação 14 (SMETS et al., 2004).

$$
J[u]=\underbrace{\psi\left(x\left(t_{f}\right), t_{f}\right)}_{\text {custo terminal }}+\underbrace{\int_{t_{t}}^{t_{t}} \phi(x(t), u(t), t) d t}_{\text {custo integral }},
$$

$\psi: \mathfrak{R}^{n_{z}} \rightarrow \mathfrak{R}^{1}$ e $\phi: \mathfrak{R}^{n_{z}+n_{u}+1} \rightarrow \mathfrak{R}^{1}$

sendo

- $\mathrm{x}(\mathrm{t}) \rightarrow$ vetor das variáveis de estado,

- $\mathrm{u}(\mathrm{t}) \rightarrow$ vetor das variáveis de controle.

A Função Objetivo (FO) definida na Equação 14 está sujeita às restrições mostradas na Equação 15 até Equação 18. Os índices max e min identificam, respectivamente, os limites superiores e inferiores das variáveis.

$$
\begin{array}{ll}
g(\dot{x}, x, u, t)=0, g: \mathfrak{R}^{n_{z}+n_{u}+1} \rightarrow \mathfrak{R}^{n_{g}} & \text { Equação } 15 \\
h(\dot{x}, x, u, t) \leq 0, h: \mathfrak{R}^{n_{z}+n_{u}+1} \rightarrow \mathfrak{R}^{n_{h}} & \text { Equação } 16 \\
x_{\min }<x(t)<x_{\max }, x \in \mathfrak{R}^{n_{z}} & \text { Equação } 17 \\
u_{\min }<u(t)<u_{\max }, u \in \mathfrak{R}^{n_{u}} & \text { Equação } 18
\end{array}
$$

Segundo BORGES (2008), a formulação de um POD da fermentação em batelada alimentada deve levar em consideração as seguintes variáveis de 
controle, Funções Objetivo e restrições de igualdade e desigualdade, obtidas na literatura.

\subsubsection{Variáveis de Controle}

Segundo KURTANJEK (1991 apud BORGES, 2008), as variáveis de controle principais em um processo de fermentação alcoólica em batelada alimentada são a taxa de alimentação de substrato, a taxa de adição de ácido e base, a velocidade de agitação e a taxa de fluxo de água em um trocador de calor. Tais variáveis são as mais controladas pois a concentração de substrato, o pH e a temperatura são as variáveis que mais se relacionam com o estado da fermentação.

Para SMETS et al. (2004), procedimentos de otimização de fermentações em batelada alimentada são tradicionalmente focadas na taxa volumétrica de alimentação do substrato, mantendo a concentração do substrato de alimentação com um valor fixo.

\subsubsection{Funções objetivo}

$\mathrm{Na}$ Tabela 1 são apresentadas algumas das funções objetivo encontradas na bibliografia.

Tabela 1 - Funções objetivo empregadas em fermentações alcoólicas conduzidas em bateladas alimentadas (BORGES, 2008).

\begin{tabular}{|l|c|}
\hline \multicolumn{1}{|c|}{ Autor } & FO \\
\hline MODAK et al. (1986) & $J=\min \left(-\frac{p\left(t_{f}\right)}{t_{f}}\right)$ \\
\hline MODAK et al. (1986) & $J=\min \left(t_{f}\right)$ \\
\hline FU e BARFORD(1993) & $\min J=-\exp \left(y_{2}\left(t_{f}\right)\right)$ \\
\hline WANG e SHYU (1997) & $J=\min _{u(t)}\left(-p\left(t_{f}\right) v\left(t_{f}\right)\right)=\max _{u(t)}\left(p\left(t_{f}\right) v\left(t_{f}\right)\right)$ \\
\hline WANG et al. (2001) & $\max _{u(t), t_{f}} J=\frac{\left(p\left(t_{f}\right) v\left(t_{f}\right)-p\left(t_{0}\right) v\left(t_{0}\right)\right)}{t_{f}}$ \\
\hline
\end{tabular}

Equação 19

Equação 20

Equação 21

Equação 22

Equação 23 
${ }^{*} \mathrm{y}_{2}=(\mathrm{pv})$

\subsubsection{Restrições de Igualdade e Desigualdade}

Resultados impossíveis podem ser obtidos em otimizações se não forem inseridas condições de restrição. Esta situação depende da variável de controle escolhida para o POD. BORGES (2008) realizou o levantamento das restrições encontradas na literatura, que estão apresentadas na Tabela 2.

Tabela 2 - Restrições impostas no Problema de Otimização Dinâmica envolvendo fermentação alcoólica em batelada alimentada (BORGES, 2008).

\begin{tabular}{|c|c|}
\hline Autor & Restrições \\
\hline $\begin{array}{l}\text { FU e } \\
\text { BARFORD }(1993)^{*}\end{array}$ & $\varepsilon \leq \frac{y_{p / s}}{x} \frac{d s}{d t}=\frac{y_{p / s}}{x} \frac{\Delta s}{\Delta t}$ \\
\hline COSTA $(1996)^{\star *}$ & $0 \leq D(t) \leq \frac{u_{\max }}{v(t)}$ \\
\hline \multirow{5}{*}{$\begin{array}{l}\text { WANG e SHYU } \\
\text { (1997) }\end{array}$} & $0 \leq u(t) \leq u_{\max }$ \\
\hline & $g_{1}=v(t)-v_{f} \leq 0$ \\
\hline & $g_{2}=-s(t) \leq 0$ \\
\hline & $g_{3}=\frac{p(t) v(t)-p_{0} v_{0}}{\left[v(t)-v_{0}\right] s_{F}+v_{0} s_{0}-v(t) s(t)}-y_{p / s} \leq 0$ \\
\hline & $g_{4}=p\left(t_{f}\right)-p_{f}=0$ \\
\hline WANG et al. (2001) & $g_{5}=s(t)-s_{r} \leq 0$ \\
\hline
\end{tabular}

Equação 25

Equação 26

Equação 27

Equação 28

Equação 29

Equação 30

Equação 31

Equação 32

${ }^{*} \varepsilon=$ Produtividade Específica

**(apud BORGES, 2008)

\subsection{Controle Não-Linear $H_{\infty}$}

O controle não-linear $\mathrm{H}_{\infty}$ consiste em garantir um nível pré-definido de atenuação dos efeitos de distúrbios na saída do sistema a ser controlado. 
Existem duas abordagens fundamentais nesta classe de controladores, sendo a primeira baseada em teoria dos jogos e a segunda baseada em técnicas de sistemas lineares a parâmetros variantes (LPV) (SIQUEIRA et al, 2011).

A abordagem baseada em técnicas do tipo LPV fornece uma metodologia sistemática para atingir o desempenho do controle Não-Linear $\mathrm{H}_{\infty}$. A dinâmica não linear pode ser representada como um sistema LPV onde cada parâmetro é função do estado, nomeado de representação quasi-LPV (SIQUEIRA et al, 2011).

Técnicas de realimentação linearizante vem sendo utilizadas na solução de problemas práticos de controle ótimo, como em controle de aviões, robôs e equipamentos de precisão. Porém, a necessidade de um modelo que represente de maneira concreta a dinâmica a ser controlada limita a sua aplicação. A obtenção da dinâmica linearizada pode ser executada de duas formas, seja por realimentação de estados ou por realimentação da saída (PIMENTEL e COUTINHO, 2012; SIQUEIRA et al, 2011).

\subsection{Controle $H_{\infty}$ via inequações matriciais lineares}

O projeto de controladores baseado em realimentação de estados e realimentação da saída é concebido a partir de sistemas LPV cujo procedimento de controle é sintetizado em termos de inequações matriciais lineares (LMI's). Para estes casos, a solução de um problema de otimização convexa através de um conjunto de LMl's leva a obtenção de um ganho de controlador que é variante no tempo (ROHR, 2009; SIQUEIRA et al, 2011).

Nesta abordagem, o problema de otimização se baseia num sistema não linear com perturbações exógenas $w \in \mathfrak{R}^{\mathrm{p}}$, a entrada de controle $u \in \mathfrak{R}^{\mathrm{m}}$ e a variável de saída $z \in \mathfrak{R}^{q}$, mostrado na Equação 33.

$$
\begin{aligned}
& \dot{x}=f(x)+b_{1}(x) w+b_{2}(x) u, \\
& z=h(x)+d_{1}(x) w+d_{2}(x) u,
\end{aligned}
$$

sendo $f(0)=0$ e $h(0)=0$, e $x \in \mathfrak{R}^{n}$ as variáveis de estado. Assume-se que $f(\cdot)$, $b_{i}(\cdot), h(\cdot), d_{i}(\cdot)$ são funções contínuas e diferenciáveis. 
O desempenho do sistema representado na Equação 33 é definido ajustando-se o controlador para garantir que o ganho $L_{2}$ entre o distúrbio e a saída Equação 34 seja satisfeito.

$\int_{0}^{T}\|z(t)\|^{2} d t \leq \gamma^{2} \int_{0}^{T}\|w(t)\|^{2} d t$ Equação 34

para todo $T \geq 0$ e todo $w \in L_{2}(0, T)$ com o sistema iniciando em $x(0)=0$.

ROHR et. al (2009) propuseram uma técnica baseada na escolha de uma dinâmica livre resultando em uma realimentação linearizante, para que a lei de controle linearizante possuísse certa robustez, considerando sistemas não lineares. No caso, foi utilizada uma função quadrática e inequações matriciais lineares (LMI's) dependendo do estado de forma a garantir robustez na estabilidade do sistema de controle devido a existência de incertezas na determinação dos parâmetros do modelo matemático.

Vale frisar que LMI's vem sendo utilizadas na formulação de problemas de controle desde o final da década de 1980 e, desde então, muitos trabalhos da teoria de controle e sistemas tem sido reescrito na forma de LMI's (BOYD et al., 1994).

Aplicar diretamente técnicas LMl's em sistemas não-lineares gera inequações não lineares (NLMl's). Uma maneira de contornar este problema é modelar as não linearidades do sistema como parâmetros variantes no tempo, denominada representação quasi-LPV (PIMENTEL e COUTINHO, 2012; SIQUEIRA et al, 2011).

\subsection{Controle $H_{\infty}$ por representação quasi-LPV}

Esta seção apresenta o projeto de um controlador robusto por representação quasi-LPV.

Considere um sistema LPV dado pelas seguintes equações de estado (Equação 35): 
$\dot{\mathbf{x}}=\mathbf{A}(\boldsymbol{\theta}(t)) \mathbf{x}+\mathbf{B}_{\mathbf{1}}(\boldsymbol{\theta}(t)) \mathbf{w}+\mathbf{B}_{\mathbf{2}}(\boldsymbol{\theta}(t)) \mathbf{u}$,

$y=\mathbf{C}_{1}(\boldsymbol{\theta}(t)) \mathbf{x}$

Equação 35

$Z=\mathbf{C}_{2}(\boldsymbol{\theta}(t)) \mathbf{x}+\mathbf{l u}$.

sendo x o vetor de estados, u o vetor de entradas de controle, w o vetor de entradas externas, y e z as variáveis de saída e $\theta(\mathrm{t})$ o vetor de parâmetros variantes. Considere que o parâmetro subjacente $\theta(\mathrm{t})$ varia conforme o conjunto dado pela Equação 36:

$$
F_{P}^{v}=\left\{\theta(t) \in C^{1}\left(\mathfrak{R}^{n}, \mathfrak{R}^{m}\right): \theta(t) \in P,|\dot{\rho}| \leq v_{i}\right\}
$$

Equação 36

para i variando de 1 a $\mathrm{k}$, onde $P \in \mathfrak{R}^{m}$ é um conjunto compacto.

O problema de controle por realimentação de estados considerado visa encontrar uma função contínua $F(\theta)$ tal que o sistema realimentado tenha um ganho $L_{2}$ menor ou igual a $\gamma$ sob a lei de realimentação de estado $u=F(\theta) x$. Logo, se existe uma função matricial contínua e diferenciável dada por $X(\theta(t))>0$, que satisfaça a Equação 37 .

$\left[\begin{array}{ccc}E(\theta(t)) & X(\theta(t)) \cdot C_{1}^{T}(\theta(t)) & B_{1}(\theta(t)) \\ C_{1}(\theta(t)) X(\theta(t)) & -I & 0 \\ B_{1}^{T}(\theta(t)) & 0 & -\gamma^{2} I\end{array}\right]<0$

Equação 37

sendo,

$$
\begin{aligned}
& E(\theta(t))=\sum_{i=1}^{m}\left(v_{i}(\theta) \frac{\partial X(\theta(t))}{\partial \theta_{i}}\right)-B_{2}(\theta(t)) B_{2}^{T}(\theta(t))+ \\
& \widehat{A}(\theta(t)) X(\theta(t))+X(\theta(t)) \hat{A}(\theta(t))^{T}
\end{aligned}
$$

Equação 38

e

$\widehat{A}(\theta(t))=A(\theta(t))-B_{2}(\theta(t)) C_{2}(\theta(t))$

Equação 39

Sendo o ganho $L_{2} \leq \gamma$, a lei de controle de realimentação de estado será: 
$u(t)=-\left(B_{2}(\theta(t)) X^{-1}(\theta(t))+C_{2}(\theta(t))\right) x(t)$

Equação 40

A solução do conjunto de LMls caracteriza um problema de otimização convexo e infinitesimal, que possui dificuldade de ser resolvido numericamente. Baseado em funções base associadas a $X(\theta(\mathrm{t}))$ e aos parâmetros definidos $\mathrm{P}$, reescrevendo as funções base $C^{1}$, tem-se a Equação 41 :

$$
X(\boldsymbol{\theta})=\sum_{i=1}^{M} \phi_{i}(\boldsymbol{\theta}) X_{i}
$$

sendo $X_{i} \in S^{n \times n}$ a matriz dos coeficientes para $\phi(\theta(t))$. Aplicando a matriz $X(\theta(t))$ na Equação 37 , as restrições se transformam em uma LMI em função das variáveis matriciais $\left\{X_{i}\right\}_{i=1}^{M}$, onde o parâmetro $\theta(t)$ é fixado, podendo ser definido o seguinte problema de otimização (Equação 42):

$$
\min _{\left\{x_{i}\right\}_{i=1}^{M}} \gamma^{2}
$$

Sujeito a:

$$
\begin{aligned}
& {\left[\begin{array}{ccc}
E(\theta) & \sum_{j=1}^{M} \phi_{j}(\boldsymbol{\theta}) X_{j} C_{1}^{T}(\theta) & B_{1}(\theta) \\
C_{1}(\theta) \sum_{j=1}^{M} \phi_{j}(\boldsymbol{\theta}) X_{j} & -I & 0 \\
B_{1}^{T}(\theta) & 0 & -\gamma^{2} I
\end{array}\right]<0} \\
& \sum_{j=1}^{M} \phi_{j}(\boldsymbol{\theta}) X_{j}>0 \\
& \text { sendo, } \\
& E(\theta(t))=\sum_{i=1}^{m}\left(v_{i}(\theta) \frac{\partial X(\theta(t))}{\partial \theta_{i}}\right)-B_{2}(\theta(t)) B_{2}{ }^{T}(\theta(t))+ \\
& \sum_{i=1}^{m}\left(\phi_{j}(\theta(t))\left(\hat{A}(\theta(t)) X_{j}(\theta(t))+X_{j}(\theta(t)) \hat{A}(\theta(t))^{T}\right)\right)
\end{aligned}
$$


COUTINHO et al. (2009) propôs uma estratégia de controle robusto para otimizar o controle de multiplicação de $S$. cerevisae em batelada alimentada. A dinâmica do processo foi caracterizada por um modelo cinético não linear baseado em inibição por etanol por um possível valor excessivo de alimentação de substrato. A estratégia de controle foi baseada em uma técnica de linearização de realimentação, onde a dinâmica livre linear resultante é projetada para garantir certa robustez a variação de parâmetros da planta. Experimentos numéricos demonstraram o potencial da aproximação proposta como uma ferramenta para o projeto de controladores para culturas baseadas em sistema de batelada alimentada.

ZHU e XU (2008) propuseram um modelo LPV baseado em modelos lineares mistos e adicionando pesos no lado das entradas. HUANG et al. (2012) estudou o funcionamento de um modelo de identificação múltiplo LPV usando várias funções de peso com duas variáveis programadas.

BACHNAS et al. (2013) utilizou abordagens locais e globais de LPV comparando-os em um modelo obtido empiricamente para uma coluna de destilação de alta pureza. Mostrou-se que os esquemas de interpolação locais, especialmente esquemas de interpolação de saída utilizando dados descrevendo a dinâmica transiente do sistema, conseguiram uma aproximação adequada do comportamento de entrada e saída. 


\section{Capítulo 3}

Neste capítulo será apresentada a descrição do procedimento para identificação dos parâmetros do modelo matemático do processo de fermentação alcoólica em batelada alimentada. Uma levedura industrial foi utilizada nos ensaios (experimentos) de fermentação e seu modelo matemático extraído. Descreve-se a metodologia utilizada na modelagem em variáveis de estado do sistema dinâmico composto pela variação do substrato, do produto, da concentração celular e do volume no tempo. A forma como são estimados os parâmetros cinéticos por um algoritmo Quasi-Newton, implementada na toolbox de identificação de sistemas, utilizando Matlab ${ }^{\circledR}$ é detalhada, bem como as variantes do processo. Será então descrita a otimização dinâmica do processo, através de técnicas de sistemas lineares a parâmetros variantes (LPV). Controladores baseados em sistemas LPV eficientes podem ser obtidos com precisão e baixa complexidade do modelo LPV a partir do comportamento básico do sistema.

\section{Procedimento para identificação dos parâmetros do modelo matemático e da otimização dinâmica}

Os experimentos foram conduzidos de maneira a se aproximarem o máximo possível da metodologia adotada no processo industrial. Levedura $P E-2$, utilizada nos experimentos, foi multiplicada nos laboratórios da empresa Fermentec (FERMENTEC TECNOLOGIAS EM ACUCAR E ALCOOL LTDA.), como cortesia.

\subsection{Condições de teste e procedimento experimental}

As fermentações foram conduzidas em garrafas (biorreatores) de volume total $3000 \mathrm{ml}$. O inóculo usado (pé de cuba) tinha um volume total de $625 \mathrm{ml}$, 
composto de $250 \mathrm{~g}$ de levedura, $312 \mathrm{ml}$ de água e $63 \mathrm{ml}$ de vinho, totalizando $25 \%$ do volume total do vinho. O mosto foi composto de melaço e água (concentração de $20 \%$ de açúcares), com pH de 4,5. O volume final de vinho esteve próximo de $2500 \mathrm{ml}$. Foram realizados dois ciclos, cada um composto por 9 (nove) biorreatores (Figura 4), igualmente distribuídos em 3 temperaturas $\left(30^{\circ} \mathrm{C}, 33^{\circ} \mathrm{C}\right.$ e $\left.36^{\circ} \mathrm{C}\right)$. Foram realizadas 6 alimentações espaçadas de 1 hora $(1 \times 325 \mathrm{ml}$ e $5 \times 310 \mathrm{ml})$ em cada fermentação, totalizando 5 horas de alimentação, como é usual nas indústrias para esta concentração de açúcar (AMORIM, 2005).

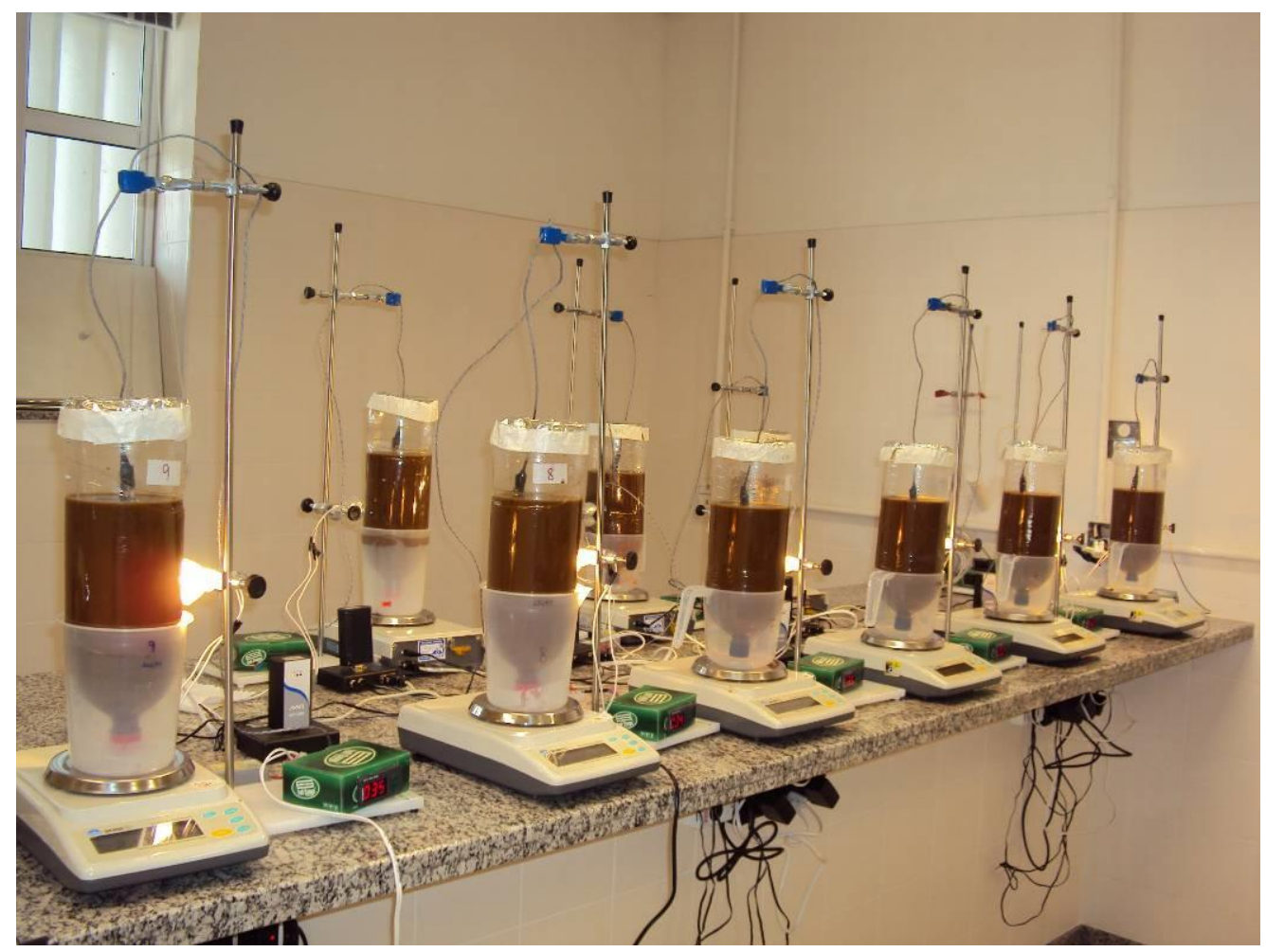

Figura 4 - Nove biorreatores igualmente distribuídos em 3 temperaturas $\left(30^{\circ} \mathrm{C}, 33^{\circ} \mathrm{C} \mathrm{e}\right.$ $36^{\circ} \mathrm{C}$ ) controladas individualmente.

A Figura 4 mostra o controle de temperatura dos biorreatores, realizado individualmente utilizando controladores de temperatura comerciais (MT-512Ri, da Full Gauge Controls). Lâmpadas Dicróicas foram utilizadas para executar o aquecimento do vinho até que a temperatura desejada fosse atingida.

O peso do vinho foi medido utilizando-se balanças de precisão, que transmitiam as medições para um computador, gravando os dados instantaneamente. 
O primeiro ciclo serviu apenas para criar o reciclo de levedura, fazendo com que 0 teste se aproximasse o máximo possível da realidade experimentada nas plantas industriais. Devido a este fato, nenhuma amostra foi retirada no processo, bem como nenhum tratamento ácido (ajuste de $\mathrm{pH}$ ) efetuado neste primeiro ciclo.

No segundo ciclo, foi efetuado um tratamento ácido $(\mathrm{pH} 2.5$ por 1,5 horas, usando $1,8 \mathrm{~g} \mathrm{H}_{2} \mathrm{SO}_{4}$ ) e amostras de aproximadamente $20 \mathrm{ml}$ foram coletadas ao início do processo e a cada hora, até que 9 horas de fermentação fossem atingidas. Para cada amostra, foram executadas análises de etanol, biomassa, açúcar residual, densidade e viabilidade (população de células vivas).

\subsection{Análises Microbiológicas}

Dentre as análises microbiológicas realizadas estão a viabilidade celular e a quantidade de biomassa existente.

A viabilidade celular revela a porcentagem de células viáveis (ou vivas) em relação às células totais existentes, através da contabilização de células vivas e mortas. Através da viabilidade celular é possível identificar as condições da fermentação, sendo que valores muito baixos (ou muito altos) indicam que ações corretivas devem ser tomadas. A metodologia empregada utiliza um corante chamado eritrosina, que colore células mortas com a cor rosa e não colore as células vivas, conforme pode ser visto na Figura 5 (OLIVEIRA, 1996; AMORIM, 2005; FERMENTEC, 2014a).

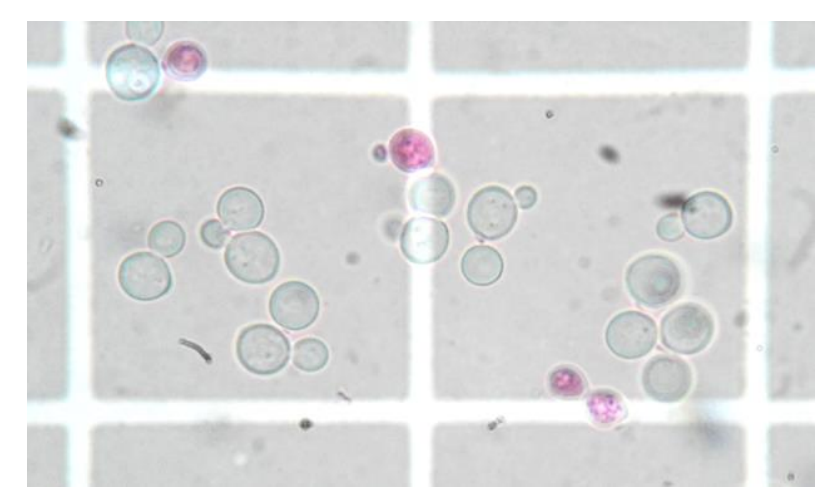

Figura 5 - Células de levedura ao microscópio óptico sob ação do corante eritrosina (Fonte: FERMENTEC, 2014a). 
A eritrosina utilizada foi preparada em duas etapas:

- Solução estoque: solução a partir da qual foi preparada a solução trabalho.

- Solução trabalho: solução utilizada para corar as lâminas, preparada diluindo-se a solução estoque em uma solução tampão fosfato.

As soluções de eritrosina e o tampão fosfato apresentam grande facilidade de contaminação, sendo necessário a sua substituição em caso de isto ocorrer (FERMENTEC, 2014a).

O preparo da solução estoque de eritrosina se deu pela pesagem de $0,1 \mathrm{~g}$ de eritrosina dissolvida em $10 \mathrm{ml}$ de água esterilizada. A solução foi conservada em frasco âmbar, fora do alcance da luz e em refrigeração.

A solução tampão fosfato foi preparada em duas soluções que posteriormente são misturadas. Em uma primeira solução, diluiu-se $17,9 \mathrm{~g}$ de $\mathrm{Na}_{2} \mathrm{HPO}_{4}$ em $250 \mathrm{ml}$ de água destilada. A segunda solução foi preparada dissolvendo-se 6,89 g de $\mathrm{NaH}_{2} \mathrm{PO}_{4} \mathrm{em} 250 \mathrm{ml}$ de água. Após o preparo das duas soluções, as mesmas foram misturadas, autoclavadas e conservadas sob refrigeração.

O preparo da solução trabalho de eritrosina se deu pela adição de $0,1 \mathrm{ml}$ da solução estoque de eritrosina para cada $5 \mathrm{ml}$ de tampão fosfato. O volume de trabalho preparado foi o suficiente para uma semana de uso, sendo que uma parte de seu volume foi transferido para um tubo de ensaio todo dia que o mesmo foi utilizado. O volume restante, após o final do trabalho foi descartado.

Após a realização da preparação da solução de trabalho, realizou-se o preparo da amostra. Transferiu-se $5 \mathrm{ml}$ de uma amostra de vinho bruto para um tubo de ensaio, adicionando-se papaína para desflocular a amostra. Homogeneizou-se a amostra, aguardando 5 minutos e realizando uma nova homogeneização. Para adequar a contagem de células ao menor erro da metodologia, realizou-se a diluição de $1 \mathrm{ml}$ de amostra de vinho em um tubo de ensaio contendo $14 \mathrm{ml}$ de água. Desta amostra, novamente homogeneizada, retirou-se uma amostra de $1 \mathrm{ml}$ diluindo-a em $1 \mathrm{ml}$ da solução trabalho de eritrosina, dentro de um tubo de ensaio, realizando-se uma nova 
homogeneização. Neste caso, a diluição final foi de 30 vezes (15 vezes na primeira e 2 vezes na segunda diluição).

Preparada a amostra, aproximadamente $10 \mu \mathrm{l}$ da amostra final diluída foi transferida para uma Câmara de Neubauer ${ }^{1}$ (Figura 6). A Câmara de Neubauer utilizada apresenta as seguintes características:

- Profundidade: 0,1 mm

- Número de quadrículos: 25

- Número de retículos em cada quadrículo: 16

- Número de retículos em cada câmara: 400

- Área do retículo: 0,0025 $\mathrm{mm}^{2}$

- Volume de líquido em cada retículo: 0,00025 mm³

- Volume total da câmara: $0,1 \mathrm{~mm}^{3}$

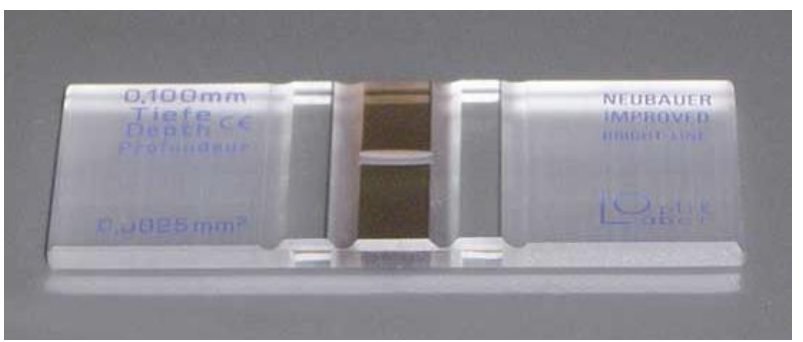

Figura 6 - Câmara de Neubauer utilizada na contagem de células de levedura (Fonte: FERMENTEC, 2014a).

As células (vivas, mortas e brotamentos) foram contadas nos 4 retículos do centro, dos 25 quadrículos, utilizando a objetiva de 100 vezes (Figura 7).

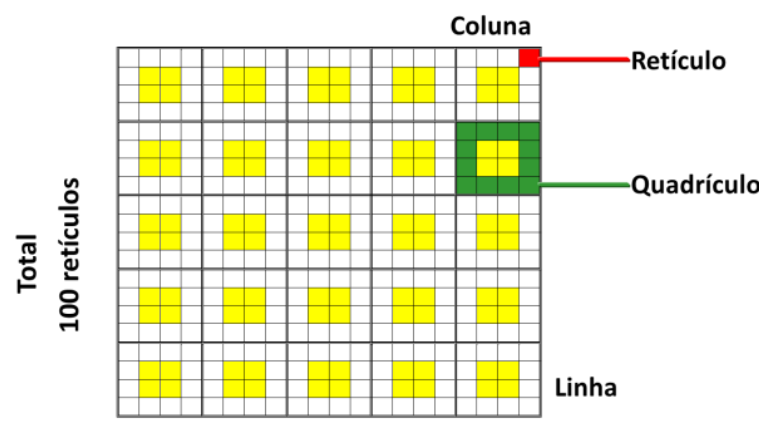

Figura 7 - Câmara de Neubauer apresentando os locais onde deve ser realizada a contagem (Fonte: FERMENTEC, 2014a).

\footnotetext{
${ }^{1}$ A Câmara de Neubauer é uma lâmina grossa para uso utilizando um microscópico. Possui formato retangular e geralmente é fabricada em vidro. Uma depressão no centro é utilizada para realizar a contagem de células por unidade de volume de uma amostra diluida.
} 
Contadas as células viáveis, não viáveis e brotos, procede-se para 0 cálculo de viabilidade (Equação 44) e de brotamento (Equação 45).

$\%$ Viabilida de $=\frac{\text { Total Células Viáveis }}{\text { Total Cél. (Viáveis + Não Viáveis) }} \times 100$

Equação 44

$\%$ Brotamento $=\frac{\text { Total Brotamento s Viáveis }}{\text { Total Cél. Viáveis }} \times 100$

Equação 45

A quantidade de leveduras/ml existente foi determinada pela Equação 46, na qual se consideram apenas as células viáveis, aderindo ao modelo matemático definido.

Leveduras/ $\mathrm{ml}=\frac{\text { Total Células Viáveis } \times 400}{\text { Total Retículos Contados }} \times 10000 \times$ Diluição Final

Equação 46

A massa de levedura existente na amostra foi contabilizada através de centrifugação da amostra coletada e pesagem do volume referente à biomassa.

\subsection{Análises Químicas}

As análises químicas realizadas foram de determinação de açúcares, densidade do vinho e teor alcoólico do vinho.

\subsubsection{Determinação da concentração de glicose, frutose, sacarose, manitol e glicerol por cromatografia de troca aniônica}

As análises de açúcares foram realizadas através de um Cromatógrafo de íons (BioLC) equipado com detector amperiométrico (ED50) e coluna PA Dionex ${ }^{\circledR}$. Os dados foram coletados através de um software de integração 
(Chromeleon v6.60) associado a uma balança analítica (precisão de $0,1 \mathrm{mg}$ ) e uma balança de precisão (precisão de $10 \mathrm{mg}$ ). A operação foi realizada com Eluente hidróxido de sódio $(\mathrm{NaOH}) 400 \mathrm{mM}$, com vazão controlada de $1 \mathrm{ml} / \mathrm{min}$. A calibração do sistema é realizada utilizando-se os seguintes padrões:

- Glicerol com teor mínimo de 99,5\%;

- Glicose com teor mínimo de 99\% (anidra ou monohidratada);

- Frutose com teor mínimo de $99 \%$;

- Sacarose com teor mínimo de 99,5\%;

- Manitol com teor mínimo de 99\%;

- Maltose com teor mínimo de 99\% (anidra ou monohidratada);

- Glicosamina com teor mínimo de 99\% (Padrão interno);

- Trealose dihidratada com rotação específica de $(178 \pm 2)^{\circ}$;

- Lactose anidra P.A. com teor mínimo de 99\%;

Para cada amostra obtida do experimento, uma sub-amostra foi coletada e homogeneizada, passando por filtração em algodão e papel de filtro qualitativo para remoção de partículas grosseiras. Por ser uma técnica de precisão elevada (sensibilidade $\approx 10^{-12}$ ), foi necessário um cuidado permanente nas diluições e preparos da amostra, já que a amostra deve estar dentro da faixa de calibração descrita anteriormente (FERMENTEC, 2014b).

\subsubsection{Determinação da concentração de Açúcares Redutores Totais em amostras de mosto.}

Foi utilizado um eletrodo de oxi-redução (Pt805 - K7 INGOLD) e um aparelho de titulação Redutec. Os equipamentos foram calibrados usando Solução de estoque de açúcar invertido $1 \%(\mathrm{~m} / \mathrm{v})$ - conhecida como padrão de AR. 


\subsubsection{Determinação do teor de sólidos solúveis dissolvidos na amostra pela medida de densidade em mosto.}

A determinação da densidade foi realizada através de um densímetro digital Anton Paar, com temperatura interna controlada. A obtenção da solução hidroalcoólica condensada foi realizada por destilação por arraste de vapor, através de um micro-destilador.

\subsection{Cálculos de Taxas de Conversão, Produtividade e Rendimento}

A taxa de conversão de substrato em biomassa celular ( $\left.\mathrm{y}_{\mathrm{xs}}[\mathrm{g} / \mathrm{g}]\right)$ e a taxa de conversão de substrato (açúcar) em produto (etanol) ( $\mathrm{y}_{\mathrm{ps}}[\mathrm{g} / \mathrm{g}]$ ) foram obtidas de acordo com a Equação 47 e Equação 48, respectivamente. A produtividade $\left(Q_{p}[g /(I . h)]\right)$ foi calculada de acordo com a Equação 49.

$$
\begin{aligned}
y_{p s} & =\frac{p(t) v(t)-p_{0} v_{0}}{\left[v(t)-v_{0}\right] s_{F}+v_{0} s_{0}-v(t) s(t)} \\
y_{x s} & =\frac{x(t) v(t)-x_{0} v_{0}}{\left[v(t)-v_{0}\right] s_{F}+v_{0} s_{0}-v(t) s(t)} \\
Q_{p} & =\frac{p_{F}-p_{0}}{t_{F}}
\end{aligned}
$$

Equação 49

sendo:

- $p_{0} \rightarrow$ Concentração de etanol no instante inicial $[\mathrm{g} / \mathrm{g}$,

- $v_{0} \rightarrow$ Volume de vinho no instante inicial [l],

- $s_{0} \rightarrow$ Concentração do substrato no instante inicial [g/l],

- $x_{0} \rightarrow$ Concentração de biomassa no instante inicial [g/l],

- $p(t) \rightarrow$ Concentração de produto no instante $t[g / l]$,

- $\quad v(t) \rightarrow$ Volume preenchido do biorreator no instante $t[l]$,

- $s(t) \rightarrow$ Concentração de substrato no instante $t[\mathrm{~g} / \mathrm{l}]$,

- $x(t) \rightarrow$ Concentração de biomassa no instante $t[\mathrm{~g} / \mathrm{l}$, 
- $S_{F} \rightarrow$ Concentração do substrato entrante [g/l],

- $p_{F} \rightarrow$ Concentração de produto ao final do processo [g/l],

- $t_{F} \rightarrow$ Tempo total de fermentação [h].

O Rendimento Fermentativo foi calculado baseado na Equação 50 e Equação 51, para cada um dos experimentos realizados (FERMENTEC, 2014b).

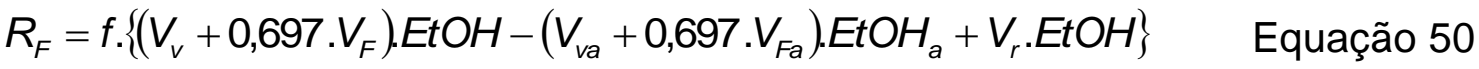

$$
\begin{aligned}
& f=\frac{10000}{64,75 \cdot \mathrm{V}_{\text {mosto }} \cdot \mathrm{ART}_{\text {mosto }(\mathrm{p} / \mathrm{v})}}
\end{aligned}
$$

sendo:

- $f \rightarrow$ fator dependente do Açúcar Total do mosto e volume alimentado, calculado pela Equação 51,

- $V_{\text {mosto }} \rightarrow$ Volume de mosto alimentado [l],

- $A R T_{\text {mosto(p/v) }} \rightarrow$ ART do mosto [\%],

- $\quad V_{v} \rightarrow$ Volume de vinho centrifugado[l],

- $V_{F} \rightarrow$ volume de fermento [l],

- EtOH $\rightarrow$ Teor Alcoólico [\%],

- $\quad V_{v a} \rightarrow$ Volume de vinho da fermentação anterior (que foi retornado após centrifugação) [l],

- $V_{\mathrm{Fa}} \rightarrow$ volume de fermento da fermentação anterior [l],

- EtOHa $\rightarrow$ Teor Alcoólico da fermentação anterior (ciclo anterior) [\%],

- $\quad V_{r} \rightarrow$ volume de amostra retirado para análises - quando for considerável [l]. 


\subsection{Obtenção do Modelo Matemático utilizando MATLAB ${ }^{\circledR}$}

O uso dos princípios básicos da física, química e biologia são comuns na construção de modelos dinâmicos. Construir um modelo matemático completo, consistente e compacto baseado no conhecimento de especialistas pode se tornar uma tarefa complexos, devido à dificuldade de distinguir parâmetros cujos efeitos são relevantes daqueles que podem ser ignorados (TOTH et al, 2012).

Neste trabalho, um algoritmo não-linear de mínimos quadrados é usado para estimar os parâmetros da levedura PE-2, usando o modelo dinâmico mostrado nas Equações 63 a 68, considerando a inibição pelo produto e pelo substrato.

A obtenção do modelo matemático da fermentação em batelada alimentada foi obtido através do programa $M \operatorname{MTAB}^{\circledR}$, utilizando-se a ferramenta de identificação de sistemas (System Identification Toolbox). Por se tratar de um modelo não linear, utilizou-se a função idnlgrey, responsável por representar um modelo não linear do tipo grey-box (Modelo Caixa Cinza).

Os dados obtidos nos experimentos foram tabulados e organizados, de forma a permitir a obtenção do modelo matemático.

Os valores de concentração do substrato entrante, taxa de conversão de substrato em biomassa e taxa de conversão de substrato em produto foram consideradas constantes no tempo, ou seja, considerou-se que uma determinada cepa de levedura possui como características intrínsecas os parâmetros $y_{p s}$ e $y_{x s}$ e que a concentração do substrato entrante não variou durante o período em que ocorreu a alimentação do biorreator.

Os "chutes" iniciais, necessários para a obtenção do modelo, foram baseados na literatura existente (LOBATO et al., 2006; BORGES, 2008).

Implementou-se um loop simulando a alimentação do sistema, adotandose uma vazão constante como padrão. Ao cessar a alimentação, a variação do volume do biorreator foi considerada desprezível, já que, em todos os casos, a variação de volume preenchido do biorreator foi menor do que $1 \%$.

O modelo matemático, descrito na Seção 2.6, utilizando a Equação 12 como função referente ao crescimento celular, foi implantado 
computacionalmente no MATLAB $^{\circledR}$. Adotou-se como número de saídas do modelo $\left(\mathrm{N}_{\mathrm{y}}=4\right)$, número de entradas do modelo $\left(\mathrm{N}_{\mathrm{u}}=0\right)$ e número de estados $\left(N_{x}=4\right)$. Os dados iniciais de concentração de substrato, produto e biomassa, bem como o volume inicial do biorreator, foram obtidos a partir dos dados experimentais, sendo utilizados diretamente na obtenção do modelo matemático.

A solução das equações diferenciais foi executada usando três diferentes métodos (FORSYTHE et al, 1977):

- Forward Euler's Method: Método de primeira ordem, apresenta muita instabilidade e erro global proporcional ao tamanho do passo.

- Runge-Kutta 23: Utiliza um par simples de fórmulas de segunda e terceira ordem com precisão mediana.

- Runge-Kutta 45: Utiliza um par de quarta e quinta ordem para uma maior precisão. Como este método utiliza fórmulas de ordem superior, geralmente leva menos passos de interação e tem uma velocidade maior na solução do problema.

Para cada um dos métodos aplicados, foi efetuada uma avaliação da aproximação do resultado com o valor dos dados experimentais. Duas curvas, considerando uma faixa de $2 \%$ com relação aos dados experimentais foram traçadas, de maneira a verificar o grau de aproximação dos dados.

Os parâmetros calculados pelos métodos acima mencionados foram salvos e então comparados para que se pudesse realizar a escolha do melhor e mais eficaz método a ser aplicado na otimização. 


\subsection{Aplicação da técnica quasi-LPV utilizando MATLAB ${ }^{\circledR}$}

O controlador $\boldsymbol{H}_{\infty}$ via representação quasi-LPV é determinado via os seguintes passos.

O estado é definido como:

$$
X=\left|\begin{array}{l}
x \\
s \\
p \\
v
\end{array}\right|
$$

sendo:

- $\quad x \rightarrow$ concentração de biomassa $[\mathrm{g} / \mathrm{l}]$,

- $s \rightarrow$ concentração de substrato $[\mathrm{g} / \mathrm{l}]$,

- $p \rightarrow$ concentração de produto [g/l],

- $\quad v \rightarrow$ volume preenchido do biorreator [l].

Define-se como os parâmetros variantes a concentração de substrato no biorreator $(s)$ e o volume $(v)$, ou seja:

$$
\theta=\left|\begin{array}{l}
s \\
v
\end{array}\right|
$$

Estas variáveis foram definidas como parâmetros variantes, pois podem ser medidas com relativa facilidade durante o processo de fermentação em relação às variáveis $x$ e $p$. 
Assim as matrizes dinâmicas $A(\theta), B_{1}(\theta), B_{2}(\theta), C_{1}(\theta)$ e $C_{2}(\theta)$ são computadas ponto a ponto, através da Equação 52 a Equação 54, com base na Equação 4 a Equação 9 e Equação 11, sendo que a entrada de controle $u$ corresponde à vazão por unidade de volume.

$$
\begin{gathered}
A(\theta)=\left|\begin{array}{cccc}
\mu(\theta) & 0 & 0 & 0 \\
\sigma(\mu(\theta)) & 0 & 0 & 0 \\
\pi(\mu(\theta)) & 0 & 0 & 0 \\
0 & 0 & 0 & 0
\end{array}\right| \\
B_{1}(\theta)=B_{2}(\theta)=\left|\begin{array}{c}
-x \\
s_{F}-s(\theta) \\
p \\
v(\theta)
\end{array}\right|
\end{gathered}
$$

$C_{1}=\left|\begin{array}{llll}1 & 0 & 0 & 0 \\ 0 & 1 & 0 & 0 \\ 0 & 0 & 1 & 0 \\ 0 & 0 & 0 & 1\end{array}\right|$ e $C_{2}=\left|\begin{array}{llll}0 & 0 & 0 & 0\end{array}\right|$

Equação 54

O sistema então é implementado na forma matricial. Utilizando-se a função SCONNECT do MATLAB ${ }^{\circledR}$, calcula-se a matriz $\boldsymbol{P}$ do sistema referente a planta aumentada, $P(s)$, associada com a estrutura de controle dada.

O segundo passo no procedimento de projeto do controlador é o cálculo da matriz $X_{i}$ que define o controlador em si. Estas matrizes definem o conjunto de LMI's (Equação 42 e Equação 43). O número de variáveis $X_{i}$ é especificado pelo número de funções $\phi(\theta)$, dependentes dos parâmetros variantes.

Neste trabalho, as funções $\phi(\theta)$ utilizadas foram as descritas conforme a Equação 55.

$$
\begin{aligned}
& \phi_{1}(\theta)=1 \\
& \phi_{2}(\theta)=s(\theta) \\
& \phi_{3}(\theta)=v(\theta)
\end{aligned}
$$


O valor de Â foi calculado conforme a Equação 39. As LMl's foram obtidas baseadas na Equação 42, onde o termo $E$ foi obtido da Equação 43.

A solução do conjunto de LMIs foi encontrada usando-se o toolbox de Matlab $^{\circledR}$ desenvolvido por GAHINET et al. (1995), obtendo-se da sua solução os valores dos ganhos do controlador.

A lei de controle utilizada está descrita na Equação 56, sendo baseada na Equação 40.

$$
\begin{aligned}
& u(t)=-\left(B_{2}^{T} X^{-1}\right) \cdot x(t) \\
& X=\left(\phi_{1} \cdot X_{1}+\phi_{2} \cdot X_{2}+\phi_{3} \cdot X_{3}\right)
\end{aligned}
$$

sendo $X_{1}, X_{2}$ e $X_{3}$ os valores dos ganhos calculados na solução do conjunto de LMls. 


\section{Capítulo 4}

Neste quarto capítulo deste trabalho serão apresentados, em ordem similar ao Capítulo 3 , os resultados obtidos durante o desenvolvimento da modelagem e otimização de uma fermentação alcoólica em batelada alimentada. Em um primeiro momento, serão apresentados os dados experimentais obtidos e uma análise sobre os mesmos. Será então apresentados os resultados da modelagem matemática, contendo tabelas e gráficos referentes ao modelo obtido, bem como uma comparação com outros resultados obtidos na literatura. Por fim, realizar-se-á o desenvolvimento da otimização do controle de alimentação, demonstrando os resultados obtidos e comparando-se com os dados experimentais realizados.

\section{Resultados Experimentais, Modelagem Matemática e Otimização do Processo de Fermentação Alcoólica em Batelada Alimentada}

\subsection{Condições de teste e procedimento experimental}

Como descrito no Capítulo 3, foram executados 2 ciclos, cada um composto por 9 biorreatores igualmente distribuídos em 3 temperaturas $\left(30^{\circ} \mathrm{C}\right.$, $33^{\circ} \mathrm{C}$ e $\left.36^{\circ} \mathrm{C}\right)$.

Foram coletadas amostras, para cada um dos biorreatores, com valor médio de $21,96 \pm 1,97 \mathrm{ml}$. Para cada uma destas amostras foram realizados as seguintes análises:

- Viabilidade e Brotamento

- Biomassa

- Etanol 
- $\mathrm{pH}$

- Açúcares

- Glicerol

- Manitol

Os dados serão aqui apresentados para permitir a reprodutibilidade dos resultados, auxiliando em outras pesquisas referentes ao assunto.

\subsubsection{Análises Microbiológicas}

Na Tabela 3 e Tabela 4 e na Figura 8 estão apresentados os dados referentes a viabilidade celular, ou seja, a quantidade de células vivas existentes em relação a quantidade de células totais, cujo cálculo foi realizado através da Equação 44. Nestas mesmas tabelas (Tabela 3 e Tabela 4) é apresentado um detalhamento quanto aos brotamentos existentes, calculados conforme Equação 45. Em ambas as tabelas, são identificados o ciclo, a temperatura e o biorreator referente.

Tabela 3 - Viabilidade e Brotamento no $1^{\circ}$ Ciclo

\begin{tabular}{|c|c|c|c|c|c|c|}
\hline & & & & $1^{\circ} \mathrm{ClCL}$ & & \\
\hline Tratamento & Biorreator & $\begin{array}{l}\text { Células } \\
\text { Vivas }\end{array}$ & $\begin{array}{l}\text { Células } \\
\text { Mortas }\end{array}$ & $\begin{array}{c}\text { Viabilidade } \\
\%\end{array}$ & Brotos & $\begin{array}{c}\text { Brotamento } \\
\%\end{array}$ \\
\hline & 1 & 360 & 4 & 98,9 & 29 & 8,1 \\
\hline $30^{\circ} \mathrm{C}$ & 2 & 413 & 5 & 98,8 & 22 & 5,3 \\
\hline & 3 & 241 & 2 & 99,2 & 16 & 6,6 \\
\hline Méc & & & & 99,0 & & 6,7 \\
\hline & 4 & 361 & 7 & 98,1 & 38 & 10,5 \\
\hline $33^{\circ} \mathrm{C}$ & 5 & 265 & 1 & 99,6 & 37 & 14,0 \\
\hline & 6 & 297 & 6 & 98,0 & 31 & 10,4 \\
\hline Méc & & & & 98,6 & & 11,6 \\
\hline & 7 & 272 & 2 & 99,3 & 72 & 26,5 \\
\hline $36^{\circ} \mathrm{C}$ & 8 & 302 & 3 & 99,0 & 81 & 26,8 \\
\hline & 9 & 291 & 6 & 98,0 & 44 & 15,1 \\
\hline Méc & & & & 98,8 & & 22,8 \\
\hline
\end{tabular}


Tabela 4 - Viabilidade e Brotamento no 2 - Ciclo

\begin{tabular}{|c|c|c|c|c|c|c|}
\hline & & & & $2^{\circ} \mathrm{CICLC}$ & & \\
\hline Tratamento & Biorreator & $\begin{array}{l}\text { Células } \\
\text { Vivas }\end{array}$ & $\begin{array}{l}\text { Células } \\
\text { Mortas }\end{array}$ & $\begin{array}{c}\text { Viabilidade } \\
\%\end{array}$ & Brotos & $\begin{array}{c}\text { Brotamento } \\
\%\end{array}$ \\
\hline & 1 & 557 & 9 & 98,4 & 20 & 3,6 \\
\hline $30^{\circ} \mathrm{C}$ & 2 & 358 & 3 & 99,2 & 25 & 7,0 \\
\hline & 3 & 201 & 4 & 98,0 & 19 & 9,5 \\
\hline Méc & & & & 98,5 & & 6,7 \\
\hline & 4 & 271 & 6 & 97,8 & 20 & 7,4 \\
\hline $33^{\circ} \mathrm{C}$ & 5 & 301 & 4 & 98,7 & 7 & 2,3 \\
\hline & 6 & 210 & 11 & 95,0 & 56 & 26,7 \\
\hline Méc & & & & $\overline{97,2}$ & & 12,1 \\
\hline & 7 & 360 & 12 & 96,8 & 103 & 28,6 \\
\hline $36^{\circ} \mathrm{C}$ & 8 & 278 & 12 & 95,9 & 90 & 32,4 \\
\hline & 9 & 270 & 10 & 96,4 & 53 & 19,6 \\
\hline Méc & & & & 96,4 & & 26,9 \\
\hline
\end{tabular}

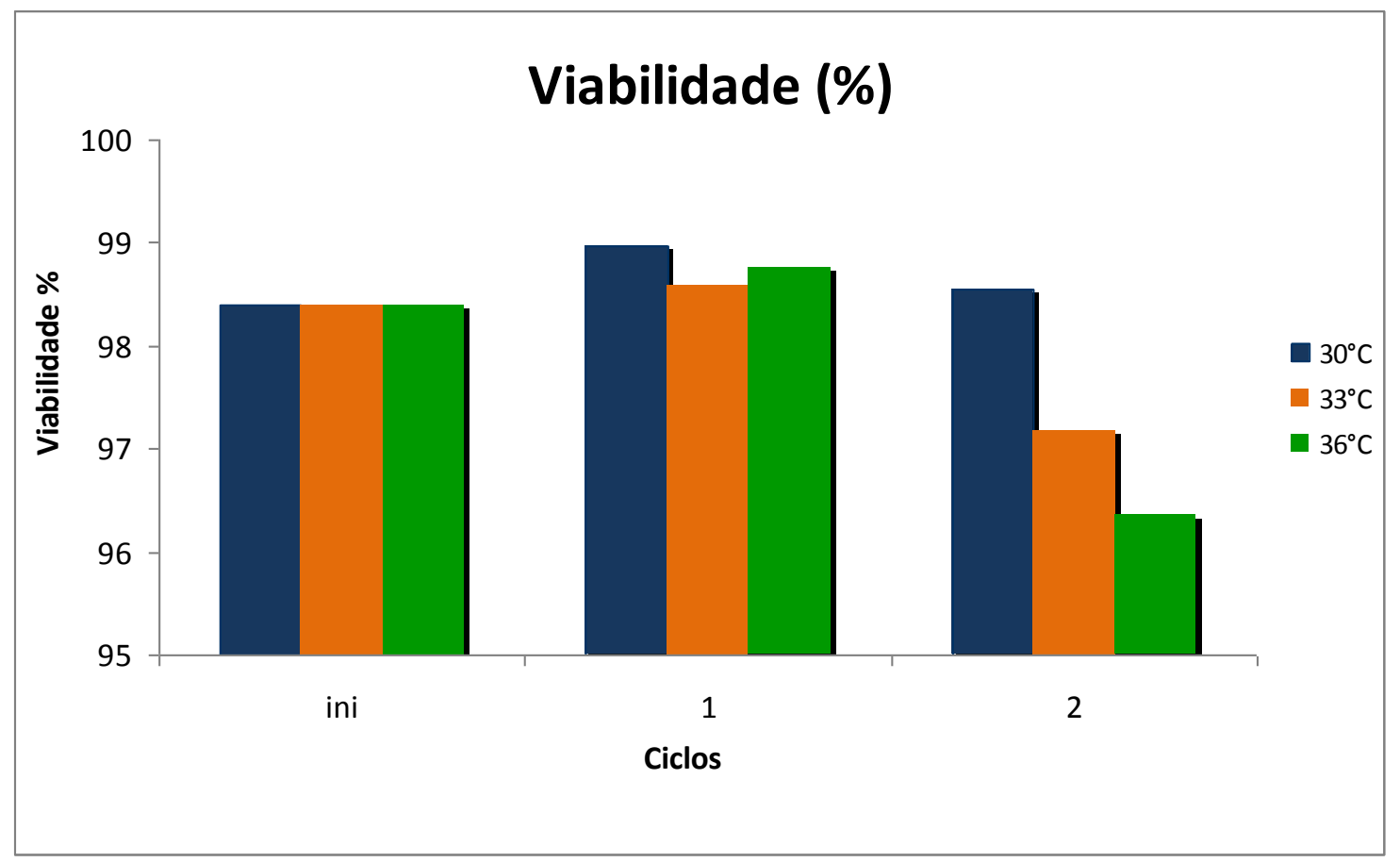

Figura 8 - Comparação referente à Viabilidade nos dois ciclos e nas três temperaturas utilizadas durantes os procedimentos experimentais.

O segundo ciclo, por possuir um ambiente considerado mais desfavorável a levedura, apresentou uma taxa de viabilidade menor, sendo que a temperatura de $36^{\circ} \mathrm{C}$ foi aquela na qual houve a maior variação de viabilidade do primeiro para o segundo ciclo. 
As concentrações de biomassa presentes nos biorreatores foram estimadas a partir das amostras coletadas ao final da fermentação. Tais amostras foram centrifugadas e então pesadas. As tabelas a seguir (Tabela 5, Tabela 6 e Tabela 7) e a Figura 9 apresentam os resultados deste procedimento.

Tabela 5 - Concentração média de biomassa $[\mathrm{g} / \mathrm{l}]$ existente nos biorreatores cuja temperatura foi mantida em torno de $30^{\circ} \mathrm{C}$

\begin{tabular}{|c|c|c|c|}
\hline & \multicolumn{3}{|c|}{$30^{\circ} \mathrm{C}$} \\
\hline Tempo & Biomassa [g] & Amostra [ml] & Biomassa [g/l] \\
\hline $0 \mathrm{~h}$ & 5,38 & 22,99 & 234,02 \\
\hline $1 \mathrm{~h}$ & 4,73 & 23,55 & 200,83 \\
\hline $2 \mathrm{~h}$ & 3,51 & 20,69 & 169,55 \\
\hline $3 \mathrm{~h}$ & 3,31 & 24,15 & 137,20 \\
\hline $4 \mathrm{~h}$ & 2,88 & 23,27 & 123,78 \\
\hline $5 \mathrm{~h}$ & 2,61 & 25,76 & 101,36 \\
\hline $6 \mathrm{~h}$ & 2,32 & 23,69 & 98,09 \\
\hline $7 \mathrm{~h}$ & 2,12 & 20,77 & 102,21 \\
\hline $8 \mathrm{~h}$ & 2,14 & 20,89 & 102,27 \\
\hline $9 \mathrm{~h}$ & 2,17 & 20,67 & 105,13 \\
\hline
\end{tabular}

Tabela 6 - Concentração média de biomassa [g/l] existente nos biorreatores cuja temperatura foi mantida em torno de $33^{\circ} \mathrm{C}$

\begin{tabular}{|c|c|c|c|}
\hline & \multicolumn{3}{|c|}{$33^{\circ} \mathrm{C}$} \\
\hline Tempo & Biomassa [g] & Amostra [ml] & Biomassa $[\mathrm{g} / \mathrm{l}]$ \\
\hline $0 \mathrm{~h}$ & 5,22 & 20,76 & 251,40 \\
\hline $1 \mathrm{~h}$ & 4,03 & 19,76 & 203,74 \\
\hline $2 \mathrm{~h}$ & 4,12 & 25,79 & 159,66 \\
\hline $3 \mathrm{~h}$ & 3,21 & 20,94 & 153,18 \\
\hline $4 \mathrm{~h}$ & 2,81 & 22,25 & 126,44 \\
\hline $5 \mathrm{~h}$ & 2,37 & 22,87 & 103,77 \\
\hline $6 \mathrm{~h}$ & 2,23 & 21,93 & 101,83 \\
\hline $7 \mathrm{~h}$ & 2,01 & 21,51 & 93,49 \\
\hline $8 \mathrm{~h}$ & 2,02 & 20,87 & 96,95 \\
\hline $9 \mathrm{~h}$ & 2,16 & 20,02 & 108,06 \\
\hline
\end{tabular}


Tabela 7 - Concentração média de biomassa $[\mathrm{g} / \mathrm{l}]$ existente nos biorreatores cuja

\begin{tabular}{|c|c|c|c|}
\hline \multicolumn{4}{|c|}{ temperatura foi mantida em torno de $36^{\circ} \mathrm{C}$} \\
\hline Tempo & Biomassa [g] & Amostra [ml] & Biomassa $[\mathrm{g} / \mathrm{l}]$ \\
\hline $\mathrm{Oh}$ & 5,08 & 26,73 & 190,07 \\
\hline $1 \mathrm{~h}$ & 3,76 & 22,38 & 167,86 \\
\hline $2 \mathrm{~h}$ & 2,66 & 17,84 & 148,84 \\
\hline $3 \mathrm{~h}$ & 2,68 & 21,77 & 122,99 \\
\hline $4 \mathrm{~h}$ & 2,33 & 22,75 & 102,29 \\
\hline $5 \mathrm{~h}$ & 2,09 & 21,03 & 99,37 \\
\hline $6 \mathrm{~h}$ & 2,06 & 20,86 & 98,74 \\
\hline $7 \mathrm{~h}$ & 2,13 & 22,49 & 94,86 \\
\hline $8 \mathrm{~h}$ & 2,04 & 19,62 & 104,16 \\
\hline $9 \mathrm{~h}$ & 2,09 & 20,16 & 103,84 \\
\hline
\end{tabular}

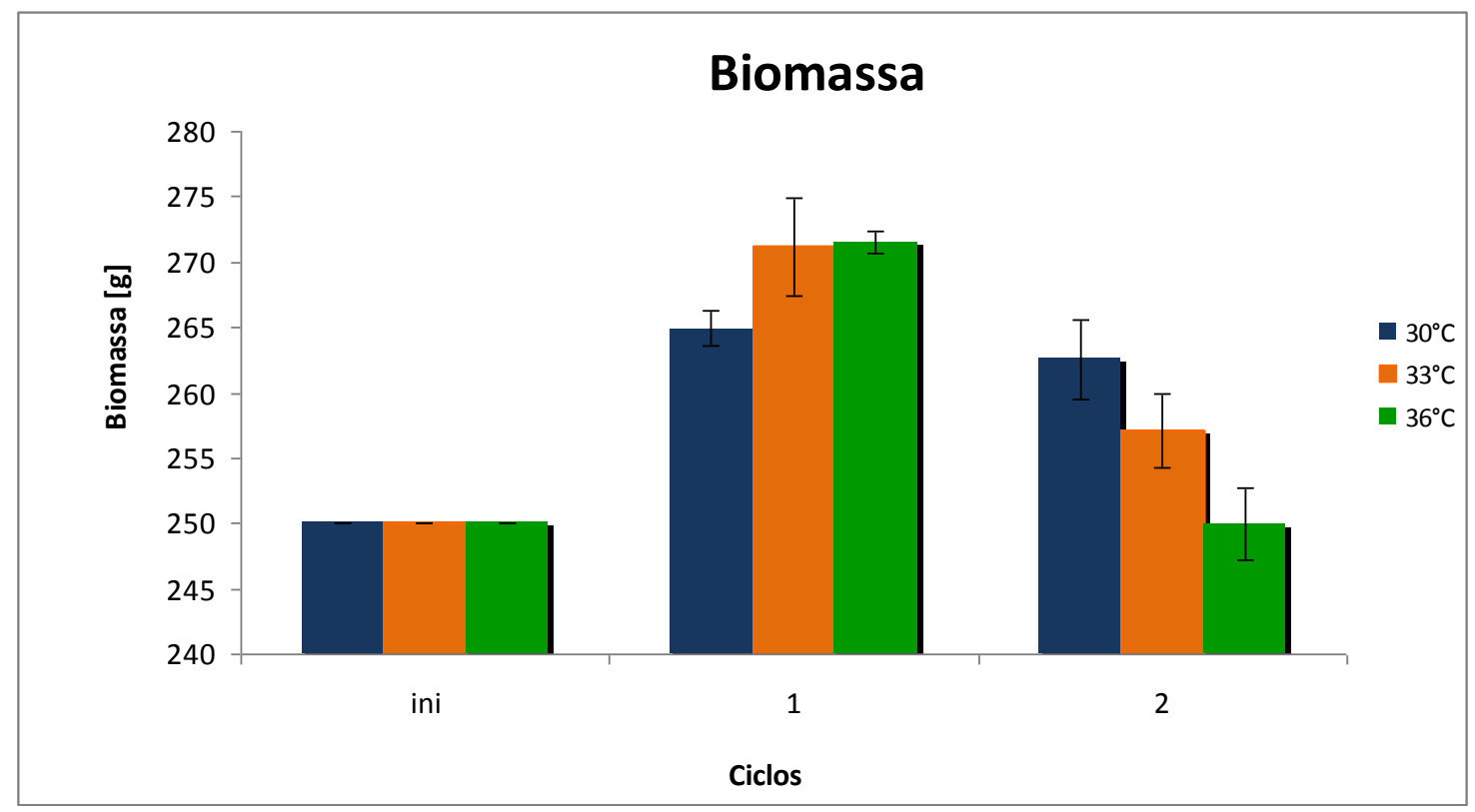

Figura 9 - Comparação referente à quantidade de Biomassa nos dois ciclos e nas três temperaturas utilizadas durantes os procedimentos experimentais.

Nas três temperaturas analisadas houve aumento da quantidade de Biomassa [g] quando comparado com a quantidade inicial. Porém, com o 
aumento da temperatura, houve uma tendência a menor reprodução celular, como pode ser visualizado na Figura 9.

\subsubsection{Análises Químicas}

Utilizando a metodologia descrita na Seção 3.3 deste trabalho, foram realizadas análises de concentração de Etanol, pH, Açúcares, Glicerol, Manitol e densidade dos vinhos.

A Tabela 8 apresenta a concentração média de Etanol para cada uma das temperaturas analisadas.

Tabela 8 - Variação da Concentração média de etanol nas amostras de vinho coletadas para cada uma das temperaturas analisadas.

\begin{tabular}{|c|c|c|c|}
\hline & \multicolumn{3}{|c|}{ Temperatura $(\stackrel{0}{0} \bar{C})$} \\
\hline \multirow{2}{*}{ Tempo } & $30 \div \bar{C}$ & $33^{\circ} \mathrm{C}$ & $36^{\circ} \mathrm{C}$ \\
\hline & Etanol [g/ll] & Etanol [g/li] & Etanol [g/li] \\
\hline $0 \mathrm{~h}$ & 34,467 & 34,467 & 34,667 \\
\hline $1 \mathrm{~h}$ & 67,500 & 67,633 & 64,700 \\
\hline $2 \mathrm{~h}$ & 77,333 & 77,533 & 71,533 \\
\hline $3 \mathrm{~h}$ & 84,167 & 85,000 & 82,200 \\
\hline $4 \mathrm{~h}$ & 85,400 & 85,200 & 85,867 \\
\hline $5 \mathrm{~h}$ & 86,533 & 89,767 & 87,533 \\
\hline $6 \mathrm{~h}$ & 86,533 & 87,200 & 88,567 \\
\hline $7 \mathrm{~h}$ & 94,533 & 96,767 & 99,100 \\
\hline $8 \mathrm{~h}$ & 102,667 & 102,133 & 102,267 \\
\hline $9 \mathrm{~h}$ & 104,433 & 104,133 & 103,333 \\
\hline
\end{tabular}

A Tabela 9 apresenta os valores de $\mathrm{pH}$ para cada um dos ciclos executados.

A variação da quantidade de açúcares redutores totais (ART) está apresentada na Tabela 10. 
Tabela 9 - Valores de pH para cada um dos biorreatores e cada um dos ciclos executados.

\begin{tabular}{|c|c|c|c|}
\hline Tratamento & Biorreator & $1^{\circ}$ Ciclo & $2^{\circ}$ Ciclo \\
\hline \multirow{3}{*}{$30^{\circ} \mathrm{C}$} & 1 & 5,24 & 5,13 \\
\hline & 2 & 5,13 & 5,16 \\
\hline & 3 & 5,38 & 5,18 \\
\hline \multicolumn{2}{|c|}{ Média } & 5,25 & 5,16 \\
\hline \multirow{3}{*}{$33^{\circ} \mathrm{C}$} & 4 & 5,52 & 5,06 \\
\hline & 5 & 5,37 & 5,08 \\
\hline & 6 & 5,20 & 5,14 \\
\hline \multicolumn{2}{|c|}{ Média } & 5,36 & 5,09 \\
\hline \multirow{3}{*}{$36^{\circ} \mathrm{C}$} & 7 & 5,14 & 5,17 \\
\hline & 8 & 5,13 & 5,09 \\
\hline & 9 & 5,12 & 4,97 \\
\hline \multicolumn{2}{|c|}{ Média } & 5,13 & 5,08 \\
\hline
\end{tabular}

Tabela 10 - Variação da quantidade de Açúcares Redutores Totais (ART) [g/l] para cada uma das temperaturas analisadas.

\begin{tabular}{|c|c|c|c|}
\hline \multirow{2}{*}{ Tempo } & $30^{\circ} \mathrm{C}$ & $33^{\circ} \mathrm{C}$ & $36 \div \bar{C}$ \\
\hline & $\mathrm{ART}[\mathrm{g} / \mathrm{l}$ & $\mathrm{ART}[\mathrm{g} / \mathrm{l}]$ & $\bar{A} \bar{T} \bar{g} / \bar{l}$ \\
\hline $\mathrm{Oh}$ & 79,951 & 85,581 & 88,949 \\
\hline $1 \mathrm{~h}$ & 18,847 & 20,670 & 29,256 \\
\hline $2 \mathrm{~h}$ & 14,999 & 15,249 & 27,968 \\
\hline $3 \mathrm{~h}$ & 12,896 & 10,868 & 15,750 \\
\hline $4 \mathrm{~h}$ & 20,883 & 18,481 & 18,955 \\
\hline $5 \mathrm{~h}$ & 24,358 & 20,722 & 19,061 \\
\hline $6 \mathrm{~h}$ & 27,108 & 25,471 & 22,126 \\
\hline $7 \mathrm{~h}$ & 13,200 & 11,234 & 7,970 \\
\hline $8 \mathrm{~h}$ & 2,047 & 1,732 & 1,542 \\
\hline $9 \mathrm{~h}$ & 1,563 & 1,484 & 1,522 \\
\hline
\end{tabular}




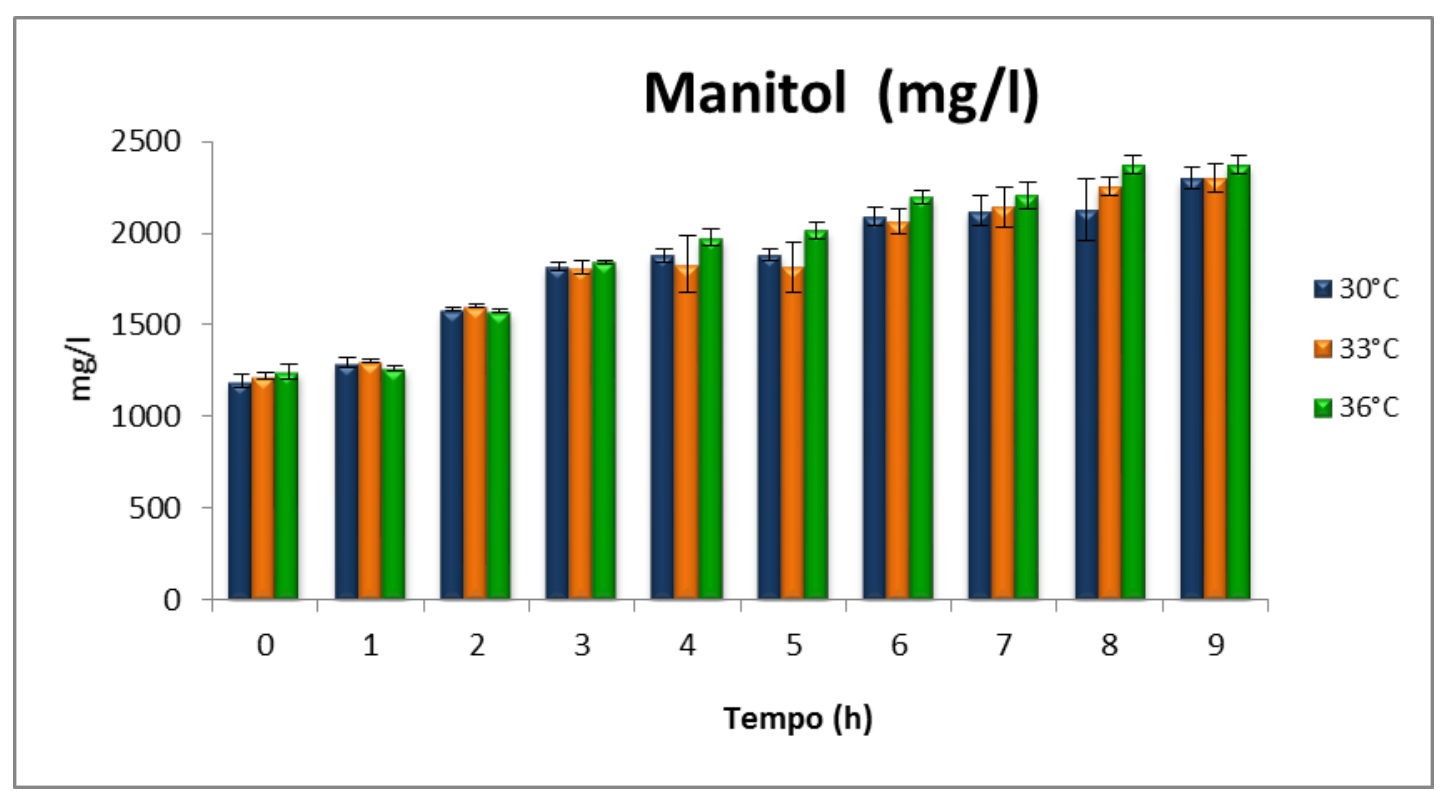

Figura 10 - Variação da Concentração de Manitol [mg/l] para cada uma das temperaturas analisadas.

Como análises complementares, estão apresentados, na Figura 10 e na Figura 11, os valores de Manitol e Glicerol (no segundo ciclo) existentes no meio ao final da fermentação, respectivamente.

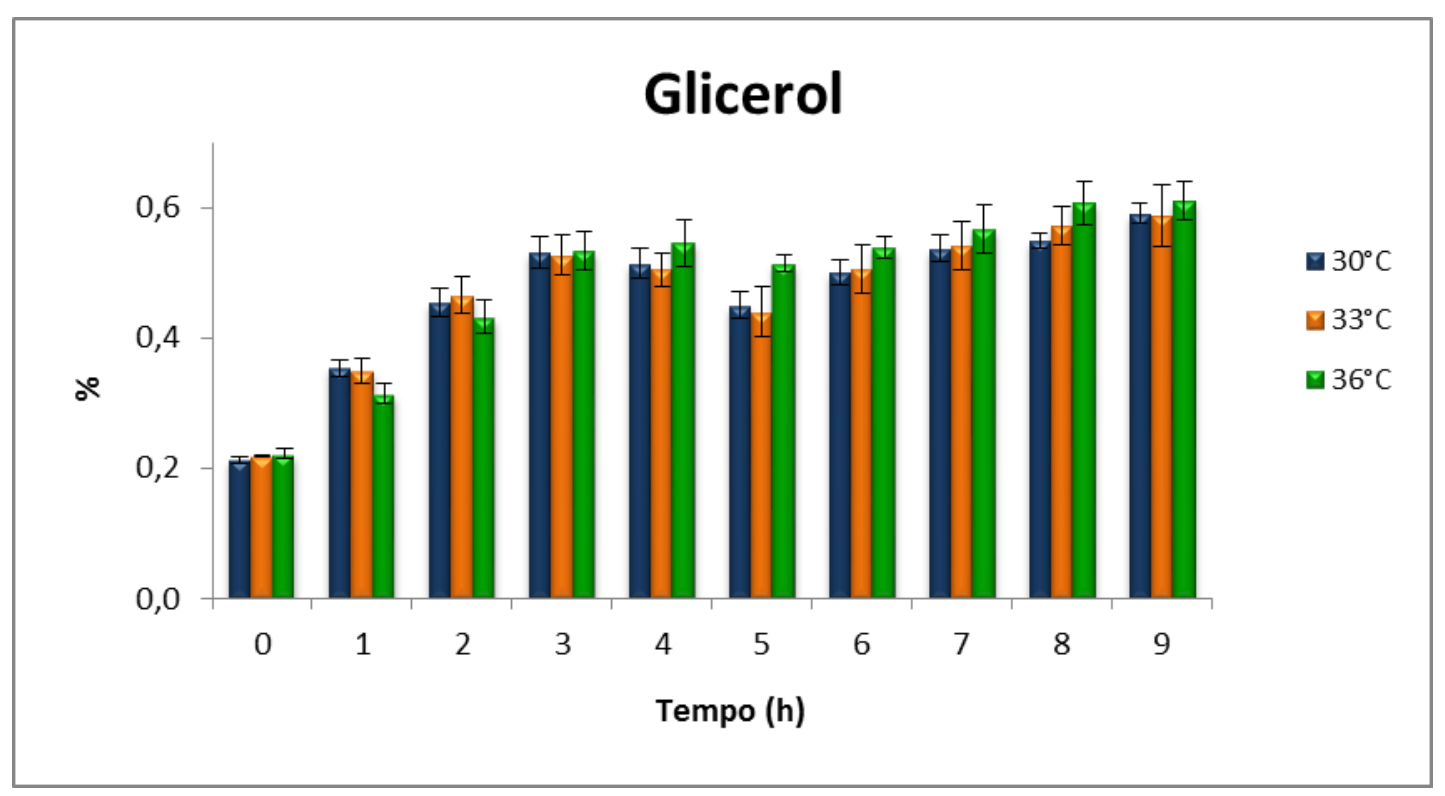

Figura 11 - Variação da Porcentagem de Glicerol para cada uma das temperaturas analisadas. 
O manitol, formado exclusivamente por bactérias láticas heterofermentativas durante a fermentação, se presta como indicador bioquímico da intensidade da contaminação bacteriana na fermentação alcoólica. O manitol é superado apenas pelo lactato quando se diz respeito ao desvio de açúcares durante a fermentação alcoólica devido a contaminação bacteriana (GOMES, 2009).

O glicerol é um produto secundário da fermentação, sendo produzido em quantidades maiores quando a levedura se encontra em condições consideradas desfavoráveis e estressantes. A produção de glicerol afeta o rendimento fermentativo de maneira negativa, já que impõe um desvio da metabolização de açúcar, ou seja, a levedura deixou de produzir etanol para produzir glicerol (GOMES, 2009).

As tabelas abaixo (Tabela 11, Tabela 12 e Tabela 13) apresentam os valores médios de densidade do vinho centrifugado analisadas para cada uma das temperaturas, bem como os valores das massas, obtidas das balanças de precisão, e o volume calculado.

Tabela 11 - Densidade $[\mathrm{g} / \mathrm{l}]$, massa $[\mathrm{g}]$ e volume $[\mathrm{l}]$ médios para a temperatura de $30^{\circ} \mathrm{C}$

\begin{tabular}{|c|c|c|c|}
\hline Tempo & Densidade [g/l] & Massa [kg] & Volume [I] \\
\hline $\mathrm{Oh}$ & 1046,7 & 1030,0 & 0,984 \\
\hline $1 \mathrm{~h}$ & 1020,1 & 1360,2 & 1,333 \\
\hline $2 \mathrm{~h}$ & 1021,3 & 1669,2 & 1,634 \\
\hline $3 \mathrm{~h}$ & 1022,7 & 1991,4 & 1,947 \\
\hline $4 \mathrm{~h}$ & 1026,4 & 2305,7 & 2,246 \\
\hline $5 \mathrm{~h}$ & 1028,1 & 2634,1 & 2,562 \\
\hline $6 \mathrm{~h}$ & 1030,7 & 2614,9 & 2,537 \\
\hline $7 \mathrm{~h}$ & 1024,1 & 2598,0 & 2,537 \\
\hline $8 \mathrm{~h}$ & 1019,0 & 2584,2 & 2,536 \\
\hline $9 \mathrm{~h}$ & 1017,9 & 2579,8 & 2,534 \\
\hline
\end{tabular}


Tabela 12 - Densidade [g/l], massa [g] e volume [l] médios para a temperatura de $33^{\circ} \mathrm{C}$

\begin{tabular}{|c|c|c|c|}
\hline Tempo & Densidade $[\mathrm{g} / \mathrm{l}]$ & Massa [g] & Volume [I] \\
\hline $0 \mathrm{~h}$ & 1046,7 & 1031,2 & 0,984 \\
\hline $1 \mathrm{~h}$ & 1020,1 & 1350,3 & 1,323 \\
\hline $2 \mathrm{~h}$ & 1021,3 & 1668,2 & 1,633 \\
\hline $3 \mathrm{~h}$ & 1022,7 & 1983,2 & 1,942 \\
\hline $4 \mathrm{~h}$ & 1026,4 & 2299,5 & 2,243 \\
\hline $5 \mathrm{~h}$ & 1028,1 & 2613,4 & 2,545 \\
\hline $6 \mathrm{~h}$ & 1030,7 & 2592 & 2,517 \\
\hline $7 \mathrm{~h}$ & 1024,1 & 2573,9 & 2,515 \\
\hline $8 \mathrm{~h}$ & 1019 & 2560,4 & 2,514 \\
\hline $9 \mathrm{~h}$ & 1017,9 & 2556,3 & 2,511 \\
\hline
\end{tabular}

Tabela 13 - Densidade $[\mathrm{g} / \mathrm{l}]$, massa $[\mathrm{g}]$ e volume $[\mathrm{l}]$ médios para a temperatura de $36^{\circ} \mathrm{C}$

\begin{tabular}{|c|c|c|c|}
\hline Tempo & Densidade [g/l] & Massa [g] & Volume [I] \\
\hline $\mathrm{O} \mathrm{h}$ & 1047,4 & 1037,6 & 0,991 \\
\hline $1 \mathrm{~h}$ & 1024,3 & 1361,3 & 1,329 \\
\hline $2 \mathrm{~h}$ & 1027,7 & 1674,2 & 1,629 \\
\hline $3 \mathrm{~h}$ & 1023,5 & 1989,9 & 1,944 \\
\hline $4 \mathrm{~h}$ & 1025,8 & 2304,7 & 2,247 \\
\hline $5 \mathrm{~h}$ & 1027 & 2620,2 & 2,551 \\
\hline $6 \mathrm{~h}$ & 1027,7 & 2596 & 2,526 \\
\hline $7 \mathrm{~h}$ & 1021,2 & 2579,2 & 2,526 \\
\hline $8 \mathrm{~h}$ & 1018,5 & 2568,9 & 2,522 \\
\hline $9 \mathrm{~h}$ & 1018 & 2563,3 & 2,518 \\
\hline
\end{tabular}




\section{Temperature $\left(30^{\circ} \mathrm{C}\right)$}

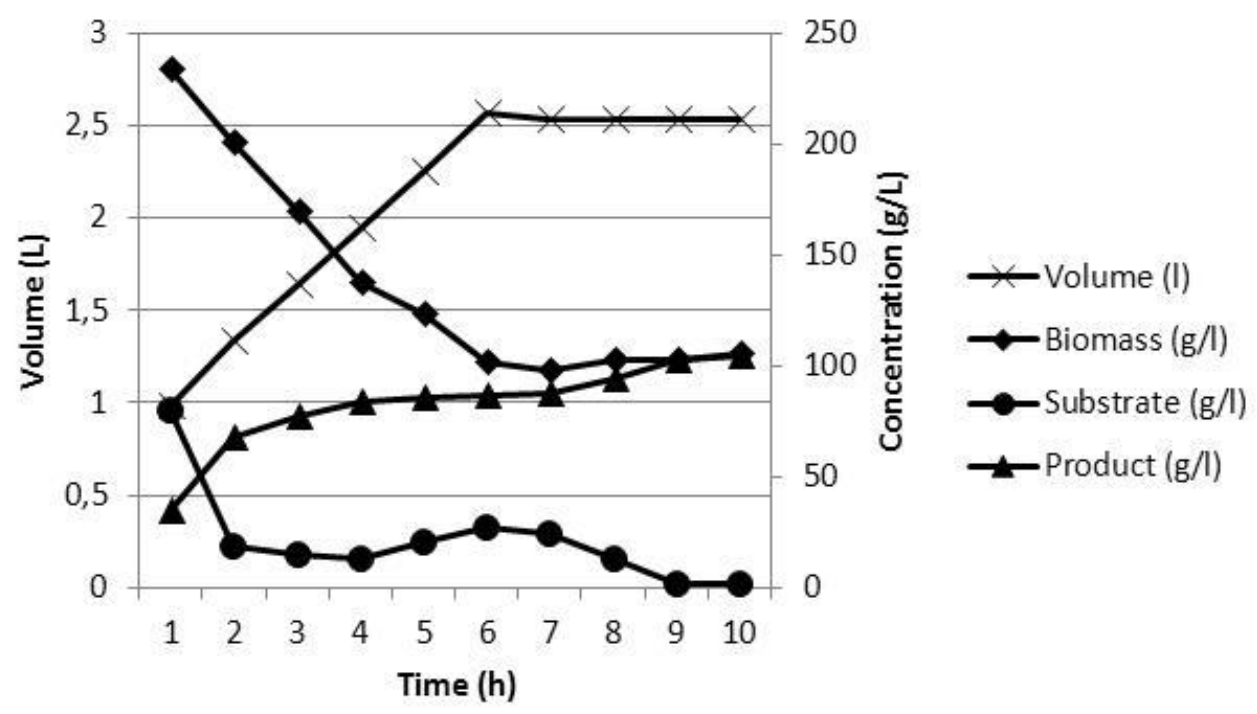

Figura 12 - Volume, Concentração de Biomassa, Substrato e Produto na temperatura de $30^{\circ} \mathrm{C}$.

\section{Temperature $\left(33^{\circ} \mathrm{C}\right)$}

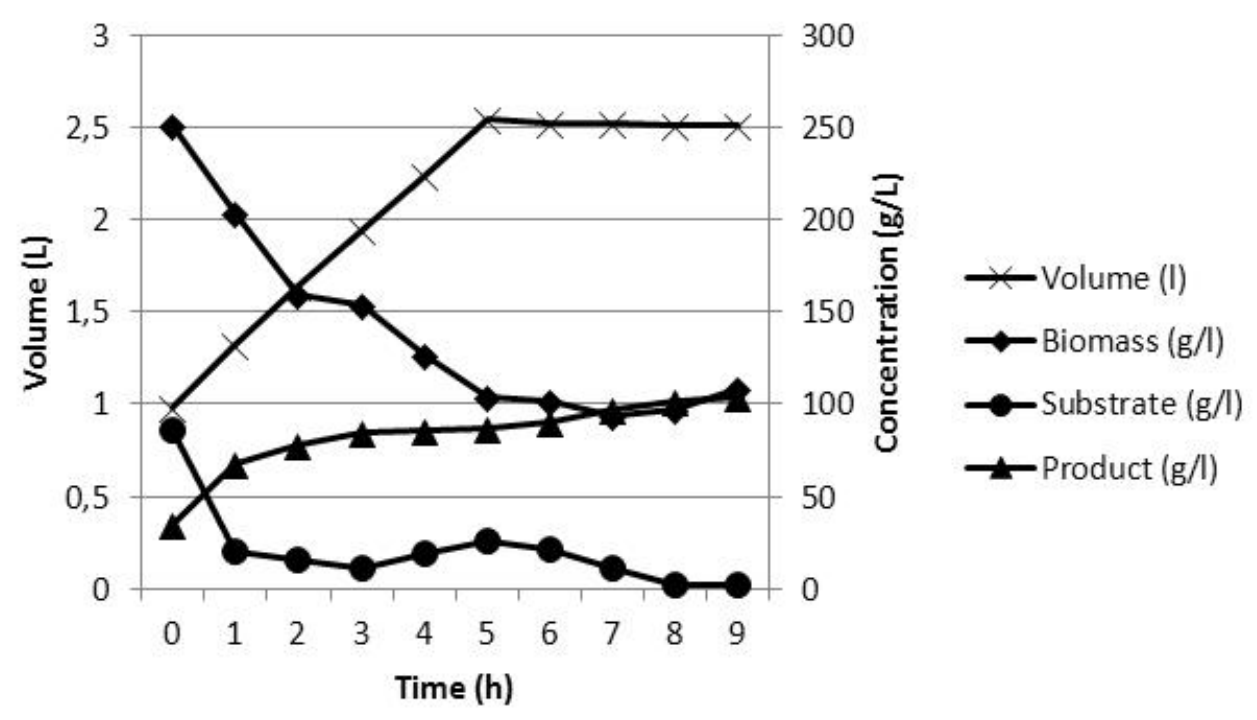

Figura 13 - Volume, Concentração de Biomassa, Substrato e Produto na temperatura de $33^{\circ} \mathrm{C}$. 


\section{Temperature $\left(36^{\circ} \mathrm{C}\right)$}

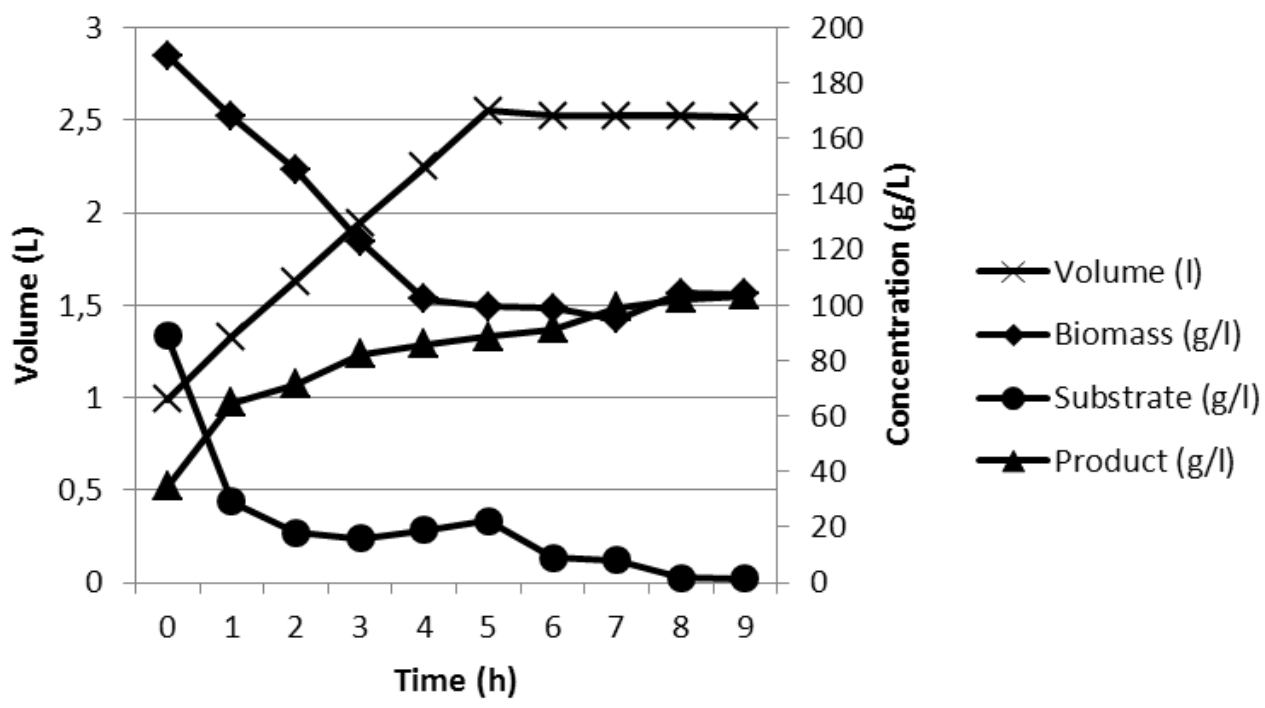

Figura 14 - Volume, Concentração de Biomassa, Substrato e Produto na temperatura de $36^{\circ} \mathrm{C}$.

As figuras Figura 12, Figura 13 e Figura 14 mostram a variação da concentração de biomassa $(g / l)$, produto $(g / l)$ e substrato $(g / l)$ e do volume do tanque de fermentação (l) para cada uma das temperaturas.

Nos três casos estudados, a alimentação cessou após 5 horas de fermentação. Os dados obtidos foram similares aos obtidos por BORGES (2008) em seus experimentos, com pequena diferença na concentração celular (biomassa), já que no experimento executado para esta tese, a reprodução celular foi menor do que no trabalho executado por BORGES (2008).

É possível observar que a biomassa apresenta comportamento de diminuição durante a fase de alimentação, devido a sua diluição no meio. A quantidade de substrato também diminui ao longo do tempo, devido a diluição e também ao consumo do mesmo.

O produto (etanol) apresenta comportamento diferenciado das outras variáveis, já que inicia com um valor diferente de zero (pois já está presente no meio, junto ao fermento inserido previamente, também chamado de "pé de cuba") e apresenta comportamento crescente. Este comportamento cessa quando a fermentação está em vias de finalizar, ou seja, a produção de etanol deixa de acontecer quando a quantidade de açúcar fermentescível existente no meio se aproxima de zero. 


\subsubsection{Taxas de Conversão, produtividade e rendimento fermentativo}

Uma comparação entre as taxas de conversão, produtividade e rendimento fermentativo foi executada para cada uma das temperaturas avaliadas.

Temperaturas altas (acima de $35^{\circ} \mathrm{C}$ ) favorecem o crescimento bacteriano (AMORIM, 2005), impactando na taxa de conversão de substrato em produto e, consequentemente, diminuindo a produtividade. Maiores produtividades e taxas de conversão de substrato em produto foram observadas em temperaturas menores, bem como uma menor multiplicação celular, o que pode ser visualizado na taxa de conversão de substrato em células. As figuras Figura 15, Figura 16 e Figura 17 apresentam os resultados finais para cada uma das temperaturas. Os cálculos referentes aos parâmetros Taxa de Conversão de Substrato em Produto, Substrato em Células e Produtividade foram executados utilizando as Equações Equação 47, Equação 48 e Equação 49, mostradas na Seção 3.4 deste trabalho.

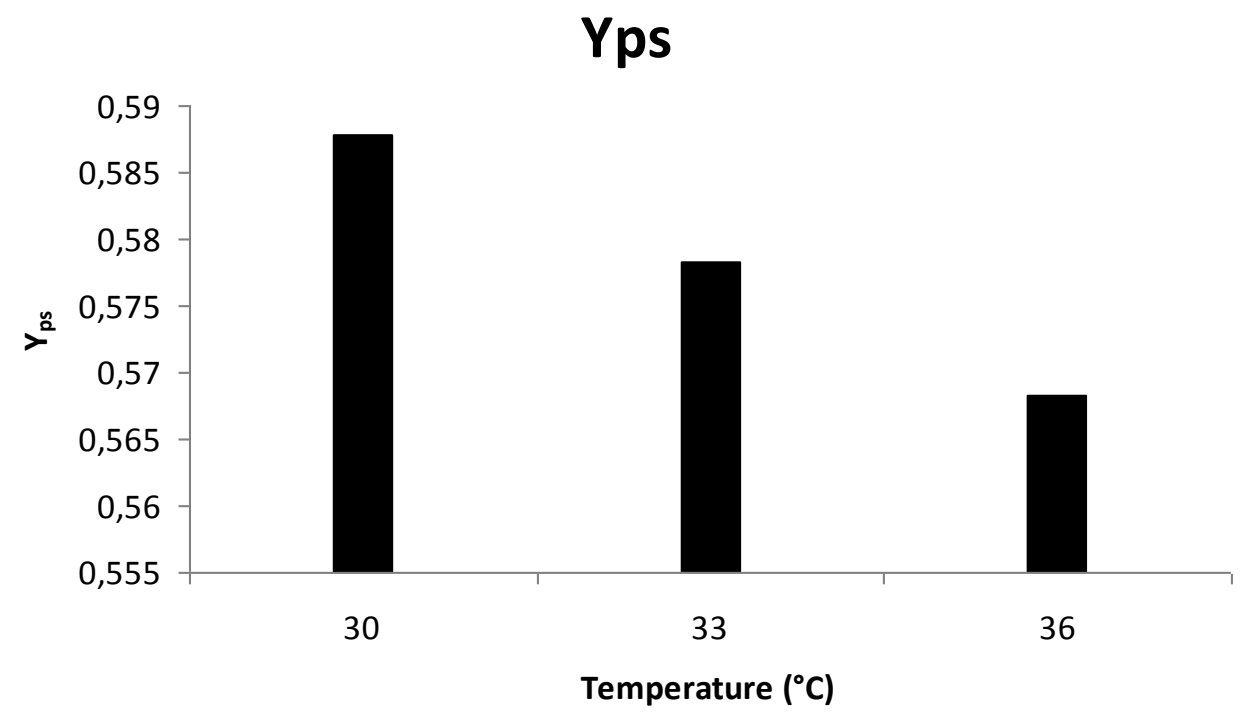

Figura 15 - Taxa de Conversão média ao final do processo fermentativo de substrato em produto em cada uma das temperaturas analisadas. 


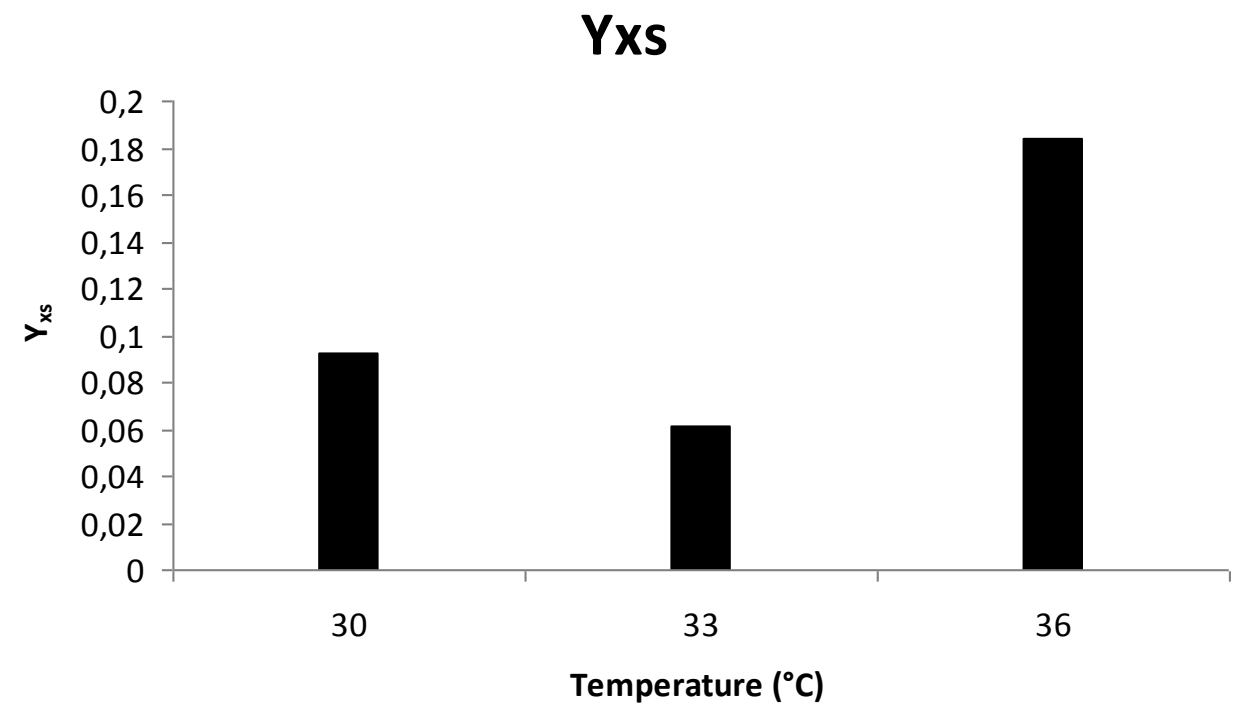

Figura 16 - Taxa de Conversão média ao final do processo fermentativo de substrato em células em cada uma das temperaturas analisadas.

A taxa de conversão de substrato em produto apresentou variação de 2 a $3 \%$ entre as temperaturas avaliadas, sendo que a temperatura em que esta conversão foi melhor realizada foi em temperaturas próximas a $30^{\circ} \mathrm{C}$, dificilmente atingíveis em situações industriais.

A taxa de conversão de substrato em células apresentou um comportamento extremo, com variações de até 2 vezes entre as temperaturas avaliadas. Na temperatura de $33^{\circ} \mathrm{C}$ obteve-se a menor taxa de conversão de substrato em células, indicando que nesta temperatura o desvio de substrato para a reprodução celular foi menor do que nas outras situações.

A produtividade apresentou variação insignificante entre as temperaturas de 30 e $33^{\circ} \mathrm{C}$ e uma variação de 1 a $2 \%$ com relação a temperatura de $36^{\circ} \mathrm{C}$.

O rendimento fermentativo, calculado a partir das equações Equação 50 e Equação 51 apresentadas na seção 3.4 deste trabalho, pode ser visualizado na Tabela 14. 


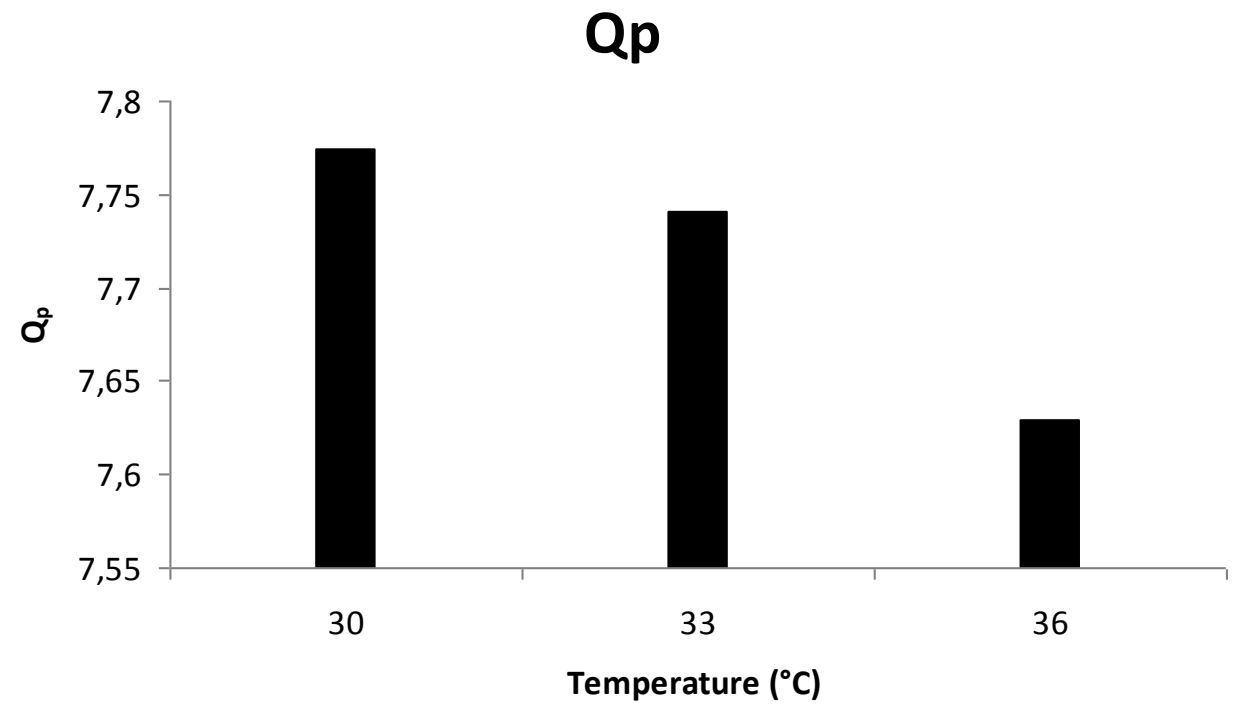

Figura 17 - Produtividade média ao final do processo fermentativo em cada uma das temperaturas analisadas.

Tabela 14 - Rendimento Fermentativo nos dois ciclos, para cada uma das temperaturas estudadas neste trabalho.

\begin{tabular}{|c|c|c|c|}
\hline & & Rendimen & ntativo (\% \\
\hline Tratamento & Tanque & $1^{\circ}$ Ciclo & $2^{\circ}$ Ciclo \\
\hline \multirow{3}{*}{$30^{\circ} \mathrm{C}$} & Tanque 1 & 94,41 & 85,09 \\
\hline & Tanque 2 & 93,52 & 82,91 \\
\hline & Tanque 3 & 92,42 & 82,69 \\
\hline \multicolumn{2}{|c|}{ Média } & 93,45 & 83,56 \\
\hline \multirow{3}{*}{$33^{\circ} \mathrm{C}$} & Tanque 4 & 93,13 & 80,31 \\
\hline & Tanque 5 & 94,26 & 82,85 \\
\hline & Tanque 6 & 92,38 & 83,03 \\
\hline \multicolumn{2}{|c|}{ Média } & 93,26 & 82,06 \\
\hline \multirow{3}{*}{$36^{\circ} \mathrm{C}$} & Tanque 7 & 92,15 & 82,10 \\
\hline & Tanque 8 & 91,47 & 80,66 \\
\hline & Tanque 9 & 91,45 & 82,04 \\
\hline \multicolumn{2}{|c|}{ Média } & 91,69 & 81,60 \\
\hline
\end{tabular}


O rendimento fermentativo foi maior no $1^{\circ}$ ciclo, pois a levedura se encontrava em condições idealizadas. Ao se realizar o reciclo da levedura, a mesma começa a trabalhar em condições semelhantes às obtidas no ambiente industrial.

Quando comparados os rendimentos no $2^{\circ}$ ciclo, percebe-se uma variação máxima de $2 \%$, sendo que em temperaturas menores obteve-se melhor rendimento fermentativo.

\subsection{Obtenção do modelo matemático}

Usando os dados obtidos nos experimentos (Tabela 16, Tabela $17 \mathrm{e}$ Tabela 18) e aplicando a metodologia descrita na Seção 3.5, foi possível obter o modelo para a levedura PE-2 na faixa de temperaturas de 30 a $36^{\circ} \mathrm{C}$. A Tabela 15 mostra as condições iniciais adotadas para cada temperatura analisada.

A Tabela 19 mostra uma comparação entre os dois métodos de RungeKutta, demonstrando que o método Runge-Kutta 45 é mais adequado ao problema proposto por ter uma melhor aproximação em todas as temperaturas examinadas, quando comparados os dados reais e o modelo obtido. Os dados apresentados nesta tabela dizem respeito ao grau de aproximação entre os valores experimentais e os valores calculados pelo modelo matemático obtido.

Tabela 15 - Resultados experimentais da fermentação em batelada alimentada: condições iniciais e finais dos experimentos.

\begin{tabular}{|c|c|c|c|}
\hline & $\mathrm{T}=30 \mathrm{O}$ & $\bar{T}=33^{\circ} \mathrm{C}$ & $\mathrm{T}=36^{\circ} \mathrm{C}$ \\
\hline $\mathrm{S}_{0}[\mathrm{~g} / \mathrm{l}]$ & 0 & 0 & 0 \\
\hline $\mathrm{X}_{0}[\mathrm{~g} / \mathrm{l}]$ & 234,0 & 251,4 & 190,1 \\
\hline $\mathrm{P}_{0}[\mathrm{~g} / \mathrm{l}]$ & 34,47 & 34,47 & 34,47 \\
\hline$V_{0}[1]$ & 0,984 & 0,984 & 0,990 \\
\hline $\begin{array}{l}V_{F}[l] \\
F[l / h]\end{array}$ & $\begin{array}{c}2,534 \\
0,25\end{array}$ & $\begin{array}{c}2,511 \\
0,25\end{array}$ & $\begin{array}{c}2,518 \\
0,25\end{array}$ \\
\hline$t_{F}[h]$ & 9 & 9 & 9 \\
\hline $\mathrm{S}_{\mathrm{r}}[\mathrm{g} / \mathrm{l}]$ & 1,56 & 1,48 & 1,52 \\
\hline$y_{p s}[\mathrm{~g} / \mathrm{g}]$ & 0,588 & 0,578 & 0,568 \\
\hline$y \times s[g / g]$ & 0,092 & 0,061 & 0,184 \\
\hline$Q_{p}[g /(I . h)]$ & 7,77 & 7,74 & 7,63 \\
\hline
\end{tabular}


Tabela 16 - Dados experimentais utilizados na obtenção do modelo matemático (Temperatura $=30^{\circ} \mathrm{C}$ ).

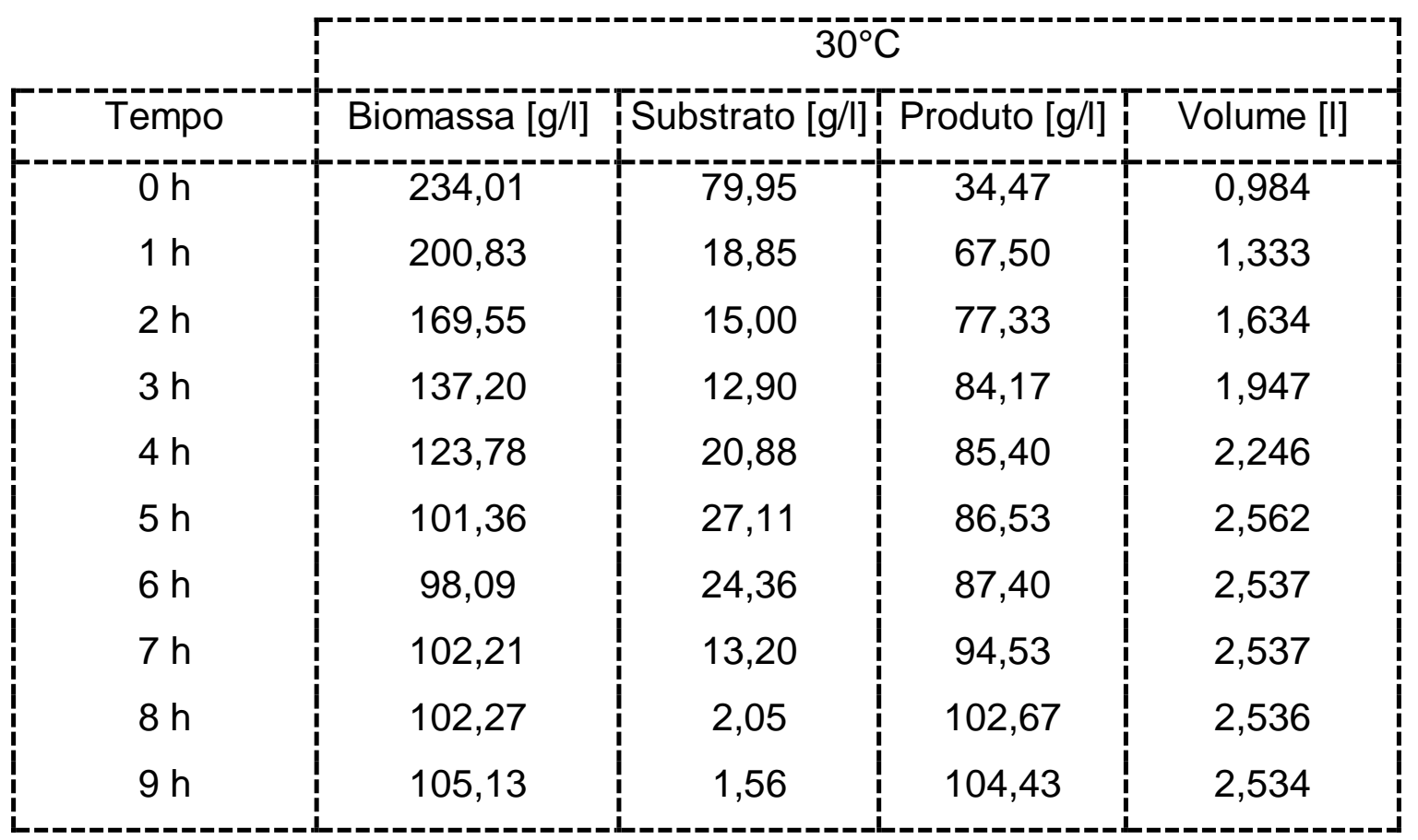

Tabela 17 - Dados experimentais utilizados na obtenção do modelo matemático (Temperatura $=33^{\circ} \mathrm{C}$ ).

\begin{tabular}{|c|c|c|c|c|}
\hline Tempo & Biomassa [g/l] & Substrato $[\mathrm{g} / \mathrm{l}]$ & Produto [g/l] & Volume [l] \\
\hline $\mathrm{O} \mathrm{h}$ & 251,40 & 85,58 & 34,47 & 0,984 \\
\hline $1 \mathrm{~h}$ & 203,74 & 20,67 & 67,63 & 1,323 \\
\hline $2 \mathrm{~h}$ & 159,66 & 15,25 & 77,53 & 1,633 \\
\hline $3 \mathrm{~h}$ & 153,18 & 10,87 & 85,00 & 1,942 \\
\hline $4 \mathrm{~h}$ & 126,44 & 18,48 & 85,20 & 2,243 \\
\hline $5 \mathrm{~h}$ & 103,77 & 25,47 & 87,20 & 2,545 \\
\hline $6 \mathrm{~h}$ & 101,83 & 20,72 & 89,77 & 2,517 \\
\hline $7 \mathrm{~h}$ & 93,49 & 11,23 & 96,77 & 2,515 \\
\hline $8 \mathrm{~h}$ & 96,95 & 1,73 & 102,13 & 2,514 \\
\hline $9 \mathrm{~h}$ & 108,06 & 1,48 & 104,13 & 2,511 \\
\hline
\end{tabular}


Tabela 18 - Dados experimentais utilizados na obtenção do modelo matemático (Temperatura $=36^{\circ} \mathrm{C}$ ).

\begin{tabular}{|c|c|c|c|c|}
\hline Tempo & Biomassa [g/l] & Substrato $[\mathrm{g} / \mathrm{l}]$ & Produto [g/l] & Volume [l] \\
\hline $\mathrm{Oh}$ & 190,07 & 88,95 & 34,67 & 0,991 \\
\hline $1 \mathrm{~h}$ & 167,86 & 29,26 & 64,70 & 1,329 \\
\hline $2 \mathrm{~h}$ & 148,84 & 17,97 & 71,53 & 1,629 \\
\hline $3 \mathrm{~h}$ & 122,99 & 15,75 & 82,20 & 1,944 \\
\hline $4 \mathrm{~h}$ & 102,29 & 18,95 & 85,87 & 2,247 \\
\hline $5 \mathrm{~h}$ & 99,37 & 22,13 & 88,57 & 2,551 \\
\hline $6 \mathrm{~h}$ & 98,74 & 9,06 & 91,30 & 2,526 \\
\hline $7 \mathrm{~h}$ & 94,86 & 7,97 & 99,10 & 2,526 \\
\hline $8 \mathrm{~h}$ & 104,16 & 1,54 & 102,27 & 2,522 \\
\hline $9 \mathrm{~h}$ & 103,84 & 1,52 & 103,33 & 2,518 \\
\hline
\end{tabular}

Tabela 19 - Comparação entre os métodos Runge-Kutta 23 e Runge-Kutta 45 durante a estimação dos parâmetros.

\begin{tabular}{|c|c|c|c|}
\hline & $\bar{T}=30 \div 0$ & $\bar{T}=33^{\circ} \mathrm{C}$ & $\overline{\mathrm{T}}=36^{\circ} \mathrm{O}$ \\
\hline \multicolumn{4}{|c|}{ Runge-Kutta 23} \\
\hline Biomassa (\%) & 82,72 & 83,75 & 83,10 \\
\hline Substrato (\%) & 85,88 & 82,93 & 89,67 \\
\hline Produto (\%) & 76,00 & 75,42 & 72,26 \\
\hline Volume (\%) & 95,12 & 96,75 & 97,29 \\
\hline \multicolumn{4}{|c|}{ Runge-Kutta 45} \\
\hline Biomassa (\%) & 82,78 & 83,81 & 82,95 \\
\hline Substrato (\%) & 87,85 & 83,87 & 88,95 \\
\hline Produto (\%) & 75,84 & 75,82 & 73,12 \\
\hline Volume (\%) & 95,31 & 96,82 & 97,34 \\
\hline
\end{tabular}

A Tabela 20 mostra as condições iniciais ("chute inicial") e os parâmetros obtidos usando o método de Runge-Kutta 45. Os critérios de parada adotados foram 100 iterações ou variação menor que $10^{-8}$ entre duas iterações consecutivas. 
Tabela 20 - Parâmetros Iniciais e estimados usando o método Runge-Kutta 45.

\begin{tabular}{|c|c|c|c|c|c|c|}
\hline & \multicolumn{2}{|c|}{$\mathrm{T}=30 \circ \mathrm{C}$} & \multicolumn{2}{|c|}{$\bar{T}=33^{\circ} \mathrm{C}$} & \multicolumn{2}{|c|}{$\overline{\mathrm{T}}=3 \mathrm{C}^{\circ} \mathrm{O} \mathrm{C}$} \\
\hline & Inicial & Estimado & Inicial & Estimado & Inicial & Estimado \\
\hline$\mu_{m}[1 / \mathrm{h}]$ & 0,1323 & 0,1277 & 0,1323 & 0,1018 & 0,1323 & 0,3128 \\
\hline$p_{m}[\mathrm{~g} / \mathrm{l}]$ & 98,3583 & 110,6718 & 98,3583 & 100,5807 & 98,3583 & 100,1301 \\
\hline$n$ & 0,9018 & 0,9445 & 0,9018 & 0,9251 & 0,9018 & 0,5206 \\
\hline$k_{s}[\mathrm{~g} / \mathrm{l}]$ & 1,2403 & 0,6084 & 1,2403 & 1,7155 & 1,2403 & 22,4115 \\
\hline$k_{i}[\mathrm{~g} / \mathrm{l}]$ & 84,0121 & 307,4217 & 84,0121 & 89,1689 & 84,0121 & 109,7352 \\
\hline$m_{s}[1 / \mathrm{h}]$ & 0,0051 & 0,0118 & 0,0051 & 0,0122 & 0,0051 & 0,0122 \\
\hline$m$ & 0,1 & 0,1927 & 0,1 & 0,0877 & 0,1 & 0,0639 \\
\hline$X_{m}[\mathrm{~g} / \mathrm{l}]$ & 105 & 10 & 100 & 105,2812 & 105 & 1607 \\
\hline
\end{tabular}

Pode-se verificar que existe alto grau de correlação entre a maioria das variáveis dependentes e a variável independente Temperatura [ $\left.{ }^{\circ} \mathrm{C}\right]$, conforme mostrado na Tabela 21. Apenas a variável $x_{m}$ não apresentou correlação linear com a temperatura. Assim sendo, mostra-se necessário um estudo mais detalhado com relação à influência da temperatura em cada um dos parâmetros.

Tabela 21 - Valor de Correlação Linear R-Múltiplo (\%) entre as variáveis dependentes e a variável independente Temperatura [ $\left.{ }^{\circ} \mathrm{C}\right]$.

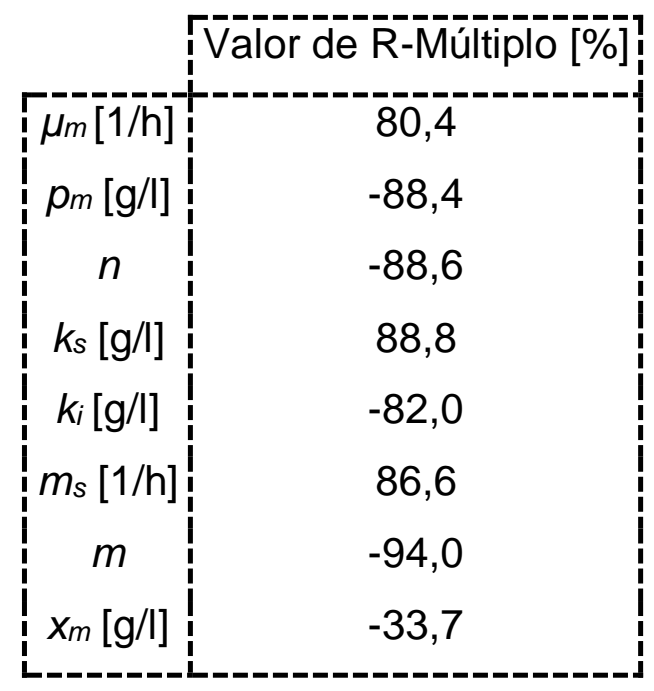

Dados experimentais e os resultados dos modelos usando os parâmetros estimados são mostrados para temperatura de $30^{\circ} \mathrm{C}$ (Figura 18 a Figura 21), 
temperatura de $33^{\circ} \mathrm{C}$ (Figura 22 a Figura 25) e temperatura de $36^{\circ} \mathrm{C}$ (Figura 26 a Figura 29).

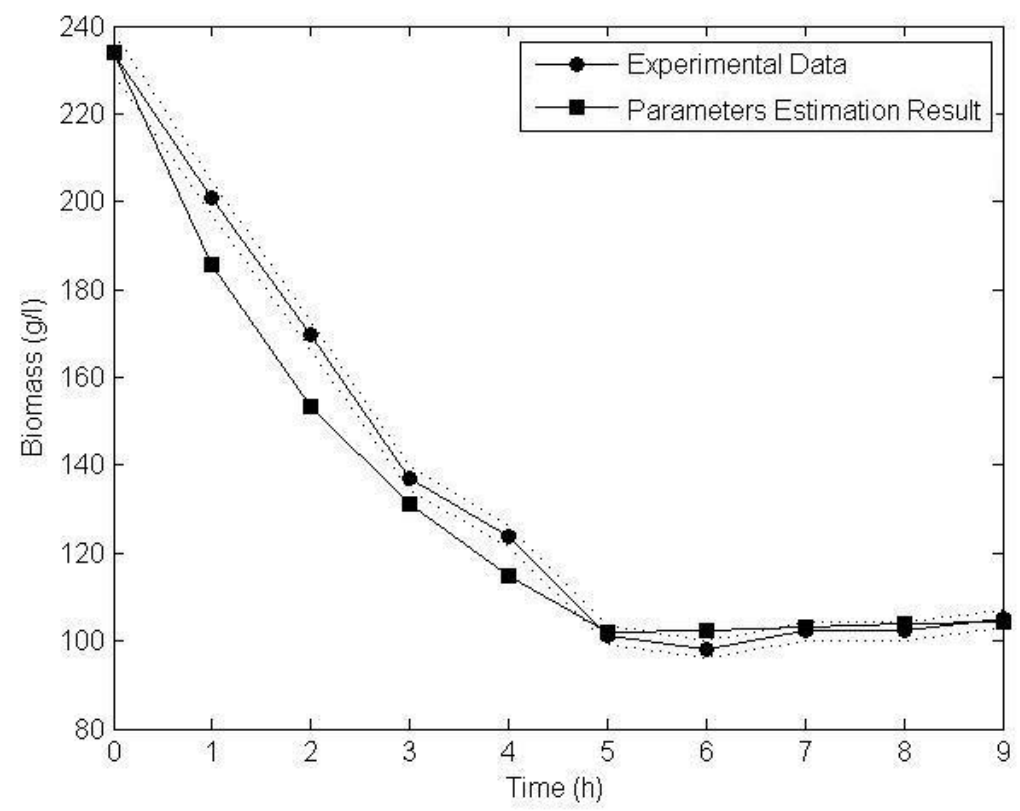

Figura 18 - Resultado da estimação dos parâmetros para temperatura de $30^{\circ} \mathrm{C}$, comparando os dados experimentais e a estimação dos parâmetros - Biomassa ( $g / l)$

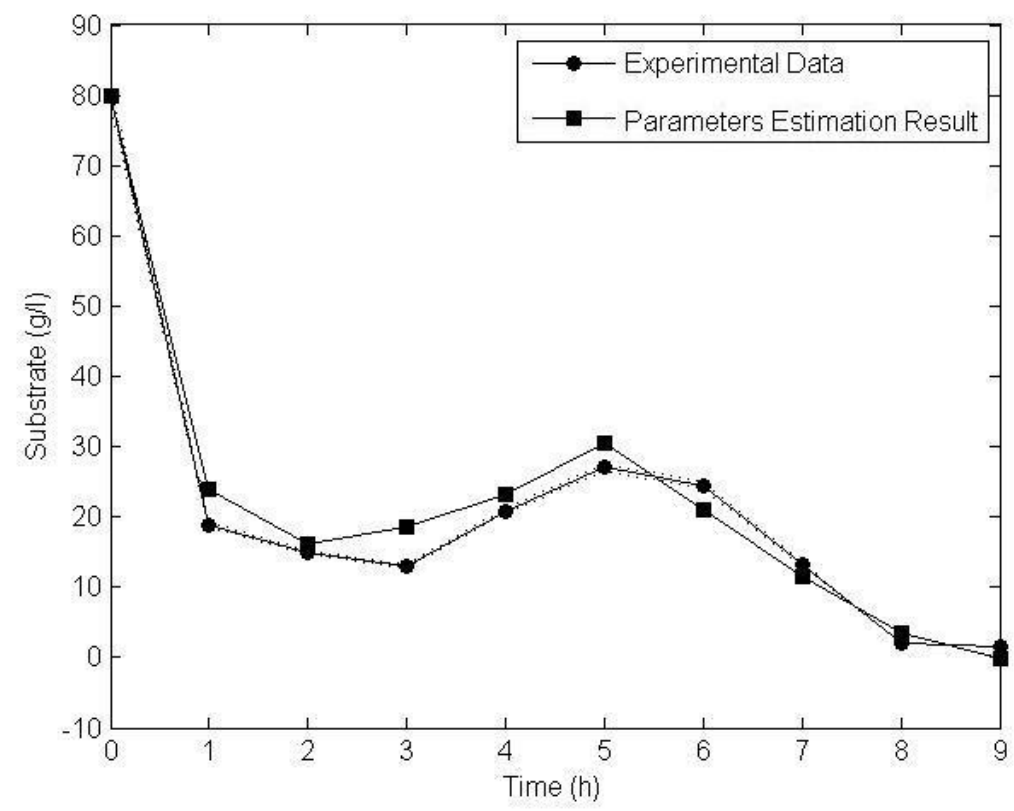

Figura 19 - Resultado da estimação dos parâmetros para temperatura de $30^{\circ} \mathrm{C}$, comparando os dados experimentais e a estimação dos parâmetros - Substrato (g/l) 


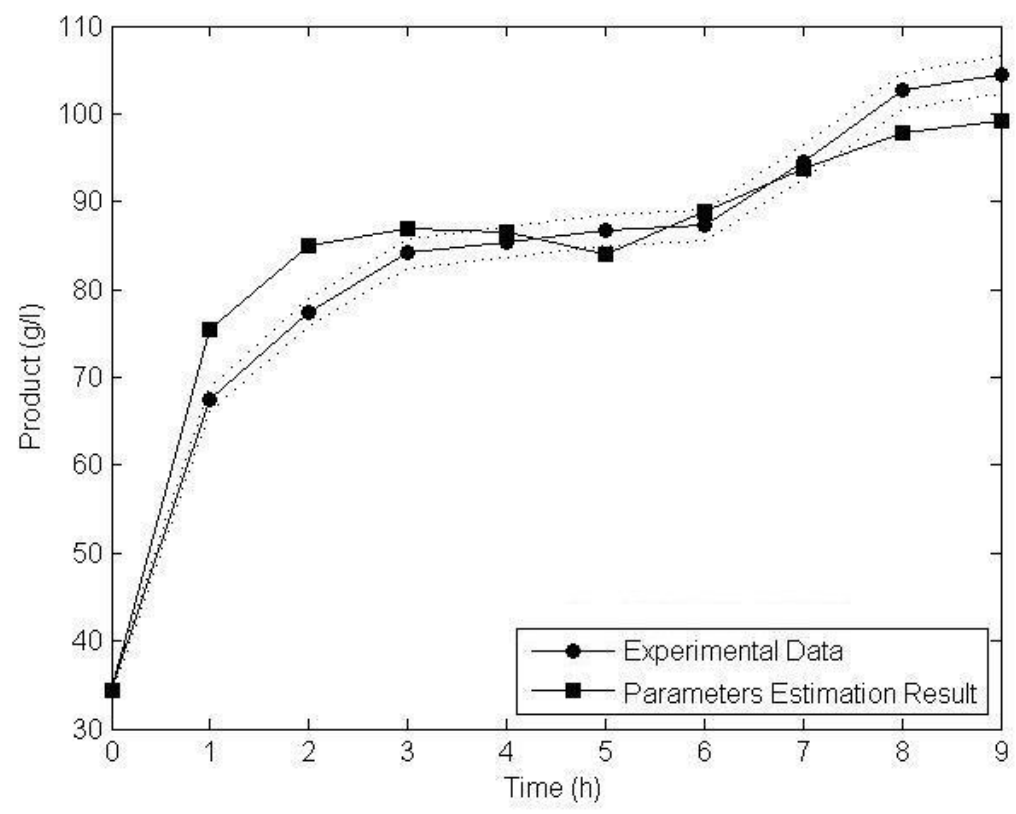

Figura 20 - Resultado da estimação dos parâmetros para temperatura de $30^{\circ} \mathrm{C}$, comparando os dados experimentais e a estimação dos parâmetros - Produto (g/l)

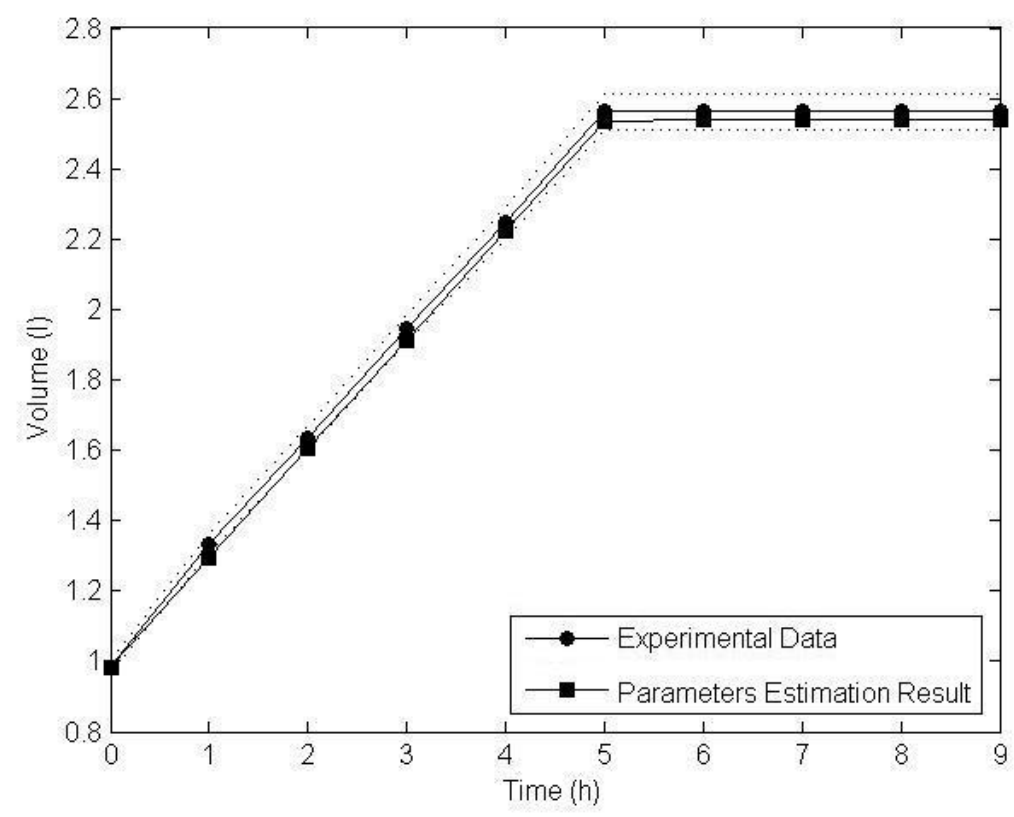

Figura 21 - Resultado da estimação dos parâmetros para temperatura de $30^{\circ} \mathrm{C}$, comparando os dados experimentais e a estimação dos parâmetros - Volume do Tanque (I) 


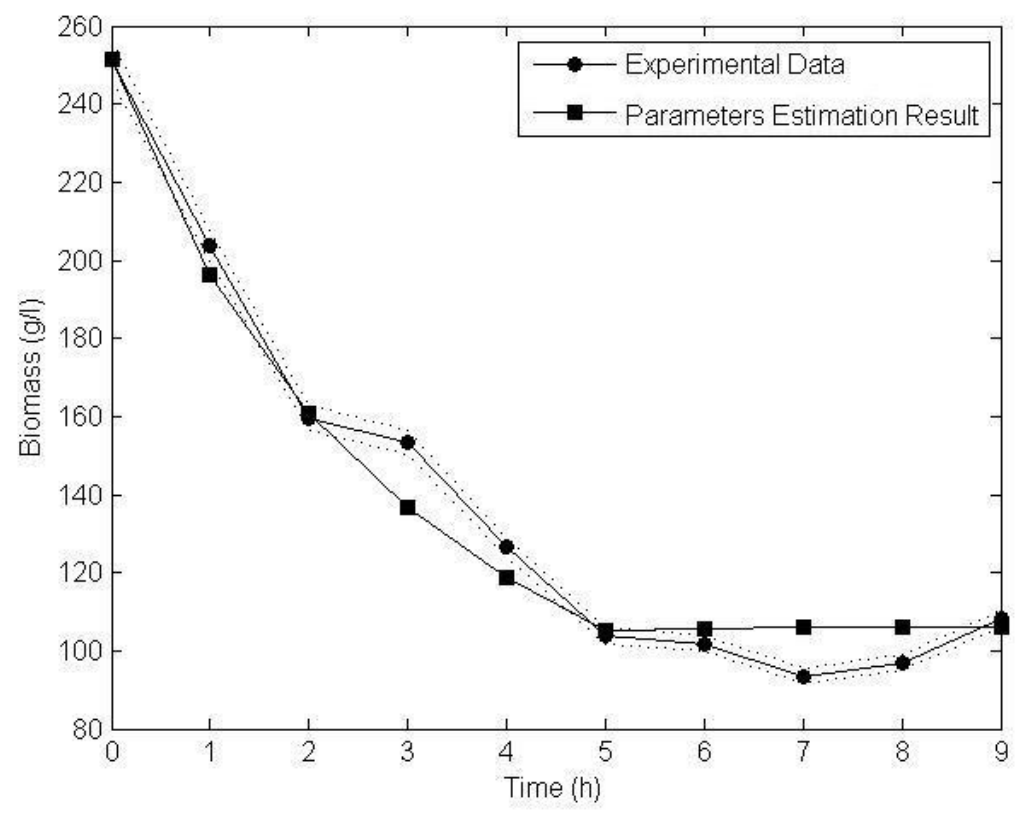

Figura 22 - Resultado da estimação dos parâmetros para temperatura de $33^{\circ} \mathrm{C}$, comparando os dados experimentais e a estimação dos parâmetros - Biomassa (g/l)

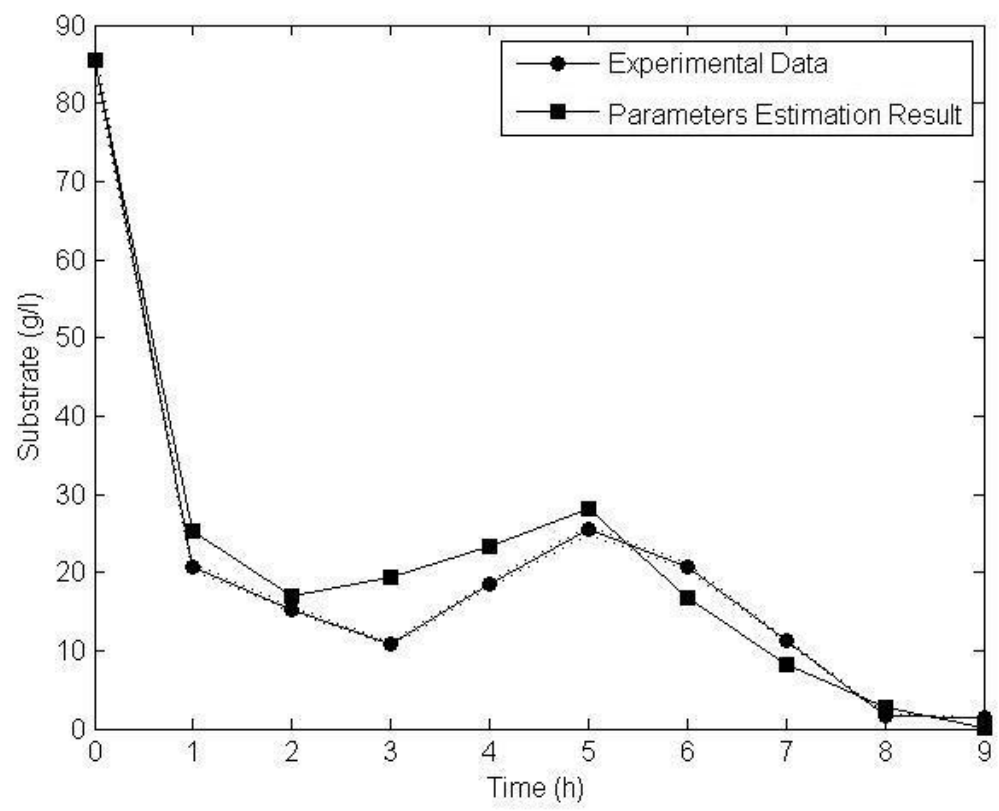

Figura 23 - Resultado da estimação dos parâmetros para temperatura de $33^{\circ} \mathrm{C}$, comparando os dados experimentais e a estimação dos parâmetros - Substrato ( $g / l)$ 


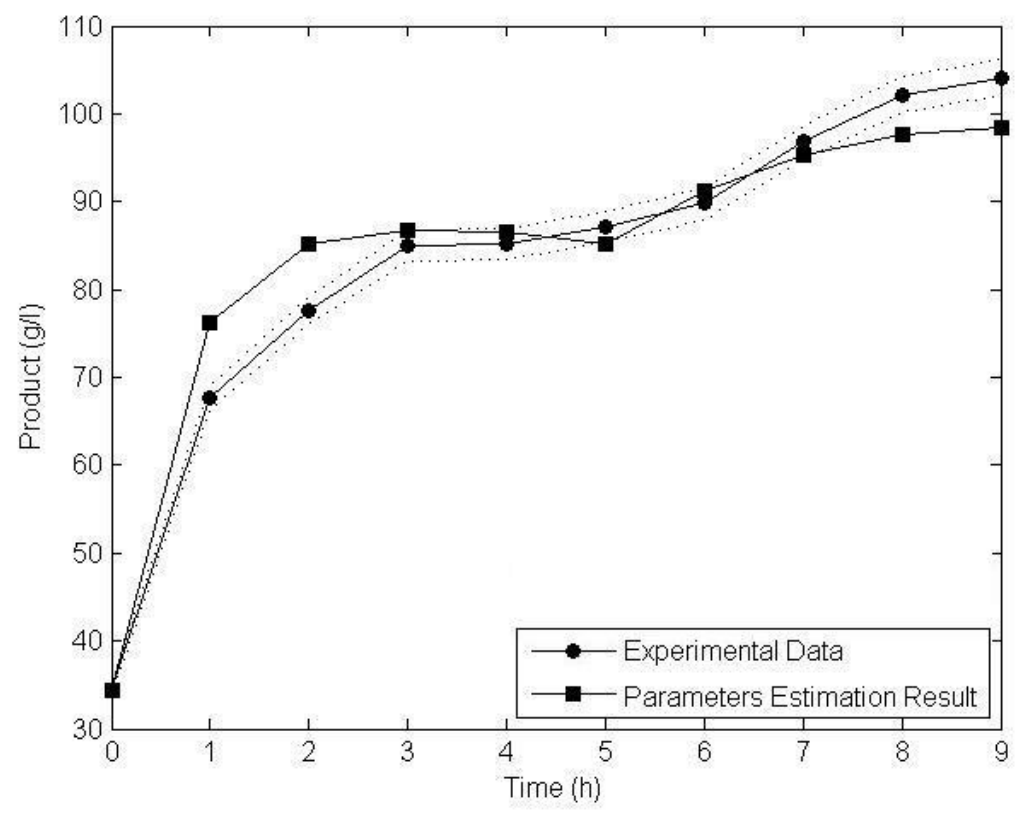

Figura 24 - Resultado da estimação dos parâmetros para temperatura de $33^{\circ} \mathrm{C}$, comparando os dados experimentais e a estimação dos parâmetros - Produto (g/l)

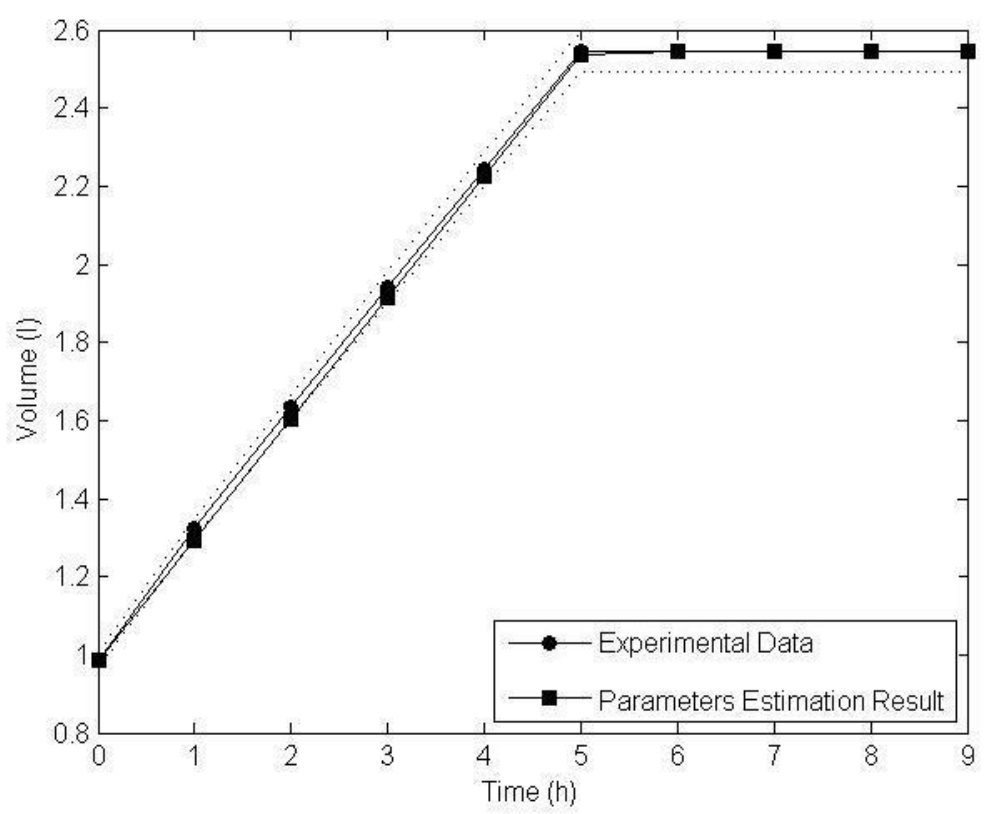

Figura 25 - Resultado da estimação dos parâmetros para temperatura de $33^{\circ} \mathrm{C}$, comparando os dados experimentais e a estimação dos parâmetros - Volume do Tanque (I) 


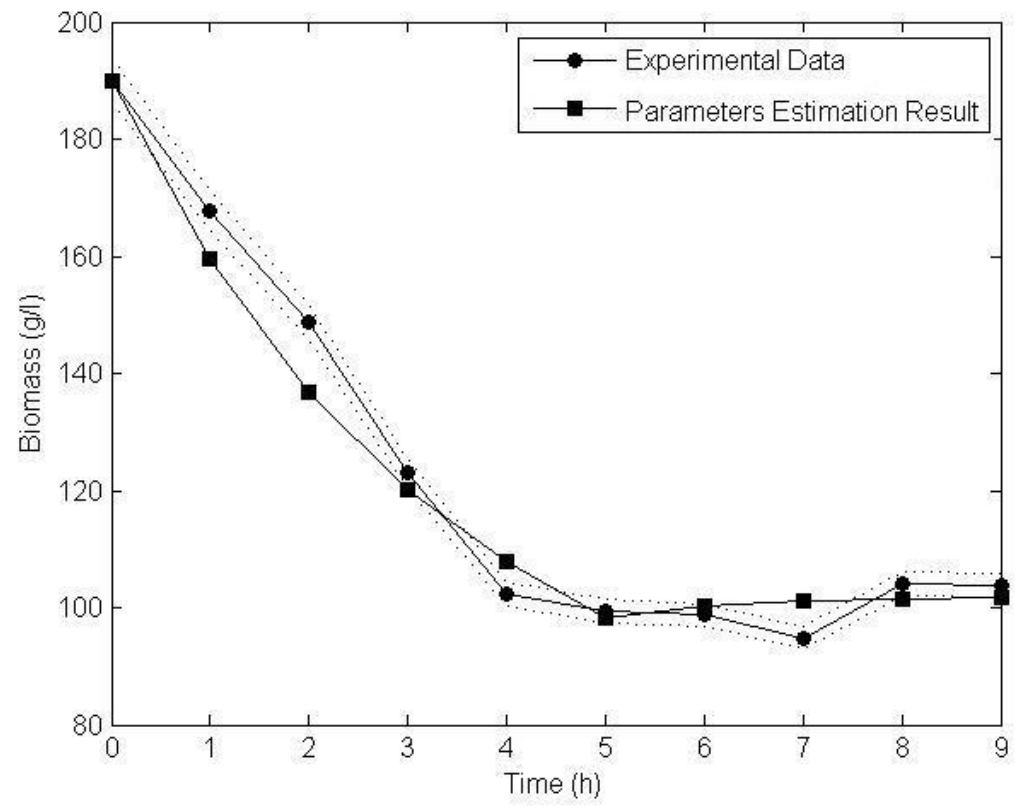

Figura 26 - Resultado da estimação dos parâmetros para temperatura de 36드, comparando os dados experimentais e a estimação dos parâmetros - Biomassa ( $(\mathrm{g} / \mathrm{l})$

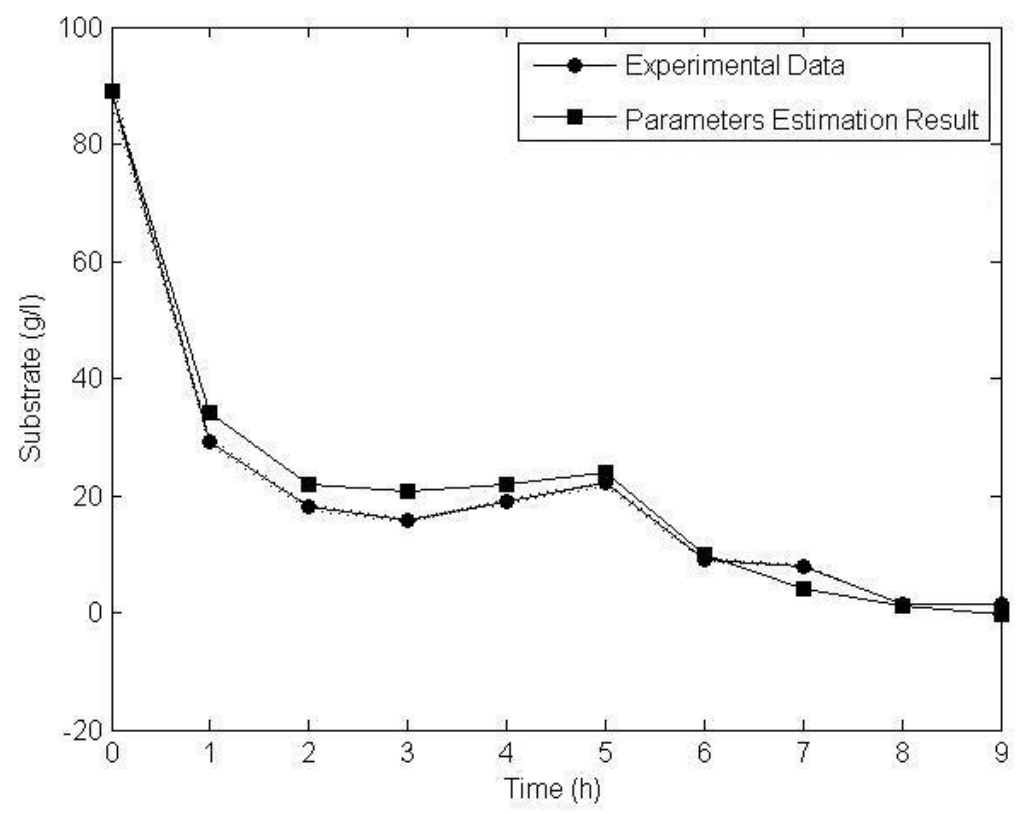

Figura 27 - Resultado da estimação dos parâmetros para temperatura de 36드, comparando os dados experimentais e a estimação dos parâmetros - Substrato ( $g / l)$ 


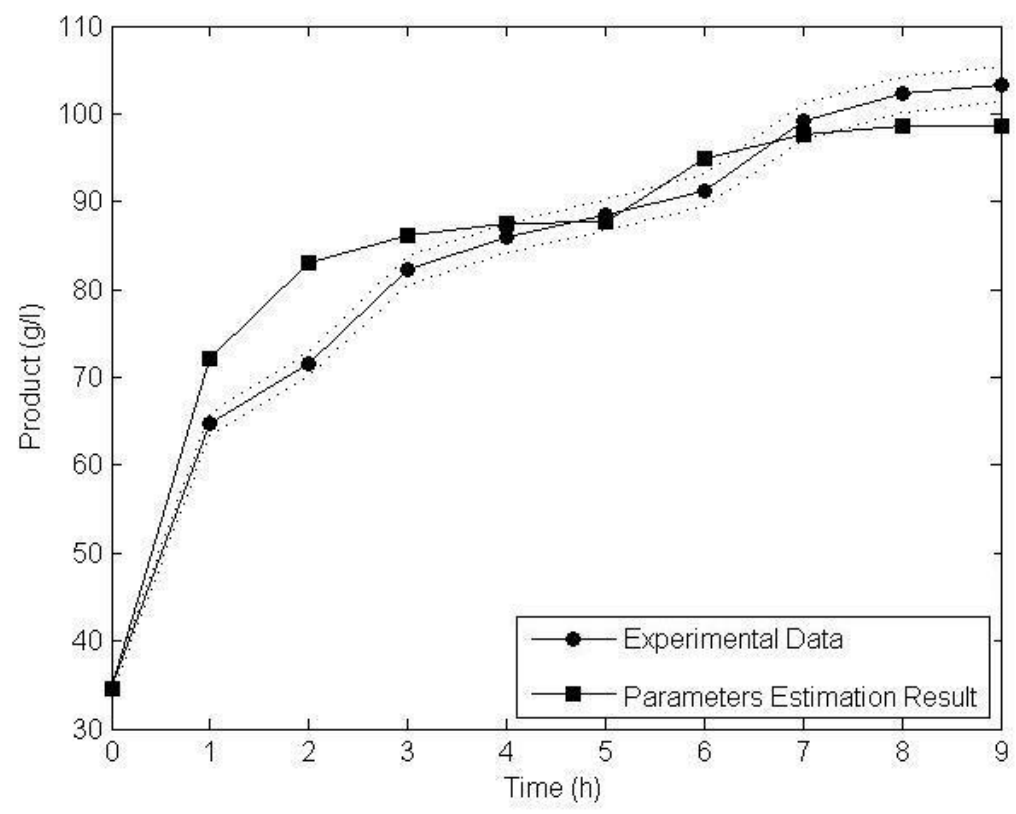

Figura 28 - Resultado da estimação dos parâmetros para temperatura de $36^{\circ} \mathrm{C}$, comparando os dados experimentais e a estimação dos parâmetros - Produto (g/l)

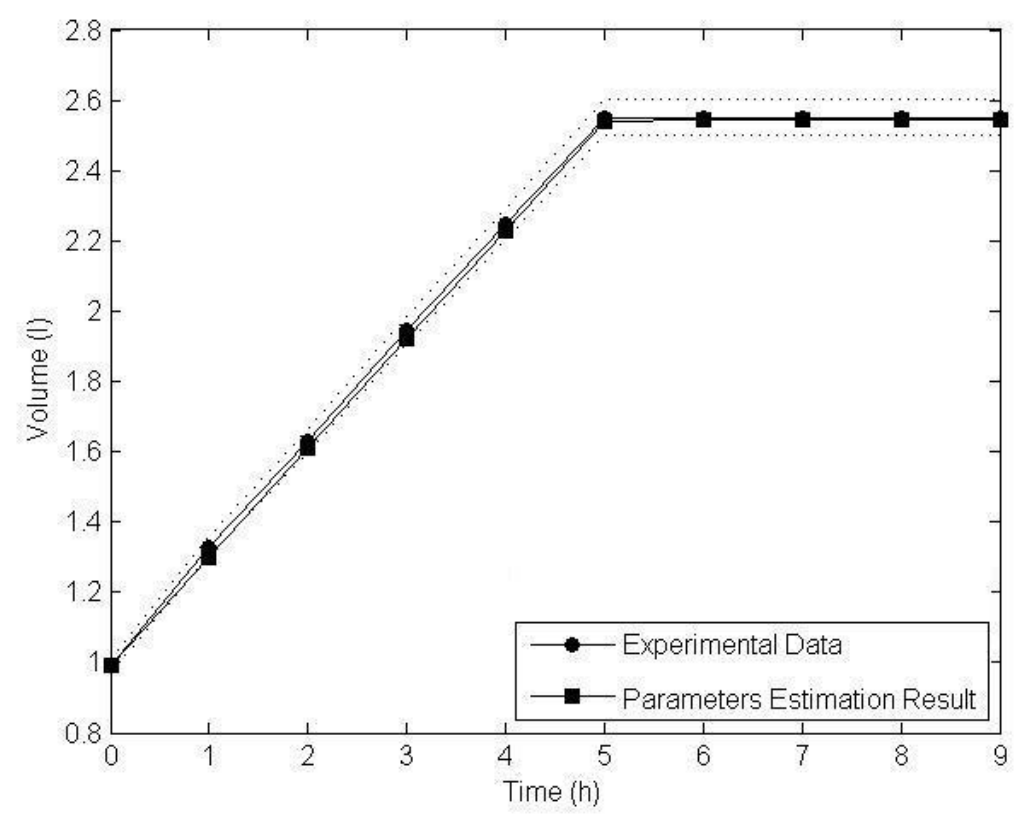

Figura 29 - Resultado da estimação dos parâmetros para temperatura de $36^{\circ} \mathrm{C}$, comparando os dados experimentais e a estimação dos parâmetros - Volume do Tanque (I) 


\subsection{Otimização dinâmica da alimentação do biorreator}

As matrizes $A, B_{1}, B_{2}, C_{1}$ e $C_{2}$ foram calculadas para a temperatura de $33^{\circ} \mathrm{C}$. Esta temperatura foi escolhida por se tratar da temperatura usual de controle no processo industrial. No cálculo das matrizes dinâmicas, considerouse que os parâmetros variantes $\theta$ assumiram os seguintes valores:

$$
\theta(1)=s=\{1,30,80\}, \theta(2)=v=\{1,1.75,2.5\} \text {. }
$$

Estes valores correspondem aos pontos em que as matrizes dinâmicas são calculadas e estão contidos nos limites observados nos experimentos realizados anteriormente. Para fins de projeto do controlador, os demais parâmetros são fixados em $x=150 \mathrm{~g} / \mathrm{l}$ e $\mathrm{p}=70 \mathrm{~g} / \mathrm{l}$, valores médios obtidos nos experimentos. Como observado anteriormente, as variáveis " $s$ " e " $V$ " foram definidas como parâmetros variantes, pois podem ser medidas com relativa facilidade durante o processo de fermentação.

Os ganhos do controlador, obtidos através do toolbox de Matlab® desenvolvido por GAHINET et al. (1995), são apresentados na Tabela 22.

Através dos resultados obtidos, foi possível obter um controle otimizado, fazendo com o que o processo de fermentação alcoólica pudesse atingir um estado otimizado nas condições de teste.

Sendo a variável de controle a vazão de entrada do processo, aplicandose a estratégia de controle acima descrita, obtém-se como resultado a otimização apresentada na Figura 30. 
Tabela 22 - Resultados dos ganhos do controlador.

\begin{tabular}{|c|c|c|c|}
\hline \multicolumn{4}{|c|}{$X_{1}$} \\
\hline$-0,0073$ & $-0,0014$ & 0,0027 & 0 \\
\hline$-0,0014$ & 0,1038 & 0,0362 & 0,0006 \\
\hline 0,0027 & 0,0362 & 0,0138 & 0,0002 \\
\hline 0 & 0,0006 & 0,0002 & 0,0019 \\
\hline \multicolumn{4}{|c|}{$\mathrm{X}_{2}\left({ }^{*} 1000\right)$} \\
\hline 0,0837 & $-0,1379$ & $-0,0672$ & $-0,0004$ \\
\hline$-0,1379$ & 0,1801 & 0,1104 & $-0,0005$ \\
\hline$-0,0672$ & 0,1104 & 0,0615 & $-0,0001$ \\
\hline$-0,0004$ & $-0,0005$ & $-0,0001$ & 0 \\
\hline \multicolumn{4}{|c|}{$\mathrm{X}_{3}\left({ }^{*} 1000\right)$} \\
\hline 0,0684 & $-0,0536$ & $-0,0589$ & $-0,001$ \\
\hline$-0,0536$ & $-0,6946$ & $-0,2232$ & $-0,0008$ \\
\hline$-0,0589$ & $-0,2232$ & $-0,0612$ & 0,0002 \\
\hline$-0,001$ & $-0,0008$ & 0,0002 & 0 \\
\hline
\end{tabular}

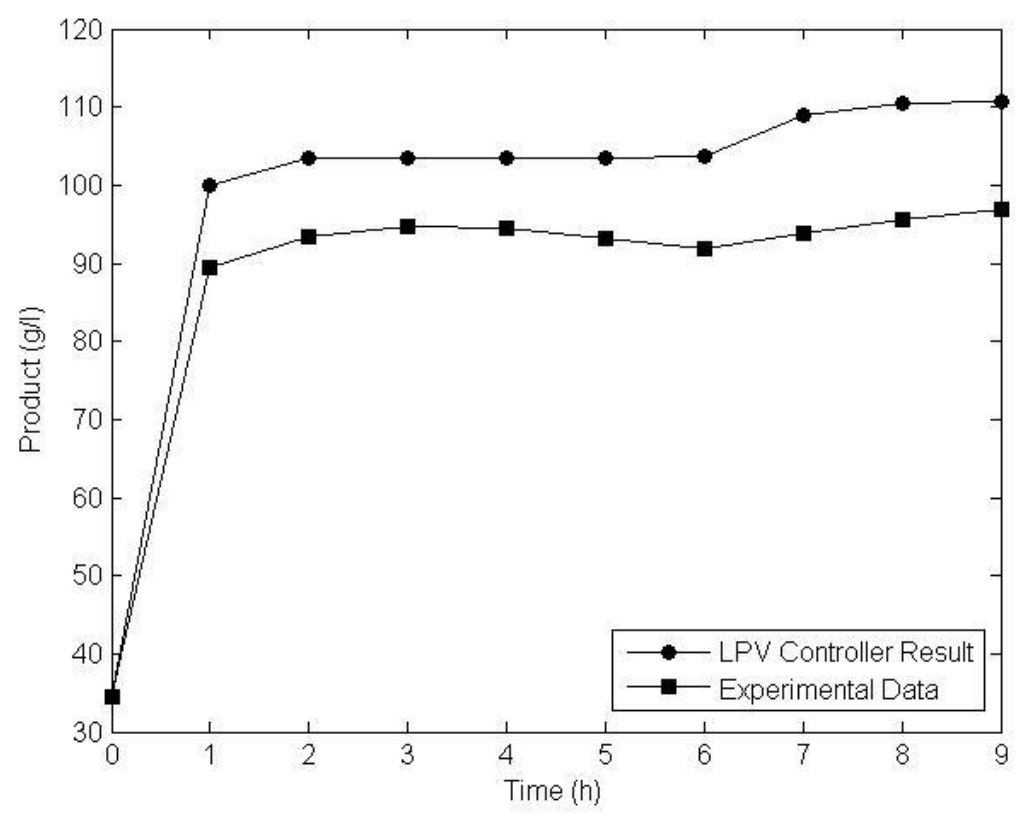

Figura 30 - Resultado da otimização da vazão de entrada sobre a concentração de produto. 


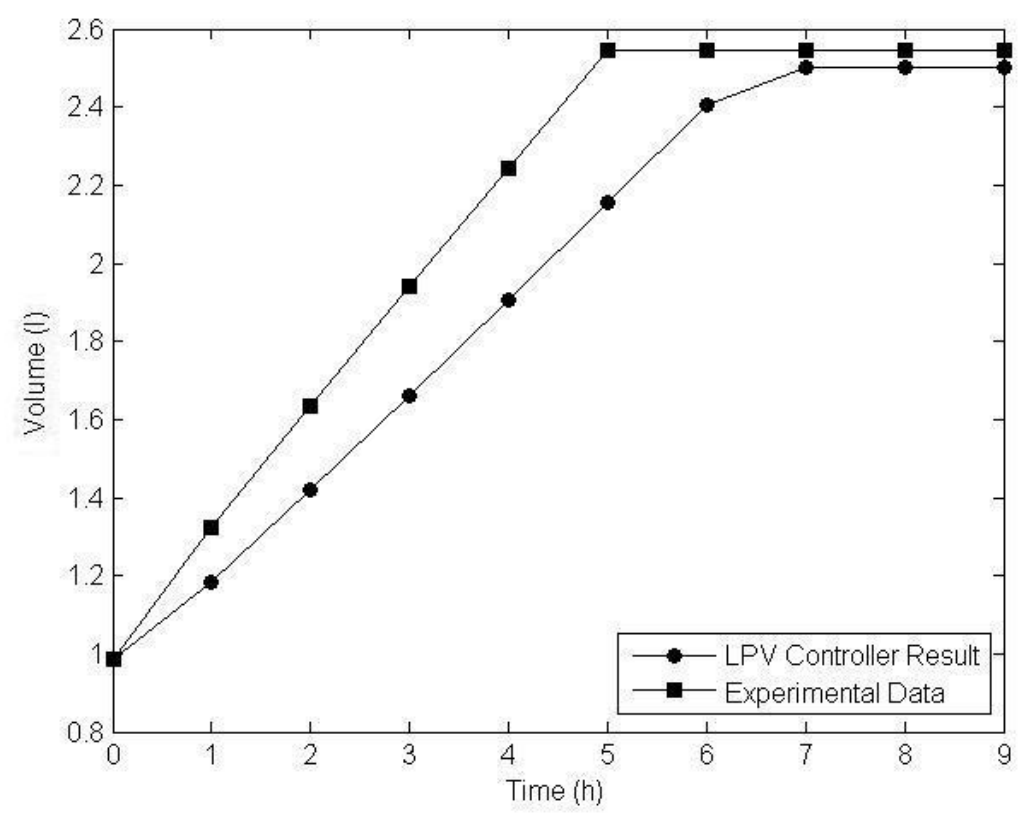

Figura 31 - Resultado do controlador sobre a vazão de entrada.

O resultado obtido, demonstrado na Figura 30, só foi possível devido a ação do controle ótimo, que possibilitou a variação da vazão (Figura 31). Ou seja, o controle ótimo possibilitou um aumento superior $10 \%$ na produtividade, com uma alteração da maneira de alimentação do biorreator, através da variação da vazão de entrada durante o procedimento de alimentação. 


\section{Capítulo 5}

Neste capítulo da dissertação são apresentadas as conclusões do trabalho e as sugestões de trabalhos futuros.

\section{Conclusões e Sugestões de Trabalhos Futuros}

\subsection{Conclusões}

Este trabalho de pesquisa apresentou como resultados um modelo não linear baseado em estimação de parâmetros. Tal estimativa possibilitou a representação adequada das características da fermentação, sendo eles o consumo de substrato, a transformação de substrato em células (através de um modelo matemático escolhido entre diversos existentes, sendo o mais adequado para os dados experimentais obtidos) e a transformação de substrato em produto.

Os dados obtidos, quando comparados com o resultado da estimação de parâmetros, se mostraram próximos a curva, apresentando grande aproximação e qualidade, além de semelhança quando comparada a outros resultados da literatura.

A grande dificuldade apresentada nesta fase foi a existência de poucos trabalhos semelhantes que utilizassem 0 MATLAB $^{\circledR}$ como programa para otimização de parâmetros.

A presença de manitol e glicerol nos experimentos mostram a existência de contaminação bacteriana (manitol) e consequentemente condições estressantes para a levedura (glicerol). Tais fatos podem ter afetado de maneira significativa o modelo matemático e, devido a isso, a aproximação não tenha se mostrado ainda maior. Porém vale ressaltar que, no ambiente industrial, é impossível a execução do processo fermentativo sem presença de bactérias, mesmo que em pequenas populações. 
Os efeitos inibitórios do substrato (açúcar) e do produto (etanol) foram identificados como dependentes da temperatura, ou seja, quanto maior a concentração de entrada de substrato e consequentemente, maior concentração final de produto, menor deve ser a temperatura do meio, favorecendo assim o processo fermentativo. Logo, um bom controle de temperatura leva diretamente a um aumento do rendimento fermentativo.

Quanto ao sistema de controle apresentado, pode-se concluir que, conforme esperado, o controlador atingiu o seu objetivo. Com alteração da vazão de entrada de mosto, foi possível simular um aumento do rendimento fermentativo. Este resultado se mostra útil no ambiente industrial, já que possibilita, através de uma alteração simples e facilmente programável em um controlador lógico (PLC), um aumento no rendimento fermentativo.

\subsection{Sugestões de Trabalhos Futuros}

Os experimentos realizados mostraram-se bem realizados e conduzidos, porém com um controle muito simplificado. Seria interessante que o controle fosse mais eficiente, e que os choques nas leveduras fossem menos impactantes. Para isso, deveria ser implantado um controlador mais atuante e um ambiente de maior controle, evitando que contaminantes atrapalhassem 0 desempenho da fermentação.

As temperaturas avaliadas, na faixa de $30^{\circ} \mathrm{C}$ a $36^{\circ} \mathrm{C}$ são hoje as temperaturas mais utilizadas na indústria sucroenergética. Porém, pesquisas recentes (http://www.fermentec.com.br/capa.asp?p=264 acessado em 17/11/2014) mostram uma tendência pelo aumento do teor alcoólico e, consequentemente, uma diminuição da temperatura de controle, já que, como mostrado neste trabalho, em temperaturas mais baixas, a conversão de açúcar em etanol é mais eficiente, possibilitando também economia na agrícola com transporte e distribuição da vinhaça, redução no consumo de vapor (energia), menor uso de água tratada no processo industrial (diluição do fermento) e diminuição no consumo de antibióticos.

Ainda quanto aos experimentos executados, seria importante utilizar diferentes linhagens de leveduras, para possibilitar a avaliação do 
comportamento de diversas linhagens sob condições específicas. Tendo a modelagem matemática destas diversas linhagens de leveduras, curvas específicas de alimentação seriam implantadas e consequentemente possibilitariam a otimização do processo industrial para cada uma das leveduras avaliadas.

A inserção da temperatura como parâmetro da modelagem é fundamental no controle de processo, por isso se torna necessária a sua utilização. A maioria dos parâmetros do modelo matemático (com exceção da variável concentração máxima de biomassa onde cessa o crescimento microbiano, $x_{m}$ ) mostraram possuir dependência com relação a temperatura, conforme pode ser visto na Tabela 21.

Avaliar outros modelos matemáticos em paralelo com o adotado neste trabalho seria de fundamental importância, já que, diferentes microorganismos possuem comportamentos diferenciados. Possivelmente, em outras condições de matéria-prima, temperatura ou interações, um modelo matemático diferente possa ser obtido, dependendo destes parâmetros citados.

Neste trabalho não foi executada uma análise estatística aprofundada da sensibilidade paramétrica dos parâmetros estimados. Seria interessante a execução deste procedimento, de forma a elucidar e garantir que os parâmetros estimados estão de acordo com os dados utilizados. Neste trabalho comparou-se os dados obtidos com dados de outros trabalhos semelhantes, de forma a sua validação.

Este trabalho apresentou características iniciais de um controle ótimo. Novos trabalhos considerando modelos matemáticos diferentes devem ser efetuados de maneira a obtenção e um controle ótimo multivariável. Sugere-se controle de temperatura, vazão e concentração do substrato entrante, realizando assim uma maior gama de controle e, possivelmente, uma otimização mais adequada do processo. 


\section{Referências Bibliográficas}

AGUIRRE, L. A. Introdução a Identificação de Sistemas: Técnicas Lineares e Não-Lineares Aplicadas a Sistemas Reais. Editora UFMG, 2007

AMORIM, H. V. Fermentação Alcoólica: Ciência e Tecnologia. Piracicaba. São Paulo, 2005. Fermentec, 448 p.

ANDRIETTA, S.R.; FERREIRA, E.; ANDRIETTA, M. G. Avaliação da Influência da Velocidade de Alimentação sobre o Rendimento e Produtividade dos Processos de Produção de Etanol Operando em Batelada Alimentada. Anais do Sinaferm 2003. Faculdade de Engenharia Química, Universidade Estadual de Campinas, Campinas, 7p.

ATALA, D. I. P.; COSTA, A. C.; MACIEL, R.; MAUGERI, F. Kinetics of ethanol fermentation with high biomass concentration considering the effect of temperature. Applied Biochem. Applied Biochemistry and Biotechnology, Vol. 91-93, p.353 - 365, 2001

BACHNAS, A. A.; TOTH, R.; MESBAH, A.; LUDLAGE, J. Perspectives of data-driven LPV modeling of high-purity distillation columns. In Proceedings of the European Control Conference, 3776-3783, 2013, Zurich.

BARD, Y. Nonlinear Parameter Estimation, Dynamic Models. Academic Press, New York, Cap. 8, 219-233, 1974.

BASSO L. C., OLIVEIRA A. J., ORELLI V. F. D. M., CAMPOS A. A., GALLO C. R. \& AMORIM H. V. Dominância das leveduras contaminantes sobre as linhagens industriais avaliada pela técnica da' cariotipagem. Anais Congresso Nacional da STAB 5: 246-250, 1993.

BASSO L. C., OLIVEIRA A. J., AMORIM H. V \& LOPES, M. L. "Yeast selection for fuel ethanol production in Brazil." FEMS yeast research 8.7: 11551163, 2008.

BORGES, P. C. S. Otimização dinâmica da fermentação alcoólica no processo em batelada alimentada. Dissertação (Mestrado em Engenharia Química) - Universidade Federal de Uberlândia, 141 f. 2008.

BOYD, S., EI GHAOUI, L., FERON, E. e BALAKRISHNAN, V. (1994). Linear matrix inequalities in system and control theory, SIAM - Society for Industrial and Applied Mathematics.

CARRERA, J. et al. Computational and Conceptual Issues in the Calibration of Seawater Intrusion models. Hydrogeology Journal. V18, p.131145, 2010. 
CARVALHO, J. C. M.; SATO S. Fermentação Descontínua Alimentada. In: SHMIDELL, W.;LIMA, U. A.; AQUARONE, E.;BORZANI, W. (Ed.). Biotecnologia Industrial: Engenharia Bioquímica. 6ª ed. São Paulo: Editora Edgard Blücher, 2001. p. 205-222.

CHIOU, J.; WANG, F. Hybrid method of evolutionary algorithms for static and dynamic optimization problems with application to a fed-batch fermentation process. Computers and Chemical Engineering, 23, 1277-1291, 1999.

COUTINHO, D.; DEWASME, L.; VANDE WOWER, A. Robust Control of Yeast Fed-Batch Cultures for Productivity Enhancement. 7th IFAC International Symposium on Advanced Control of Chemical Processes, P. 709-714, 2009

DORAN, PAULINE M. Bioprocess Engineering Principles. Academic Press, London, 1995

DRAKUNOV, S. V.; LAW, V. J. Parameter Estimation Using Sliding Mode Observers: Application to the Monod Kinetic Model. Chemical Product and Process Modeling, 2, Iss. 3, Art. 21, 1-27, 2007.

DUNN, Barbara, et al. Analysis of the Saccharomyces cerevisiae pangenome reveals a pool of copy number variants distributed in diverse yeast strains from differing industrial environments. Genome research 22.5 (2012): 908-924.

EDGARD, T. F., HIMMELBLAU, D. M., LASDON, L. S. optomozarion of Chemical Process, Second Edition, McGraw-Hill Chemical Engineerring Series, 651 p., 2001.

ENGL, H. W.; HANKE, M.; NEUBAUER, A. Regularization of Inverse Problems: Mathematics and its Applications, Kluwer, 1996

FERMENTEC. Controle Microbiológico por Microscopia e Plaqueamento. Piracicaba, 2014, 235 p. Apostila do Treinamento Analítico Laboratorial em Microscopia e Plaqueamento. (a)

FERMENTEC. Métodos Analíticos para o Controle da Produção de Açúcar e Álcool. Piracicaba: Fermentec, 2014. 5ª Edição. (b)

FERREIRA, A. A. Simulação da Fermentação Alcoólica de meios à Base de Glicose por Saccharomyces cerevisiae. Dissertação (Mestrado em Engenharia Química) - Universidade Federal de Uberlândia, 98 p. 1998.

FILHO, M. V. A. C.; MONTEIRO, J. B.; MAGAZONI, F. C.; COLLE, S. Modeling, Simulation And Analysis Of Ethanol Fermentation Process With Control Structure In Industrial Scale. 22nd International Conference on Efficiency, Cost, Optimization, Simulation and Environmental Impact of Energy Systems, p. 10, August 31 - September 3, 2009, Foz do Iguaçu, Paraná, Brazil. 
FORSYTHE, G. E.; MALCOM, M. and MOLER, C. Computer Methods for Mathematical Computations. Prentice-Hall, 1977.

FU, P. C.; BARFORD, J. P. Nonsingular optimal control for fed-batch fermentation processes with a differential-algebraic system model. J. Proc. Control, 3, ํㅜ, 211-218, 1993.

GAHINET, P; NEMIROVISKI A, Laub; AJ, Chilali M. (1995) LMI Control Toolbox. The MathWorks, Inc., Natick

GHOSE, T. K.; THYAGI, R. D. Rapid Ethanol Fermentation of Cellulose Hydrolysate. II Product and Substrate Inhibition and Optimization of Fermentor Design. Biotechnology and Bioengineering, 21, 1401-1420, 1979.

GOMES, F. S. Antagonismo entre leveduras e bactérias láticas na fermentação alcoólica. Piracicaba, 172 p. Dissertação (Mestrado em Ciências Ciência e Tecnologia de Alimentos) - Escola Superior de Agricultura "Luiz de Queiroz", Universidade de São Paulo, 2009.

GOSWAMI, V.; SRIVASTAVA, A. K. Fed-batch propionic acid production by Propionmibacterium acidpropionici. Biochemical Engineering Journal, 4, 121 128, 2000.

HUANG, J.; Jl, G.; ZHU,Y; BOSCH, P. Identification of multimodel LPV models with two scheduling variables, Journal of Process Control, vol. 22, no. 7, pp. 1198-1208, 2012.

IMPE VAN, J. F., NICOLAY, B. M., VANROLLEGHM, P. A., SPRIET, J. A., MOOR, B. B., VENDEWALLE, J. Optimal control of the penicillin G. fed-batch fermentation: an analysis of the model of Heijnen et al. Optima Control Appl. \& Methods, 15, p. 13-34, 1994.

KELLEY, J. H. A transformation approach to singular subarcs in optimal trajectory. SIAM J. Control, 2, 234-240, 1965.

KRUMOV, A. D.; MÓDENES, A. N.; TAIT, M. C. A. Development of new unstructured model for simultaneous saccharification and fermentation of starch to ethanol by recombinant strain. Biochemical Engineering Journal, 28, 243-255, 2006.

LEE, Y.; LEE, W. G.; CHANG, Y. K.; CHANG, H. N. Modelling of Ethanol Prodiction by Saccharomyces cerevisiae from a Glicose and Maltose Mixture. Biotechnology Letters, 17, №8, 791-796, 1995.

LOBATO, F. S. Determinação do perfil ótimo de alimentação de substrato no processo de Fermentação Alcoólica - Influência da Condição inicial. TEMA Tend. Mat. Apl. Comput., 12, No. 1, 1-10. 2011.

LOBATO, F. S.; OLIVEIRA-LOPES, L. C.; MURATA, V. V. Optimal Feed Policy for Fed-Batch Fermentation with Events Identification Based on 
Switching Structures, XXII IACChE (CIIQ) 2006/ V CAIQ AAIQ Associación Argentina de Ingenieros Químicos IACCHE - Interamerican Confederation of Chemical Engineering, 2006.

LUONG, J. H. T. Kinectics of Ethanol inhibition in Alcohol Fermentation. Biotechnology and Bioengineering, p. 280-285, 1985

MODAK, J. M.; LIM, H. C. Feedback optimization of fed-batch fermentation. Biotechnol. Bioeng., 30, 528-540, 1987.

MODAK, J. M.; LIM, H. C.; TAYEB, Y. J. General characteristics for optimal feed rate profile for various fed-batch fermentation process. Biotechnol. Bioeng., 28, 1396-1407, 1986

OLIVEIRA, A.J.; GALLO, C.R.; ALCARDE, V.E.; GODOY, A; AMORIM, H.V. Métodos para o controle microbiológico na produção de açúcar e álcool. Piracicaba: FERMENTEC/ FEALQ/ESALQ, 1996. 89p.

PACHECO, T. F. Fermentação Alcoólica com Leveduras de Características floculantes em reator tipo torre com escoamento ascendente. Dissertação (Mestrado em Engenharia Química) - Universidade Federal de Uberlândia, 107 p., 2010.

PANCHAL, Chandra J. (ed.). Yeast strain selection. Marcel Dekker, INC., New York, p. 225-243, 1990.

PIMENTEL, G.; COUTINHO, D, 2012. Controle Robusto Por Realimentação Linearizante Parcial De Bioreatores Em Modo De Operação Descontínua Com Alimentação. Revista Controle \& Automação. Vol.23 №.2. p. 138-152. APR. 2012.

PFEIFER, A. A. Controle Ótimo de Sistemas Algébrico-Diferenciais com Flutuação do Índice Diferencial. Uberlândia, 106 p. Dissertação (Mestrado em Engenharia Química) - Faculdade de Engenharia Química, Universidade Federal de Uberlândia, 2007. 1981.

RAY, W. H. Advanced Process Control. McGraw-Hill, New York, p. 87-90,

RIVERA, E. A. C. Otimização de Bioprocessos: Avaliação de Desempenho das Abordagens Determinística e por Algoritmos Genéticos. Tese (Doutorado) - Universidade Estadual de Campinas, Faculdade de Engenharia Química. Campinas, SP: 194 p., 2006.

ROHR, E., PEREIRA, L. e COUTINHO, D. (2009). Robustness analysis of nonlinear systems subject to state feedback linearization, Revista Controle \& Automação 20(4): 482 - 489.

SANTOS, K. G.; LOBATO, F. S.; MURATA, V. V. Controle on-off de um fermentador batelada alimentada para altas concentrações de substrato. VI 
Congresso Brasileiro de Engenharia Química em Iniciação Científica, Campinas - São Paulo, 6 p. 2005.

SCHMIDELL, W.;FACCIOTTI, M. C. R. Biorreatores e processos fermentativos. In: SHMIDELL, W.;LIMA, U. A.; AQUARONE, E.;BORZANI, W. (Ed.). Biotecnologia Industrial: Engenharia Bioquímica. 6 6 $^{\underline{a}}$ ed. São Paulo: Editora Edgard Blücher, 2001. p. 179-192.

SIQUEIRA, A. A. G., TERRA, M. H., BERGERMAN, M., 2011 Robust Control of Robots: Fault Tolerant Approaches. London : Springer, v.1. p.228.

SILVA, E. C. N. Apostila do curso PMR 5215 - Otimização Aplicada ao Projeto de Sistemas Mecânicos. Departamento de Engenharia Mecatrônica e Sistemas Mecânicos. Escola Politécnica - USP. São Paulo, 44 p. 2015.

SMETS, I. Y.; CLAES, J. E.; NOVEMBER, E. J.; BASTIN, G. P.; VAN IMPE, J. F. Optimal adaptive control of (bio)chemical reactors: past, present and future. Journal of Process Control, 14, p. 795-805, 2004.

SOUZA, C. S. Avaliação da produção de etanol em temperaturas elevadas por uma linhagem de S. Cerevisiae. Tese (Doutorado em Biotecnologia) - Universidade de São Paulo/Instituto Butantan/IPT, 155 f. 2009.

STORN, R.; PRICE, K. Differential Evolution - A simple and efficient adaptative scheme for global optimization over continuous spaces. International Computer Science Institute, Berkeley, 1-15, 1996.

THATIPAMALA, R.; ROHANI, S.; HILL, G. A. Effects of High Product and Subtrate Inhibitions on the Kinectics and Biomass and Product Yields During Ethanol Batch Fermentation. Biotechnology and Bioengineering, 40, p. 289-297, 1992.

TOTH, R., HEUBERGER, P.S.C. \& HOF, P.M.J. Van den (2012). Prediction-error identification of LPV systems present and beyond. In $\mathrm{J}$. Mohammadpour \& C. W. Scherer (Eds.), Control of linear parameter varying systems with applications (pp. 27-60). Heidelberg Springer.

VANDERPLAATS, G. N. Numerical Optimizarion Techniquyes for Engineering Design. Colorado Springs, CO, Third Edition, 1999.

VILLEN, R. A. Mauá: Biotecnologia - Histórico e Tendências. Escola de Engenharia de Mauá. Apostila, 2009.

WANG, F. S.; SHEU, J. Multiobjective parameter estimation problems of fermentation processes using a high ethanol tolerance yeast. CHEMICAL ENGINEERING SCIENCE, 55, 3685-3695. 2000.

WANG, F. S.; SHYU, C. H. Optimal feed policy for fed-batch fermentation of ethanol production by Zymomous mobilis. Bioprocess Engineering, 17, 63-68, 1997. 
WANG, F. S.; SU, T.; JANG, H. Hybrid Differential Evolution for Problems of Kinetic Parameter Estimation and Dynamic Optimization of an Ethanol Fermentation Process. Ind. Eng. Chem. Res., 40, 2876-2885, 2001.

UNICA, 2012. "1a ESTIMATIVA DA SAFRA 2012/2013 - 12/04/2012". União da Indústria de Cana de Açúcar. 12 Apr. 2012 < http://www.unica.com.br>

UNICA, 2015. "Histórico de produção e moagem". União da Indústria de Cana de Açúcar. 14 Jul. 2015 < http://www.unica.com.br>

YABARRENA, J. M. S. C. Modelagem do processo de fermentação etanólica com interferência de bactérias heterofermentiva e homofermentativa. São Carlos, 182 p. Dissertação (Doutorado em Ciências - Engenharia Mecânica) - Escola de Engenharia de São Carlos, Universidade de São Paulo, 2012.

ZHU, Y.; XU, Z. A method of LPV model identification for control, in Proceedings of the 17th World Congress of the International Federation Automatic Control, pp. 5018-5023, Seoul, Republic of Korea, 2008. 